The author(s) shown below used Federal funds provided by the U.S. Department of Justice and prepared the following final report:

Document Title: Final Report: Participatory Evaluation of the Lummi Nation's Community Mobilization Against Drugs Initiative/Bureau of Justice Assistances Indian Alcohol and Substance Abuse Demonstration Project

Author: Jennie R. Joe, Ph.D. ; Jeanette Hassin, Ph.D. ; Xenia King, Ph.D. ; Robert S. Young, Ph.D. ; Darlene Lopez, Ph.D. ; Danita Washington ; Evelyn Jefferson

Document No.: 222741

Date Received: May 2008

Award Number: 2005-AC-BX-0011

This report has not been published by the U.S. Department of Justice. To provide better customer service, NCJRS has made this Federallyfunded grant final report available electronically in addition to traditional paper copies.

Opinions or points of view expressed are those of the author(s) and do not necessarily reflect the official position or policies of the U.S. Department of Justice. 


\title{
Final Report: \\ Participatory Evaluation of the Lummi Nation's Community Mobilization Against Drugs Initiative/ \\ Bureau of Justice Assistance's \\ Indian Alcohol and Substance Abuse Demonstration Project
}

Grant Award No. 2005-AC-BX-0011

March 31, 2008

Submitted to:

U.S. Department of Justice

Office of Justice Systems

$8107^{\text {th }}$ Street, NW

Washington, D.C. 20531

Jennie R. Joe, Ph.D., Principal Investigator

\author{
Report submitted by: \\ Jeanette Hassin, Ph.D. (NARTC) \\ Xenia King, Ph.D. (NARTC) \\ Robert S. Young, Ph.D. (NARTC) \\ Darlene Lopez, Ph.Dc. (NARTC) \\ Danita Washington (CMAD Coordinator, Lummi Nation) \\ Evelyn Jefferson (Tribal Chairwoman, Lummi Nation)
}

Native American Research and Training Center

University of Arizona

1642 E. Helen Street

Tucson, Arizona 85719 


\section{TABLE OF CONTENTS}

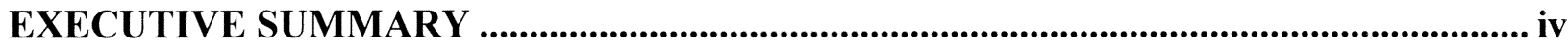

I) PROGRAM DESCRIPTION........................................................................................................... 1

I.1) Background: Substance Abuse Problems in American Indian Communities ..................... 1

I.2) Background: Community Based Substance Abuse Prevention/Treatment Programs.......... 3

I.3) Lummi Demonstration Project: Community Mobilization Against Drugs (CMAD)

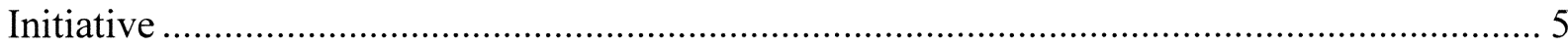

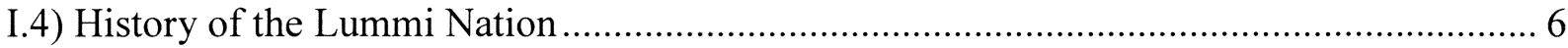

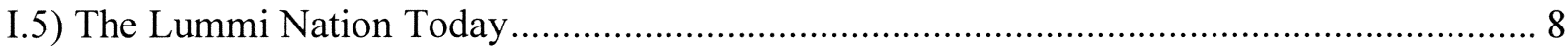

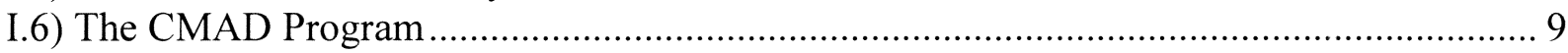

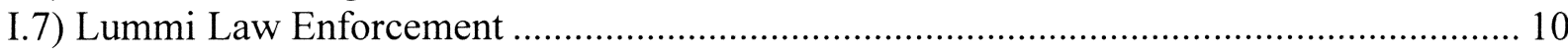

I.8) Implementation of a Participatory Evaluation with the CMAD Initiative ...................... 11

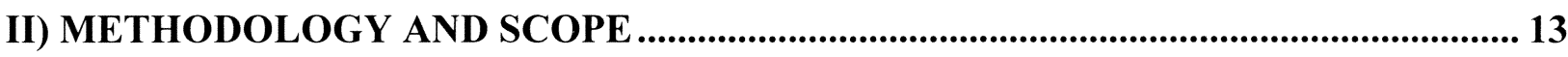

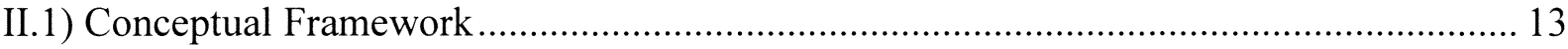

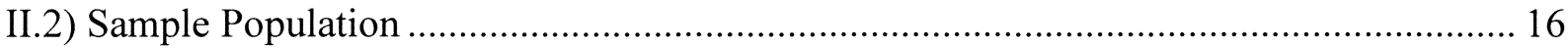

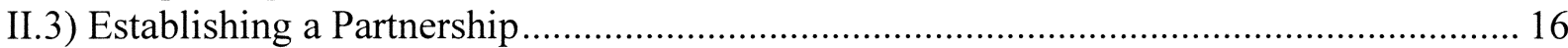

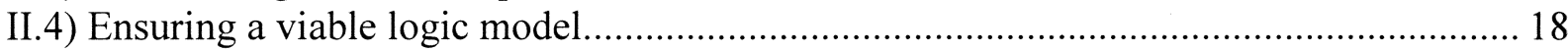

II.5) Methods Used in Conducting the Evaluation ................................................... 19

II.5.1) Lummi Nation's Community Survey. ................................................................. 19

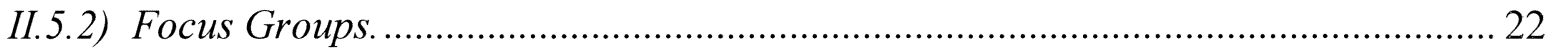

II.5.3) Secondary data collection ............................................................................. 24

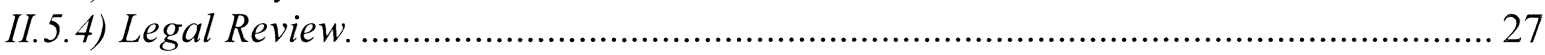

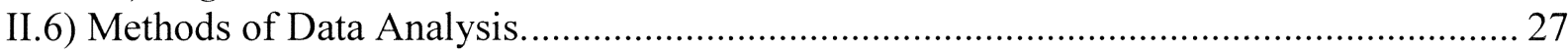

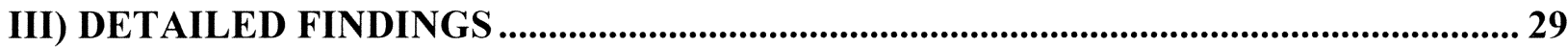

III.1) Goal 1: To increase the identification, apprehension, and prosecution of those engaged in illegal drug and alcohol transportation, distribution, or use ........................................... 29

III.1.1) Raising awareness in the community and among Northwest Coast Salish Tribes... 29

III.1.2) How the drug problem and law enforcement efforts are perceived in the community 然.

III.1.3) Impact of law enforcement efforts on the perception of change and reduction of alcohol and drug related crimes in the community ....................................................... 44 III.2) Goal 2: Reduce and organize and educate to prevent the number of highway fatalities and injuries caused by alcohol and drug use.

III.3) Goal 3: Expand Lummi Nation partnerships with federal, state, and local law enforcement agencies consistent with existing law enforcement issues through formal MOUs.

III.4) Goal 4: Increase access points to contact Lummi Nation law enforcement and provide information about crimes and criminal activity. 
III.5) Goal 5: Plan, develop and implement a holistic treatment model consistent with the alcohol/substance abuse needs of Lummi youth, adults, and families.

III.6) Goal 6: Provide active and consistent coordination of the treatment, enforcement, and support services needed by Lummi Nation youth, adults, and families. ............................... 62

III.7) Goal 7: Plan, develop, and implement transitional housing for clients....................... 69

III.8) Goal 8: Plan, develop, and implement a subsidized employment program for clients. .. 70

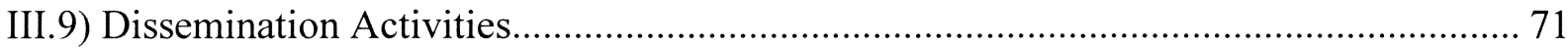

III.10) Technical Assistance Data System Findings .................................................... 72

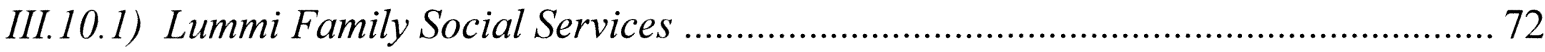

III.10.2) Lummi Nation Police Department (LNPD) ................................................... 72

III. 10.3) Lummi C.A.R.E. .............................................................................................. 73

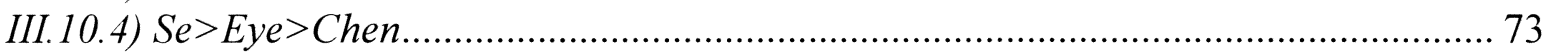

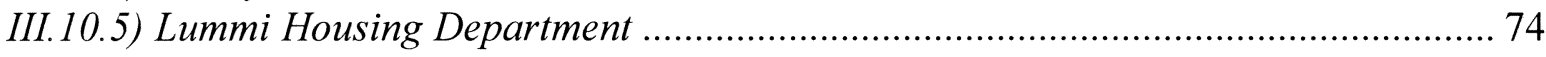

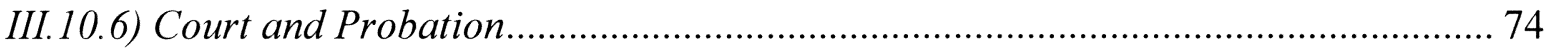

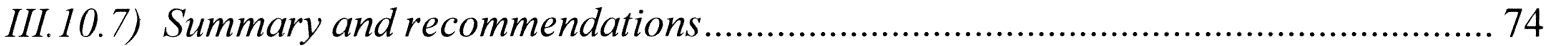

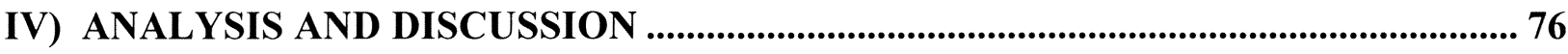

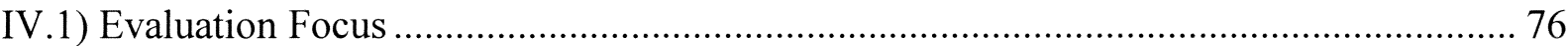

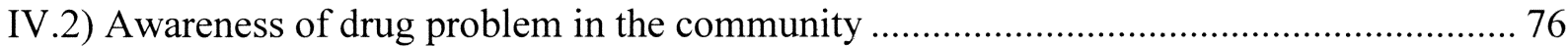

IV.3) Perception of drug problem: now and compared to three years ago .......................... 77

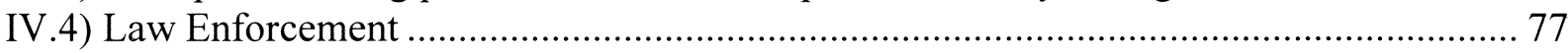

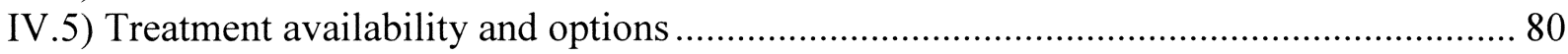

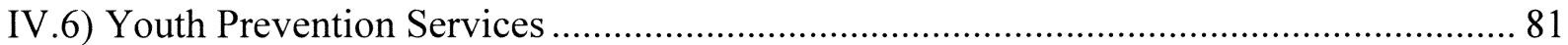

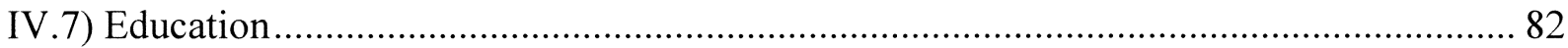

IV.8) Replication and dissemination to other tribal nations ...................................... 83

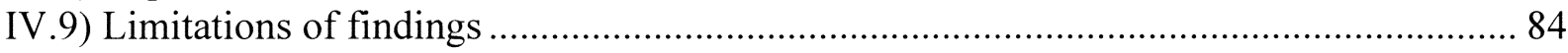

V) CONCLUSION AND IMPLICATIONS OF FINDINGS ............................................... 85

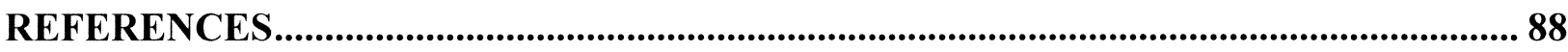

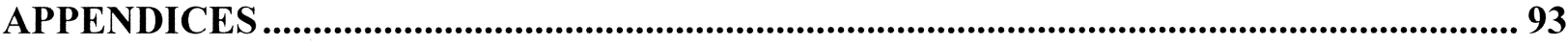




\section{EXHIBITS}

Exhibit 1: Map of the Lummi Nation and surrounding area..................................... 7

Exhibit 2: Contact record for community survey participants by number....................... 21

Exhibit 3: Demographics of community survey participants................................. 21

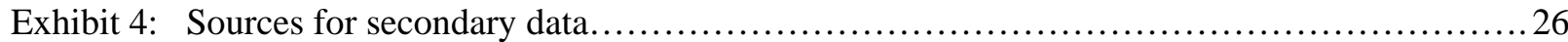

Exhibit 5: CMAD Lummi Nation Presentations............................................. 30

Exhibit 6: Lummi people view drugs and alcohol as major community problems, 2006............. 32

Exhibit 7: Drug abuse is considered a very serious problem in the community, 2006................ 32

Exhibit 8: Seriously addressing problem of drugs, drugs and/or alcohol by gender .................. 33

Exhibit 9: Regional Intertribal Presentations................................................. 35

Exhibit 10: Percentage of drugs considered a big problem for Lummi Nation, 2006................... 36

Exhibit 11: Most frequently cited "big problems" in the community ............................... 36

Exhibit 12: How powerful are outside drug connections compared to 3 years ago? ........................... 37

Exhibit 13: How good a job are the police doing at handling alcohol-related crime? ............................ 39

Exhibit 14: Effectiveness of alcohol-related crime prosecutions by gender........................... 40

Exhibit 15: How good a job are the police doing in reducing sale and use of illegal drugs? ................. 40

Exhibit 16: Reasons for dissatisfaction with police's job to reduce sale and use of drugs............. 41

Exhibit 17: How effectively do you feel drug related crimes are being prosecuted? ............................. 41

Exhibit 18: How well is exclusion working to reduce drug related crimes? ..........................................42

Exhibit 19: Perceived situation regarding drug dealers in the community $\ldots \ldots \ldots \ldots \ldots \ldots \ldots \ldots \ldots \ldots \ldots \ldots$

Exhibit 20: Most frequently cited problems in the community that are getting worse compared to 3

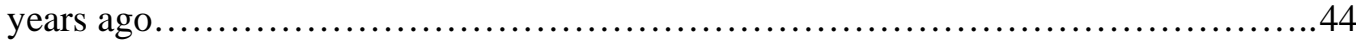

Exhibit 21: Most frequently cited problems in the community that are getting better compared to 3

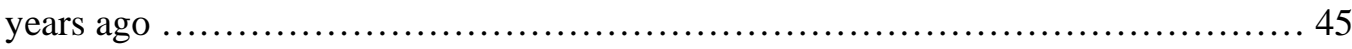

Exhibit 22: Crimes reported from 2002-2006 to Lummi Nation Police Department by tribal members

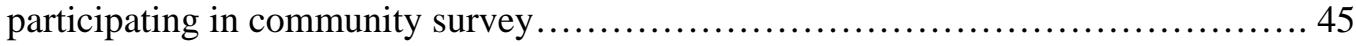

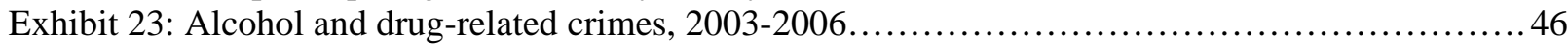

Exhibit 24: Criminal Court Cases: Adult and Juvenile Drug Offense 2002-2005................... 46

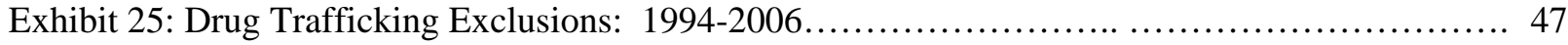

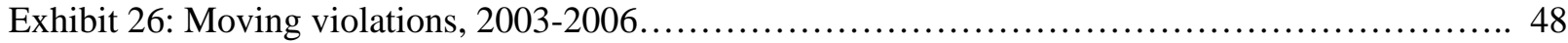

Exhibit 27: In general, how responsive is tribal police department to the community's concerns? ........ 50

Exhibit 28: Lummi C.A.R.E. Outpatient Treatment Admissions, 2002-2005......................... 55

Exhibit 29: $S e>$ Eye $>$ Chen Client Data, April 2005-March 2006................................ 56

Exhibit 30: Satisfaction with substance abuse treatment availability.............................58

Exhibit 31: Changes in health conditions: Number of clinic visits for frequent alcohol and other drug

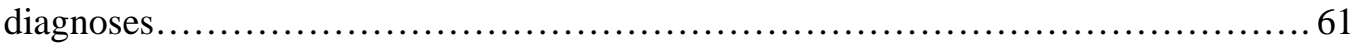

Exhibit 32: How satisfied are you with the availability of sports, recreation, enrichment opportunities, after school activities, spring break, etc....................................... 65

Exhibit 33: Youth Enrichment and Social Services: Unduplicated encounters reported to Medicaid,

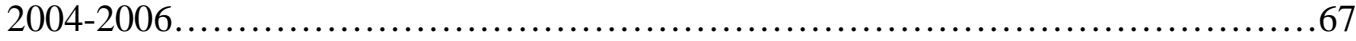

Exhibit 34: CMAD Tribal and Intertribal Presentations $(9 / 1 / 2004-8 / 31 / 2006) \ldots \ldots \ldots \ldots \ldots \ldots \ldots \ldots \ldots . \ldots \ldots$ 


\section{EXECUTIVE SUMMARY}

\section{I) PROGRAM DESCRIPTION}

In 2006, the National Institute of Justice awarded a 24-month contract to the Native American Research and Training Center (NARTC) at the University of Arizona (UA) to conduct a participatory evaluation of the Community Mobilized Against Drugs (CMAD) program implemented by the Lummi Nation (LN) in Washington State under funding provided by the Bureau of Justice Assistance’s Indian Alcohol and Substance Abuse Demonstration Programs (IASADP).

This report addresses the results of the evaluation conducted in partnership with the LN through the Lummi Indian Business Council (LIBC), which serves as the tribal authority. The primary aims of the evaluation were to determine if (1) the LN-IASADP successfully achieved its stated program goals, and whether (2) the outcomes of the demonstration project have application for other tribal communities. The proposed goals through the CMAD program were to reduce illicit drug trafficking, reduce rates of substance abuse and addiction, prevent drug abuse and underage drinking among youth, and mobilize the community in all aspects of prevention, intervention, and suppression of alcohol, drug abuse, and drug trafficking.

\section{I.1) The Lummi Nation:}

The Lummi are a Coast Salish people whose reservation includes 20,500 acres of land on two peninsulas and the Puget Sound tidelands in northwestern Washington. As of February 2006, there were 4285 enrolled members, median age 29. The tribal economy is based on a salmon and shellfish hatchery, seafood processing plant, a convenience store, a marina, a foreign trade zone, and the Silver Reef Casino and Hotel. In 2004, 74.6\% of enrolled Lummi in Whatcom County were in the labor force; unemployment was $15.9 \%$.

\section{I.2) The CMAD Initiative:}

The Lummi Nation's effort to address substance abuse and related crime issues is twopronged: (1) the Enforcement Initiative (“Stop the Harm”) enacted in 2002 in response to drug trafficking and abuse problems in the community, and (2) the CMAD Wellness Initiative begun in 2003, which aimed at curtailing drug trafficking, substance abuse, and addiction through raising community awareness. 


\section{II) SCOPE AND METHODOLOGY}

To accomplish this evaluation, the evaluation team: (1) established an Evaluation Oversight Committee (EOC) comprising tribal members and UA evaluators; (2) developed a logic model that described the evaluation process; and 3) evaluated the project based on the goals described in the LN-IASADP proposal. The evaluation process utilized quantitative, qualitative, and secondary data. The quantitative source was based on a survey conducted with 100 community members to assess their perceptions of tribal efforts to address alcohol and drug abuse related problems. The qualitative source was based on data obtained from six focus groups, informal and formal interviews, discussions with key staff members during field visits, etc. Relevant secondary data sources were obtained to support and expand on the empirical data. A fourth goal involved providing technical assistance on data management to the IASADP.

A detailed historical review was also conducted on the interplay of federal, state, and tribal law in dealing with drug-related crimes.

\section{III) RESULTS}

Results of the evaluation of the Lummi Nation CMAD Initiative are presented in response to the goals listed in the Lummi Nation's BJA-IASADP proposal.

\section{III.1) Goal 1: Increase identification, apprehension, and prosecution of those engaged in illegal drug and alcohol transportation, distribution, or use.}

Most respondents (41\%) felt the Lummi Nation Police Department (LNPD) was doing a "fair" job, and 36\% felt they were doing a "very good" and "good" job.

Over 59\% felt that rates of underage drinking today compared to three years ago were "about the same;" 9\% felt they were "worse."

Over $59 \%$ of respondents felt the police were doing "about the same level as three years ago" in reducing the sale and use of illegal drugs; $28 \%$ felt the police were doing "better" now.

Over 52\% felt exclusion was working "very well" and "well” in reducing drug related crimes. Community members see a reduction compared to three years ago in drunk and disorderly conduct, violent crimes, and gang activity, but less positive changes in the area of drug dealers in the community. Drug use was most often cited as getting "worse" compared to three years ago. 
III.2) Goal 2: Educate to prevent the number of highway fatalities and injuries caused by alcohol and drug use.

There were no fatal motor vehicle accidents in 2005, a slightly reduced number of accidents resulting in injury, but a 39\% increase in DWIs since 2003.

III.3) Goal 3: Expand Lummi Nation partnerships with federal, state, and local law enforcement agencies through formal Memorandums of Understanding (MOU)

No MOUs were signed between the LNPD, the LIBC, and any federal, state or local law enforcement agencies. A network has developed to share information and expertise about alcohol and drug use, to reduce traffic accidents and fatalities and drug trafficking and recidivism, and to support wellness and recovery among incarcerated American Indians. The LN is currently working on developing a Restorative Justice Center with neighboring Coast Salish Tribes.

III.4) Goal 4: Increase access points to contact LNPD and provide information about crimes and criminal activity.

Seventy percent of respondents felt the police are "very responsive” and "somewhat responsive” to criminal activities.

III.5) Goal 5: Plan, develop, and implement a holistic treatment model consistent with the alcohol/substance abuse needs of Lummi youth, adults, and families.

Under the CMAD Initiative, Lummi C.A.R.E. offers group session therapy to adults and youth; additional outpatient treatment is offered through the Suboxone Clinic. In addition, CMAD opened an in-patient youth treatment facility (Se>Eye>Chen).

Over $71 \%$ of respondents were "very satisfied" and "somewhat satisfied" with the availability of treatment services, although they called for increased duration of treatment, improved outreach to those in need, and better aftercare support.

III.6) Goal 6: Provide support services needed by Lummi Nation youth, adults, and families.

Over $82 \%$ of respondents were "very satisfied" and "somewhat satisfied" with the availability of youth oriented services. The "Safe House" provided a safe and structured environment for 165 youth between 2003 and 2005, and the Youth Enrichment and Social 
Services Program provided mental health and supportive services to over 1000 youth and families from 2004-2006.

\section{III.7) Goal 7: Plan, develop, and implement transitional housing for clients.}

The Transitional Recovery Program was developed to provide transitional off-reservation subsidized housing for Lummi adults and emancipated youth in their first year of drug and/or alcohol recovery. In 2006, 50\% of the clients successfully completed the assistance program. Data for 2007 (first 8 months) showed that approximately 32 \%, respectively, successfully completed or were enrolled in the program at the time of data collection. Development of an onsite transitional housing program is in the planning stage.

III.8) Goal 8: Plan, develop, and implement a subsidized employment program for clients.

Approximately $60 \%$ of those responding to the community survey were "very satisfied" and "somewhat satisfied" with job opportunities in the community. No new employment programs are in place.

\section{IV) ANALYSIS AND DISCUSSION}

\section{IV.1) Awareness of drug problem in the community}

The CMAD Initiative raised awareness about the dangers of drug use and the legal consequences of drug trafficking and use. Community members associate CMAD with fighting drugs and/or alcohol in the community.

\section{IV.2) Perception of drug problem: now and compared to three years ago}

Drug use remains a critical concern within the community, which feels the problem has not diminished over the last three years. Drug dealers are also considered a major problem by community members.

\section{IV.3) Law Enforcement}

Community members believe alcohol related crimes are handled better by the police and prosecuted more effectively than are drug-related crimes. More men than women view the police as doing a better job and the courts as being more effective.

Exclusion has impacted the discussion on drug crimes through community awareness of it as a more serious and life altering punishment than a jail sentence.

\section{IV.4) Treatment availability and options}


The community views the availability of treatment services favorably. Many feel treatment should be longer and accessibility to treatment increased. Community members called for more prevention services for young people of the community.

Implementation of aftercare services has been challenging. The Housing Department is working on implementing on-site transitional housing. It has already successfully launched its off-site housing program, and numbers of clients served in that program continue to rise.

\section{IV.5) Replication and dissemination to other tribal nations}

The CMAD model has been presented through workshops, intertribal conferences, and events, giving hope to many tribes who see the holistic approach the Lummi are using as innovative, appropriate, and audacious.

\section{V) CONCLUSION AND IMPLICATIONS OF FINDINGS}

The CMAD Initiative implemented many of the components defined in its IASAD proposal, made a significant impact on the consciousness of community members about drug use and alcohol and drug related crimes, and alerted many tribal communities to a new broad, holistic method for tackling those problems.

The CMAD Initiative has not been able to develop formal external MOUs with other Coast Salish tribes and law enforcement agencies. The concern about the flow of drugs and drug traffickers into the community remains a major concern of the Lummi people. Obtaining MOUs would be an important step towards addressing this problem.

Based on the validation it has received from other tribes, CMAD is a culturally appropriate method that draws in key departments and programs to address substance abuse problems. Because many of the programs fostered under the initiative are new, it is not clear whether they are successful. Only additional, careful internal evaluation and monitoring can assess their effectiveness.

Finally, whether CMAD stays in its present form or takes on a new configuration, the work it has begun certainly merits continuation. 


\section{I) PROGRAM DESCRIPTION}

In 2006, the National Institute of Justice awarded a 24-month contract to the Native American Research and Training Center (NARTC) at the University of Arizona (UA) to conduct a participatory evaluation of two demonstration projects funded under the Bureau of Justice Assistance’s (BJA) Indian Alcohol and Substance Abuse Demonstration Programs (IASAPD). The two tribal communities that agreed to participate in the evaluation were the Lummi Nation in Washington and the Sisseton-Wahpeton Oyate (SWO) tribe in South Dakota.

This report addresses the participatory evaluation conducted in partnership with the Lummi Nation through the Lummi Indian Business Council (LIBC), which serves as the tribal authority. The general purpose of the evaluation was to determine 1) Is the initiative successful in achieving its stated goals? and 2) The outcomes of the demonstration project have application for other tribal communities? While it was not possible to assess the projected long term outcomes of CMAD, evaluations of the short term outcomes were conducted to determine the visibility of the initiative, community support and awareness, and the impact on public safety and tribal policy.

\section{I.1) Background: Substance Abuse Problems in American Indian Communities}

Understanding substance abuse problems in the Lummi Nation requires the researcher to have an historical perspective of substance abuse issues among American Indians in general and of the types of community based programs that have been developed to address alcohol and drug abuse in Indian Country.

At the encouragement of many tribal leaders, the federal government in 1832 established a policy prohibiting possession and use of alcohol by Indians as well as the selling of alcohol to Indians. This policy was not repealed until 1953. Despite the prohibition, alcohol abuse and alcoholism continued throughout the generations, and when motor vehicles became the most popular mode of transportation, alcohol related motor vehicle accidents caused drastic increases in alcohol related mortality and morbidity in Indian Country. As alcohol-related mortality and morbidity continued unabated over the years, the federal government initiated a number of resources to prevent and treat alcohol abuse and alcoholism in tribal communities. In addition to resources under IASADP, various alcohol and substance abuse prevention and treatment programs have been implemented. For example, one of the more recent key policies enacted by Congress has been the passage of the 1986 Indian Alcohol and Substance Abuse Prevention and 
Treatment Act, PL 99-570, which authorized a comprehensive and coordinated attack on illegal drug trafficking in Indian country and on the deleterious impact of alcohol and substance abuse on tribal communities. The policy also gave tribes an opportunity to develop and implement coordinated programs for prevention and treatment. Amendments to this policy expanded the authority to include problems of alcohol and substance abuse among Indian youth.

Scholarly and public health interests in this problem are also ongoing. Numerous studies and reports indicate that alcohol and drug abuse and related crimes continue to be a challenge for many tribes, including the Lummi Nation. According to the recent federal Indian Health Service (IHS) statistical report, alcohol related mortality among American Indians (AI) for 1995-1998 was 7.4 times the U.S. rate, all races (I.H.S., 2004). Studies of specific tribes and urban Indian populations also show that rates of alcohol and substance abuse vary inter-tribally (Spicer et al., 2003; Denny et al., 2003), by age group, and by gender (May 1995). Most reported drinking behavior occurs among AI/ANs between ages 15 - 44. Rates of alcohol use among AI youth are also quite high. Oetting and Beauvais (1989) report that 96 percent of AI males and 92 percent of AI females in the $12^{\text {th }}$ grade report they have used alcohol. National Center for Health Statistics (NCHS) data indicate that 21 percent of AIs, ages 12 - 17, have used alcohol within the previous month (NCHS, 1999) and that AIs are five times as likely to die from alcohol related causes as non-Indians (NCHS, 1999).

The IHS calculates that mortality rates from alcoholism and alcohol abuse among reservation based American Indians compared to rates in the general population were 13.5 times the rate for ages 25-34 and 9.1 times the rate for ages 35-44 (I.H.S. 2004). Four of the ten leading causes of death among AI—chronic liver disease and cirrhosis, suicide, homicide, and accidents — are alcohol related (May 1995; Wallace et al., 1997). Citing I.H.S. statistics for the period 1986 - 1988, May (1995) found that 17 - 19 percent of all American Indian/ Alaska native (AI/AN) deaths were alcohol related compared with 4.7 percent for the U.S., all races. These figures include alcohol related deaths from vehicular accidents (65\%), suicide (75\%), and homicide (86\%). Alcohol related motor vehicle deaths for 1997 were three times the U.S., all persons rate, and motor vehicle accidents and unintentional injuries were the leading cause of death for AIs, ages 1-44 (I.H.S., 2004). May attributes most alcohol related deaths to “recreational” or "binge” drinking (predominantly men, ages 15 - 35) as opposed to "chronic 
alcoholism” (anxiety drinking), and notes that among Indians, recreational or binge drinkers outnumber chronic alcoholics by 3:1 (May, 1995).

According to the BJA, 62 percent of crimes (1992 - 2001) in Indian Country were alcohol related compared to 42 percent for the U.S. resident population (Perry, 2004). In reported cases of violent crimes where the substance user was known to the victim, 48 percent were under the influence of alcohol, 9 percent were under the influence of drugs, and 14 percent were under the influence of both alcohol and drugs. This report also indicated the rates of violent crime on Indian reservations were 2.5 times that of the U.S. resident population. Notably, AI women experience double the rate of sexual assault compared to the U.S. all women rate, and 40 percent of domestic violence cases among Indians involve alcohol use. Liquor law violation arrest rates among Indians during 1992 - 2001 were 2.8 times that of the U.S. population, all races (Perry, 2004).

Age adjusted rates of AI morality associated with illicit drug use in 1997 were 1.8 times greater than the U.S., all races rate (I.H.S., 2004). Over 51 percent of AI over age 12 report using illicit drugs (marijuana, inhalants, prescription drugs, methamphetamine, cocaine) in the past year compared to rates of use among other ethnic groups, which range from 20.8 percent (Asians) to 42 percent (Whites) (SAMHSA, 2000). Among all American youth, 31.2 percent report using drugs within the past year. The National Institute on Drug Abuse (NIDA, 1998) survey results show decreasing drug use for AI students except for marijuana and hallucinogen use, which show an increase in use. American Indians have higher rates for marijuana use across all age groups compared to non-Indians: $12-17$ years, 18.4 percent vs. 6.9-7.3 percent; 18-25 years, 25.4 percent vs. 6.1-14.4 percent; 26-34 years, 12.6 percent vs. 3.6-9.2 percent. The rate of current illicit drug use among 12-17 year olds is 22.2 percent (SAMHSA, 2000). Rates of hallucinogen use by 12-17 year olds were 3.79 percent for AI compared to 0.2-1.1 percent for non-Indians (SAMHSA, 2000). Many of those who use illicit drugs are polysubstance abusers.

\section{I.2) Background: Community Based Substance Abuse Prevention/Treatment Programs}

Results of community-wide intervention and prevention efforts have been mixed. The most noted example of a community-based program that successfully rallied the whole community to eliminate the problem of alcohol abuse is that of the Alkali Lake Band of the Shuswaq Indians in British Columbia, a unique community effort which reduced alcohol consumption from 95 percent to 5 percent (Guillory et al., 1988). Using a modified Alcoholics 
Anonymous program, the Alkali Lake group achieved this remarkable result by creating a community culture that refused to tolerate drinking. Unfortunately, this type of community level approach has not been replicated elsewhere, and a much needed longitudinal study of the sustainability of this community effort has not been conducted.

Another approach successfully implemented in Indian communities is based on the Community Readiness Model (CRM) developed by the Tri-Ethnic Center for Prevention Research at Colorado State University (Edwards et al., 2000; Oetting et al., 1995). The CRM program employs six primary dimensions that enable the community to provide a perspective of a community's ability to address a problem. Each of the dimensions is scored using a "nine stages of readiness” scale that ranges from "no awareness” to "professionalization.” After assessing the readiness stage, community leaders then develop strategies for moving to the next higher stage. This model requires multiple systems and is dependent on the development and use of community resources and strengths (Jumper-Thurman et al., 2004).

Another interesting intervention has been the community based Healthy Nations Initiatives (HNI) projects funded by the Robert Wood Johnson Foundation (RWJF). The HNI were implemented by a number of tribes in the early 1990’s to develop community wide programs to combat substance abuse, to implement prevention programs, to develop public awareness programs, to develop aftercare programs, and to facilitate treatment services (Noe et al., 2004). Each community was asked to find and to develop its own solutions/programs. Programs were evaluated based on whether or not they generated interest in the problem, were successful in engaging people as advocates or volunteers, enhanced community capacity by training and by allocating resources to the programs, influenced policy, and were able to create the necessary infrastructure to sustain the programs (Noe et al., 2004). According to Noe and his colleagues, the HNI program demonstrated that AI/AN programs have the capacity to successfully address substance abuse problems if the resources are available (2004).

Although very few tribal communities have participated, one of NIJ's more effective community based programs to combat drugs and crime is Operation Weed and Seed, a strategy used in urban neighborhoods to control violent crime, drug trafficking, and drug related activities in order to create a safe environment (Roehl et al., 1996; Dunworth and Mills, 1999; Plested et al., 1998). Implemented in over 200 communities by 2000, the program links law enforcement efforts ("weeding) with human services activities ("seeding”), i.e., seeding the neighborhood 
with “prevention, intervention, treatment, and revitalization” to deter crime (Roehl et al., 1996). Evaluation of the program found six key factors to program success: 1) strength of the social/institutional infrastructure; 2) severity of crime problems; 3) economic development potential; 4) transience of population; 5) strength of leadership; and, 6) how sites concentrated their program resources (Dunworth and Mills, 1999).

In summary, alcohol and drug abuse are clearly major problems among AI communities. Recent studies show that AI community based approaches for the treatment of substance abuse are evidencing success when appropriate resources are available to develop and sustain these treatment modalities (Noe et al., 2004).

\section{I.3) Lummi Demonstration Project: Community Mobilization Against Drugs (CMAD) Initiative}

The focus of this participatory evaluation is the CMAD initiative implemented by the Lummi Nation, one of the Pacific Northwest Coast Salish tribes. The impetus for the creation of a formal community mobilization effort against all substance abuse, its suppliers, and the resulting crime, came from several “tipping points.” Between 2002 and 2003 there were six drug-related deaths, five drive-by shootings, the birth of 13 drug-addicted babies, and the arrest of 33 tribal members for smuggling drugs from Canada. Of the drug-related deaths, one was an 18-month old baby who had accidentally ingested Oxycontin from the floor of her home; another was a two-month old infant found dead in a baby swing while surrounded by drug abusers. There were also 1833 tribal members in need of treatment for substance abuse, including 500 who were addicted to Oxycontin and 200 who were addicted to heroin (Mapes, 2003). Estimates are that the Lummi reservation has \$2 million annually in illegal Oxycontin sales (Kershaw \& Davey, 2004).

These events led to a proactive stance on the part of the tribal leaders of the Lummi Nation and the passage of two resolutions by the Lummi Indian Business Council (LIBC). The first resolution, passed in November 2002, created CMAD (\#2003-127) and placed it within the office of the Chairman; the second resolution (\#2004-087) approved amendments legitimizing "banishment” to Title 12, the Exclusion Code of the Lummi Code of Laws. The Nation also submitted an application to BJA for IASADP funding to plan and develop a number of interventions under the umbrella of CMAD to address the epidemic of substance abuse and related criminal activities on Lummi. 
The authorization for the IASADP funding from BJA was allowed under the Fiscal Year 2001 Consolidated Appropriation Act. The purpose of the IASADP resource is to help tribes plan and implement programs to reduce and control crime associated with the distribution and abuse of alcohol and other controlled substances. According to a BJA fact sheet, 57 tribes from 19 states have thus far received IASADP funding (BJA, 2007). Each tribal application addresses a different problem. Some have focused on increasing collaboration with their respective states, counties, and other local criminal justice agencies, while others have implemented treatment programs that incorporate culturally appropriate treatment services.

In 2003 the Lummi Nation was one of six tribes receiving IASADP funding that enabled the Nation to address its alcohol and drug problems at multiple levels through the Community Mobilization Against Drugs (CMAD) Initiative. The CMAD Initiative was also being funded in part by proceeds from the Lummi Nation owned Silver Reef Casino.

\section{I.4) History of the Lummi Nation}

The Lummi are Salishan Indians who speak the Songish dialect of the Salish language. A Coast Salish people, the Lummi were a Sovereign Nation prior to being discovered by nonIndian explorers and were ruled through tribal leadership held accountable to the people. Aboriginal lands of the Lummi people included the San Juan Island network and the mainland along the now designated Nooksack River system. Land holdings by the tribe encompassed the island system and extended into western and northern Canada. The territory flowed to Point Roberts along the bay to include the lands of the Semiahmah and Birch Bay tribes. The southern boundaries were demarcated by the lands of the Upper Skagit and Samish tribes. The scope of the original lands is important to the Lummi as they ascribe many of their current woes to the loss of the bounty these lands and waterways provided for physical and spiritual survival (Lummi Nation, 2005).

The Lummi people, known as a salmon harvesting people, were the first to use reef netting to harvest the plentiful salmon stocks. The main mode of transport for the Lummi was cedar canoes, and hence they were also known as the Cedar people. Status was determined by possession of rights to harvest grounds and first rights of access as well as knowledge passed on within the spiritual, ceremonial, and sacred domains. Political alliances were formed through marriages among leadership families of tribes. 
The Europeans and their diseases invaded the lands of the Coast Salish tribes resulting in the deaths of 60 -100 percent of village inhabitants by the late 1700s. The Lewis and Clark expedition opened up the Pacific Northwest in the early 1800s to United States expansion. The Discovery Doctrine (1823) set the stage for the United States claims to the Pacific Northwest with Indians as temporary occupants to be displaced either by war or by a peace treaty. The Lummi people were never conquered through an act of war by the United States; rather they have a government-to-government relationship based upon a peace treaty. The Lummi peoples' permanent homeland was established in 1855 by the Point Elliot treaty (See Exhibit 1 for a map of the current land mass of the Lummi Nation).

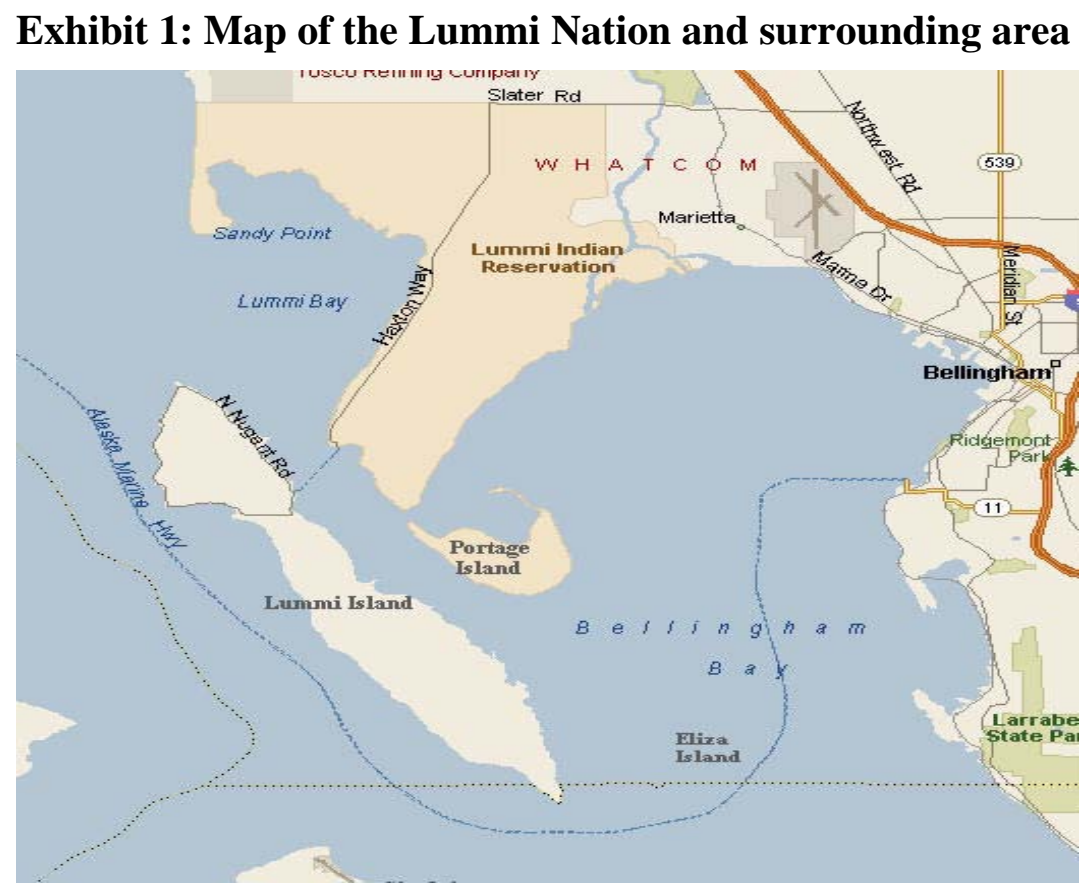

The Lummi Nation became a self-governing tribe under the Indian Reorganization Act of 1934 and adopted its own constitution in 1948, which it amended in the 1970s and the 1990s. Lummi does not have enough land to support its people. Although the reservation was defined by the Point Elliot Treaty, land holdings were diminished through the presence of non-Indian squatters (1860s) and the Oregon Donation Land Claims Act (1873), which opened up sales of land on Lummi to non-Indians. The General Allotment Act (GAA) of 1887, amended in 1910, destroyed tribal cultural bases and traditional land ownership patterns. Inherited lands, unavailable for development due to fractionated titles held by multiple heirs, were sold by the 
BIA. Today, some of the choicest pieces of waterfront real estate on Lummi are owned by nonIndians. Some lands are no longer considered suitable for development due to their designation as wetlands.

\section{I.5) The Lummi Nation Today}

The current Lummi Reservation occupies 12,500 acres of land on two peninsulas in addition to 8,000 acres of Puget Sound tidelands on the western end of Whatcom County in northwestern Washington. The reservation is eight miles from the city of Bellingham, 20 miles south of the Canadian border, and approximately 90 miles north of Seattle.

As of February 28, 2006, there were 4285 enrolled members with a median age of 29, with 29 percent under 18 years of age, and 12 percent 55 years or older (Vital Statistics, 2006). There is approximately a 50 percent gender split. Over 78 percent live on or near the reservation, and the average household size is 4.5 persons (Wikipedia Encyclopedia, 2005).

In 2004, almost 85 percent of enrolled Lummi in Whatcom County, 25 to 64 years of age, had a high school diploma or GED, and approximately 9 percent had a bachelor's or higher degree. This represents a lower figure for advanced degrees than is true for American Indians in general (Northern Economics Inc., 2005). Educational opportunities on Lummi include the Northwest Indian College offering AA and BA degrees, Lummi Tribal High School, Lummi Nation School including Lummi Grade School and Lummi Middle School, and Home Start and Head Start programs (Lummi Nation, 2005). A residential leadership academy for homeless or frequently homeless students is in the construction phase (J. Folsom, personal communication, 9 October 2007).

Traditionally, one of the primary economic activities of the Lummi and other Coast Salish tribes has been fishing. In 1855, a treaty was signed with the Suquamish, Swinomish, and Lummi reservations securing fishing, and hunting and gathering rights to the tribes. Upon attaining statehood in 1889, Washington failed to protect Indian fishing rights and restricted Indian secured water rights by outlawing off-reservation fishing. The affected tribes sued the state (U.S. v. Washington Decision, 1974) and won back their fishing rights, although by that time, the salmon runs were almost extinct through commercial depletion. El Niño currents, the entry of Norway, Chile, Korea, and Japan into the salmon and shellfish supply market, and the tripling of the state fleet all contributed to the collapse of the Indian fishing fleet in the 1980s. The traditional Lummi lifestyle of tribal salmon fishing and collecting shellfish has also 
disappeared because of the reduction in annual Salmon catches in the early 1990s, resulting in the loss of almost 500 jobs. A reduced salmon and shellfish hatchery and a seafood processing plant are part of the economy of Lummi today, but are a mere shadow of what was.

Federal withdrawal of funding during the Reagan era forced the closure of a number of other Lummi economic enterprises. Lummi Aquaculture, the school of Lummi Aquaculture (LISA), the Lummi Fishing Buying Company (LIFCo), the Lummi Construction Company, and Lummi Indian Tribal Enterprises (LITE), an enterprise management company, all closed their doors due to cessation of support. The tribal economy today is based on the salmon and shellfish hatchery, the seafood processing plant, a convenience store, a marina, a foreign trade zone, and the Silver Reef Casino and Hotel. Over 61 percent of adults, ages 18-64, are employed and have a median monthly income of \$2000 (Walker, 2003). As of 2004, approximately 15 percent of Whatcom County Lummi own or are partners in small businesses (Northern Economics, 2005). The most common types of business are commercial fishing, crabbing, and shellfish (135 persons), followed by fireworks (26 persons), construction (26 persons), sales (22 persons), and food preparation (22 persons).

In 2004, 74.6 percent of enrolled Lummi in Whatcom County between the ages of 18 to 64 were in the labor force; unemployment was 15.9 percent. Almost 67 percent of employed enrolled Whatcom County Lummi held full-time, year-round jobs, 20 percent held part-time jobs, and 13 percent had full- time seasonal or temporary jobs. In 2004, the top five occupations of Whatcom County Lummi included fishing and forestry (17 percent), office administration (13.5\%), personal care and service (11.3\%), management (7.2\%), and construction and extraction (5.8\%).

The Lummi educational system, the Lummi TERO office, and Human Resources are attempting to meet the retraining needs of Lummi fishermen and others in helping them develop the necessary job skills for available positions such as in the Silver Reef Casino and Hotel. One issue is that with nation-wide drug testing, many tribal members cannot pass tests that verify they are drug and alcohol-free (Lummi Nation, 2005).

\section{I.6) The CMAD Program}

The Lummi Nation's effort to address substance abuse and related crime issues was twopronged: (1) the Enforcement Initiative ("Stop the Harm”) put forth in 2002 in response to the drug trafficking and abuse problems in the community, which enabled the Lummi Nation Tribal 
Law Enforcement and the Tribal Court to work in conjunction with CMAD according to the amended law and codes (Juvenile Code, Nation-Wide Drug Testing, Banishment Code), and (2) the CMAD Wellness Initiative begun in 2003, which aimed at curtailing drug trafficking, substance abuse, and addiction through raising awareness of the community so that the services available (Lummi C.A.R.E, Youth Safe House, Y.E.S.S.) were known to and used by the Lummi people, and new services, such as the proposed inpatient drug treatment facility, would be well planned and advertised.

The CMAD Initiative is based in part on the CRM (see previous description). It was adopted to assess the receptivity of tribal members to confront drug-related crime in the community. CMAD saw a match between its desire for a holistic approach to crime and substance abuse and the Comprehensive TEPEE Strategy, renamed Shxwolewen in Salish. CMAD embraced the guiding principles of TEPEE, which represent a strategy for addressing five ongoing community needs: treatment, education, prevention, employment, and enforcement.

Tribal activities under CMAD have included hiring a narcotics detective, increasing police coverage, adopting a zero tolerance policy for drugs and alcohol at schools, initiating

drug-testing nation-wide, establishing a new tribally administered adult drug court targeting nonviolent drug abusers with misdemeanors, and implementing a 'banishment” policy for those convicted of selling drugs (Shukovsky, 2002; Washington, 2005). The proposed goals for further mobilization through CMAD were to reduce illicit drug trafficking, reduce rates of substance abuse and addiction, prevent drug abuse and underage drinking among youth, and mobilize the community in all aspects of prevention, intervention, and suppression of alcohol, drug abuse, and drug trafficking (Lummi Nation, 2003).

On October 30, 2004, the Lummi Nation through CMAD initiated renovation of a former apartment complex into a treatment center. As part of CMAD, Lummi opened the Se>Eye $>$ Chen youth wellness home in April 2005 for young persons between the ages of 8 and 18, who were referred by courts, schools, or social services (Lei, 2005). In 2002, the Lummi Nation received $\$ 429,844$ from SAMHSA to help fund its youth family wellness program (now a component of CMAD). Among its other responsibilities, the Y.E.S.S. program provides counseling services for social and emotional support to children, youth, and their families.

\section{I.7) Lummi Law Enforcement}

As of October 31, 2005, the Lummi Tribal Police Department had 19 commissioned 
officers and two civilian employees (Washington State Agencies, 2005). Included in the department were administrative staff, fish and natural resource officers, police officers, a building housing the police department, multiple squad cars, and a mobile response unit. The Lummi Tribal Court is a fully functioning judicial system and a self-government division of the Lummi Nation. It comprises a new court house, a chief judge and nine pro tem judges, six prosecutors and over two dozen support staff (Lummi Nation, 2005). The Lummi Adult Drug Team, which consists of nine persons, integrates judges, public defenders, drug counselors, police officers, case coordinators, data analysts, and evaluators in addressing adult drug cases. Juvenile probation officers and the chief welfare attorney, who is one of the prosecutors, address the needs of the youth.

\section{I.8) Implementation of a Participatory Evaluation with the CMAD Initiative}

The purpose of this participatory evaluation for the Lummi Nation (LN) was to determine if the Community Mobilization Against Drugs (CMAD) Initiative has been implemented, is effective in meeting its goals, and can be generalized to other tribal nations confronting similar issues related to alcohol and drugs. To fulfill this goal, the University of Arizona (UA) evaluation team conducted a participatory evaluation with the Lummi Nation. Participatory evaluation mandates the inclusion of expertise from both the nation through an evaluation oversight committee (EOC) and the UA evaluation team so that the evaluation process is sensitive to the tribal environment while being conducted within a framework that is scientifically rigorous. Recommendations from the site visit conducted by BJA contractor staff indicated that CMAD would benefit strongly from a formal and rigorous evaluation process that addressed its short-term goals and the impact of the initiative to date.

Since there is a lack of jail facilities and correctional resources throughout the Pacific Northwest, the Chief of Police for the Lummi Nation is working with other Coast Salish tribes (Nooksack, Samish, Sauk-Suiattle, Stillaquamish, Swinomish, Tulalip, and Upper Skagit) to secure a state-of-the-art Regional Tribal Restorative Justice Center in the Pacific Northwest. Such a facility, an example of the Coast Salish outreach efforts, would provide a full range of services to native offenders, including corrections, treatment, recovery, and skills building (James, 2007).

Participatory evaluation supports both high visibility of the community in project implementation and in maintenance of sustained community collaboration in dealing with 
substance abuse trafficking and substance abuse prevention. The goals of the CMAD initiative placed emphasis on law enforcement and fostering well-being, with the key elements focusing on community and agency collaboration and mobilization. As part of the evaluation, coordination of Lummi law enforcement with federal, state, and county agencies was examined as well as the coordination of services for treatment and recovery. 


\section{II) METHODOLOGY AND SCOPE}

The purpose of the evaluation of the Lummi Nation's Community Mobilization Against Drugs Initiative (CMAD) was to determine if the model program is effective and if it has application for other tribal nations confronting similar public safety issues related to substance abuse. As a formative evaluation, it should provide information that can be used for program improvement or redirection. It addresses the question: What, if any, changes need to be put into place to enhance the effectiveness of the program's implementation? Subsumed under that question, the evaluation must ask: Is CMAD meeting its stated goals? What was successful? What were the barriers? and Does the model have application for other tribes?

To conduct this evaluation, the team from the University of Arizona (UA) partnered with community stakeholders, including the program coordinator, on all components of the evaluation process. In doing so, the evaluation process remained sensitive to the tribal environment, constraints, and cultural and social perspectives while being conducted within a scientifically rigorous framework.

\section{II.1) Conceptual Framework}

The conceptual framework used to conduct the evaluation of the Lummi Nation's CMAD Initiative centered on the development and implementation of a community-based participatory evaluation (CBPE). Participatory evaluation is a process by which community stakeholders are directly involved in the identification of evaluation issues, the design of the evaluation, and the collection and analysis of data and the actions resulting from the outcomes of the evaluation (Jackson 1998). In this type of evaluation, the notion of collective participation centers on structured methods of evaluation that dictate the direction and implementation of the process.

This CBPE framework benefits the researcher, the stakeholders, and the community. It benefits the researcher by providing an ethnographic base of in-depth knowledge about the community and the program. It also commits the evaluation team to using culturally appropriate methods of data collection. It helps ensure that the results obtained reflect the community. Obtaining the support and commitment of community stakeholders to the evaluation process supports the implementation of the evaluation, enhancing the likelihood that it will be successfully completed. Involvement of the stakeholders helps ensure that the interpretation of the data is informed and representational. Their continued involvement and participation assures them of their role in the process and how their input informs it. In the current project, CBPE 
offers the community and the evaluation team a means to measure a uniquely holistic approach to combating drug use and drug-related crimes. It provided a means for assessing commitment and awareness of these and related issues with community members. It validated efforts to attempt a broad encompassing approach that included intertribal efforts, and it enriched knowledge and appreciation of evaluation as a viable tool for understanding the program and the importance of collecting accurate data. Participants benefited from participation in this form of evaluation in many ways. The evaluation measured awareness and level of acceptance of the status quo, e.g., what community members were willing and not willing to live with. Finally, it measured commitment to change and assessed awareness and knowledge of support, services, and policies.

Two overarching research questions drove this study: (1) Is the program successful in achieving its stated program goals? and (2) How effective is the participatory evaluation model in assisting the program to develop its own sustainable program evaluation process? The evaluation had four goals:

Goal 1: Establish a partnership at LN that fosters tribal ownership, support, and input in the evaluation process.

Goal 2: Construct a logic model for the Lummi site that summarizes program mechanisms of evaluation and change through the linking of resources, activities, and program outcomes (see Appendix A).

Goal 3: Evaluate the program in place using the program goals-reduce illicit drug trafficking and reduce rates of substance abuse disorder and addiction.

Goal 4: Provide (where needed) on-going technical assistance in order to foster program sustainability.

The above goals dictated the evaluation plan, which covered three phases over the course of the two-year funding period.

- Phase 1: Start up. During this phase (10 October 2005 - 30 March 2006) the evaluation team met with the CMAD coordinator and the CMAD members; established the evaluation oversight committee (EOC) with the assistance of the CMAD coordinator; visited with key programs; discussed, amended, and obtained consensus on the evaluation plan and logic model; reviewed and revised instruments (community survey and focus group questions) and consent forms with input from the EOC; mapped out a workable timetable for on-site visits, trained on- 
site Lummi interviewers in interview procedures and protocols, data collection, and presentation; hired and provided training for on-site interviewers; and submitted IRB paperwork for approval to the University of Arizona Institutional Review Board (IRB) paperwork and the NIJ IRB.

- Phase 2: Implementation. Primary and secondary data collection, entry, and analysis (1 April 2006-30 May 2007) were conducted during this time period. In addition, interviewers received human subjects training, and the project was approved by the University of Arizona's and the NIJ's IRBs in late February 2006, which enabled data collection to proceed. During this phase there was extensive collection, entry, and analysis of quantitative and qualitative data, presentation of drafts of findings, presentations on methodology, and initiation of dissemination. As part of the data collection, 100 community surveys were administered to a random sample of adult tribal members living within the Lummi Nation. Six focus groups were held with individuals representing the following populations: service providers, policy makers, adult clients and family members, youth, traditional tribal healers/practitioners, and community members. Secondary data was collected from multiple tribal departments and from units that are part of the CMAD collaborative and deal directly with issues identified by the Initiative as key areas to address in combating drug use and drug-related crimes in the community. These units included the Lummi Nation Police Department, Lummi Tribal Court, CARE (adult and youth out-patient treatment), Se $>$ Eye $>$ Chen (youth in-patient treatment, Youth Enrichment and Social Services Program, or “Y.E.S.S.” (prevention programs, youth outreach, and counseling services), the Home of Healing Spirits, or "Safe House" (youth in-patient mental health respite), the Lummi Health Clinic, and the Housing Department. In addition to the primary and secondary data collection, a detailed historical review was completed of U.S. law and its impact on American Indian tribes’ ability to handle drug trafficking in their communities. This review, while broad in outlining the series of acts and laws governing criminal jurisdiction on reservations, was also specific in scope in detailing the legal quagmire of constraints and conditions faced by the Lummi Nation in handling drug-related crimes (see Appendix B for the complete report). First review of findings occurred on May 12, 2007, during which the CMAD coordinator met with the University of Arizona evaluation team for an all-day review and discussion of the data results. No dissemination of data outside of this meeting occurred during this phase of the evaluation. Two presentations, one on methodology and the other on 
community based participatory evaluation, were given by one of the evaluation team members at the $10^{\text {th }}$ National Indian Nations Conference held in Palm Springs, CA, in December 2006.

- Phase 3: Review and Dissemination of Findings (6/1/-11/30/2007). A presentation was given at the Indian Health Service (IHS) Research Conference in Phoenix, AZ, in June 2007 by one of the evaluation team members, and a second presentation was given on lessons learned in accessing and evaluating secondary data in Indian Country at the Annual NIJ Conference in Arlington, VA, in July 2007. The evaluation team reported findings of the evaluation to the Lummi Indian Business Council (LIBC) and the Lummi General Council on August $6^{\text {th }}$ and $8^{\text {th, }}$ respectively. Penultimate and final drafts of this report were submitted to NIJ during Phase 3. Additional papers, one on culture clashes in conducting participatory evaluation and the second on the problems and methods of measuring change in community awareness were developed and presented during this time period.

The remainder of this section will be devoted to a detailed description of the implementation of the evaluation. This will include population, data sources and types, and methods of data analysis.

\section{II.2) Sample Population}

All participants in the primary data collection component of the evaluation were enrolled members of the Lummi Nation living on the reservation. While it is conceivable that some of the secondary data may include non-tribal members, e.g., treatment or prevention program participants, the majority of the individuals involved in the programs were Lummi.

\section{II.3) Establishing a Partnership}

Goal 1: Establish a partnership at LN that fosters tribal ownership, support, and input in the evaluation process.

During the first site visit (November 7-9, 2005), the ground work for the development of the partnership was set. One member of the evaluation team went to a presentation to the Squamish First Nations in North Vancouver, British Columbia, and the other members visited with additional CMAD members at Lummi. In this manner we received both a detailed and general perspective of the components of the role of CMAD in the community. During this first visit, the working relationship that this kind of evaluation involves was addressed fully with the then Chairman of Lummi Nation, who was also the project director of CMAD; with the CMAD 
coordinator; and with multiple other key CMAD stakeholders. It was important that the evaluation be seen as a partnership and that no decisions about its implementation or analysis be made without consultation and agreement of the tribe. The importance of having an evaluation oversight committee (EOC) that could provide guidance and feedback was also stressed. Subsequent to this meeting, the CMAD coordinator chose key stakeholders from the CMAD committee she thought would provide a broad spectrum of views while also reflecting key areas of specialization that would be important to have represented on the EOC. At this time a presentation of the proposed evaluation plan was also offered to selected members of the CMAD committee for review and comment.

The EOC met a total of six times to work on issues ranging from review and feedback on instruments to hiring concerns. During three of those meetings, at least one member of the evaluation team was present. During the second site visit (January 26, 2006), the survey and focus group instruments and the consent forms were reviewed. This review occurred after both submission and receipt of comments through email and through personal meetings with EOC members and the CMAD coordinator. Subsequent meetings addressed the timeline for the community survey, composition of focus groups, obtainment of a random sample for the community survey, and the hiring of on-site personnel. The EOC members and the CMAD coordinator were very active in all of these defined components, including identifying an ideal candidate for the senior interviewer position and providing office space for the interviewers.

In addition, the CMAD coordinator often served as the intermediary for several aspects of the evaluation. She helped provide regular detailed updates of her many activities (including a log of tribal and intertribal presentations); worked with the evaluation team, the tribal enrollment office, and the Vice Chairman to obtain a random list of tribal members for the community survey; took on the role of chairing the EOC and overseeing the job of identifying key stakeholders for the six focus groups; contributed to and participated in the interviewer training; and helped the evaluation team secure necessary data from the multiple units involved in addressing drugs and/or drug-related crimes in the community.

Following the recommendation of an EOC member and a subsequent interview by the UA evaluation team, the project hired its senior survey interviewer. A person recognized as a well-respected, honest elder who is well versed in the community and in survey interviewing methods and protocol, she was able to both inform the evaluation team about appropriate and 
inappropriate ways of handling the interviewing process in the community and provide a wealth of information about the community from her perspective as a life-long resident. Her detailed interviews provided both complete quantitative data and detailed qualitative data. A second interviewer was also hired. This interviewer did not work out for the project, so the senior interviewer was asked to and accepted the full responsibility of interviewing all but one of the 100 useable surveys. (Because of errors in administration, 22 additional surveys had to be administered to reach the requisite number of 100.) The $100^{\text {th }}$ survey was conducted by a member of the evaluation team.

Another critical factor was maintaining an effective working relationship and connection with the Office of the Tribal Chair during and after the transition from one chairperson to this person's successor. Because the CMAD Initiative was so strongly identified with the Chairperson's Office, it was important to develop a connection with the new Chair. This was achieved through a meeting and informal presentation of the evaluation with the lead evaluator representing the UA team; the chairperson; the senior science analyst for NIJ; the principal investigator of the NIJ-funded evaluation of the Victims of Crime Program on Lummi; the CMAD coordinator; the former chairperson, who is still a council member; and another tribal employee and LIBC councilman who entered after the meeting began. This meeting was important for clarifying the purpose and responsibilities of the evaluation process and providing an opportunity to meet with the new Chairwoman to discuss the progress of the evaluation and the importance of the partnership in its implementation and success.

\section{II.4) Ensuring a viable logic model.}

Project Goal 2: Construct a logic model for each site that summarizes program mechanisms of evaluation and change through the linking of resources, activities, and program outcomes.

The logic model was developed and used to detail how the multiple components of the CMAD strategy and the evaluation strategy lead to their desired outcomes — one to achieve certain programmatic outcome objectives and the second to measure the fidelity, progress, and implementation of those objectives. It provided a graphic picture of the key elements of the evaluation: inputs (available resources), activities, outputs, process impact, and long term outcome objectives.

The original logic model was presented to selected CMAD members to review at the initial site visit (November 8, 2005). Based on additional information about the program and the 
resources available on site, the logic model was modified to incorporate both the goals of the CMAD Initiative and the evaluation.

All activities were addressed with the exception of reviewing the Community Readiness Assessment. This was conducted prior to the current CMAD coordinator's tenure. After an exhaustive search, it was determined that the report on the results of the assessment was lost. Consequently, this report was not reviewed by the evaluation team.

\section{II.5) Methods Used in Conducting the Evaluation}

Goal 3: Evaluate the program in place at each site using the respective tribal programs as outcome measures.

The evaluation addressed the four outcome goals of the Lummi Nation's CMAD Initiative. They are as follows:

- Reduce illicit drug trafficking;

- Reduce rates of substance use disorder and addiction;

- Prevent drug abuse and underage drinking among youth; and

- Mobilize community in all aspects of prevention, intervention, and suppression of alcohol and drug use and abuse and trafficking.

Three major methods of data collection were used to conduct the evaluation: survey interview, focus groups, and secondary data. Data generated by the use of multiple methods was triangulated, a procedure first describe by Campbell and Fiske (1959) under the rubric of “multiple operationalism.” As a procedure in the social sciences, triangulation entails the juxtaposition of multiple data sets, both quantitative and qualitative, as a means of contextualizing and cross-check findings in order (a) to check for the trustworthiness of data, (b)to gain insight into what extent the data may be an artifact of an instrument or a method of data collection, and (c) to explore contextual aspects of an experience or understanding (Guba 1981; Duffy 1987).

II.5.1) Lummi Nation's Community Survey. Data collection using this survey instrument was collected from May 2006-September 2006. This survey addressed knowledge and perception of the purpose of the Initiative, impact of alcohol and drug-related crimes on the community now as compared to three years ago, and effectiveness of services currently available as compared to three years ago. There were 104 items on the survey. It included both quantitative and qualitative questions, which enabled the evaluation team to capture both normative and more 
detailed, nuanced responses. The evaluation team modified an existing and tested community survey used to assess the effects of the Weed and Seed program (Dunworth and Mills, 1999; Roehl et al. 1996). Sponsored by the Department of Justice, the Operation Weed and Seed strategy uses a community-based approach to law enforcement, crime prevention, and community revitalization. The instrument lent itself well for adaptation and modification to the needs of the evaluation of the Lummi Nation's CMAD Initiative because it addressed similar, if not the same, community concerns. The resulting instrument was modified multiple times and tested prior to submission to the EOC in order to ensure (1) it captured the key areas of concern and the objectives of the goals of the CMAD Initiative as outlined in the Lummi Nation proposal to BJA, and (2) it was comprehensive and culturally appropriate.

Training of interviewers. Two Lummi tribal members with experience in survey administration were hired to administer the surveys. One individual had considerable experience and the second had less. They were trained in administering the instruments on 23 March 2006 by a member of the evaluation team. They were also instructed on the need for confidentiality in handling the data they were collecting. In addition, they were provided with a history of the CMAD Initiative and its purpose by the CMAD coordinator, who participated in this day-long training. On 23 April 2006, another member of the evaluation team did a human subjects training with the interviewers. Both interviewers received their official certification from the University of Arizona prior to any administration of the surveys.

Criteria for participation in the community survey. All adults who are enrolled tribal members living on the Lummi Reservation were eligible for participation in the survey.

Recruitment and sampling strategy. A randomized list of 400 members was requested from the Lummi Tribal Enrollment Office. Interviewers were instructed to start at the beginning of the list of tribal members and proceed down it. Contact sheets were kept and interviewers were instructed to call each potential participant up to three times to make contact or, if an appointment was broken, to reschedule. After the unsuccessful third attempt to make contact, the interviewer was instructed to abandon this contact and proceed to the next. Additionally, some individuals on the list were rejected as potential interviewees if they were known to be active drug users and/or dealers or deemed otherwise unsafe for the interviewer to work with. The following table presents the sample broken down by participation and non-participation by reason. 
Exhibit 2: Contact record for community survey participants by number

\begin{tabular}{|c|c|c|c|c|c|c|c|}
\hline $\begin{array}{c}\text { Total } \\
\text { sample } \\
\text { pool }\end{array}$ & $\begin{array}{c}\text { Contacted } \\
\text { and } \\
\text { interviewed }\end{array}$ & $\begin{array}{c}\text { Unused } \\
\text { Incomplete } \\
\text { interviews }\end{array}$ & $\begin{array}{c}\text { Unable } \\
\text { to } \\
\text { contact }\end{array}$ & $\begin{array}{c}\text { Left the } \\
\text { community }\end{array}$ & $\begin{array}{c}\text { Refused/ } \\
\text { unable to be } \\
\text { interviewed }\end{array}$ & $\begin{array}{c}\text { Rejected from } \\
\text { interview pool }\end{array}$ & $\begin{array}{c}\text { Unused } \\
\text { sample }\end{array}$ \\
\hline 400 & 100 & 22 & 49 & 16 & 23 & 4 & 186 \\
\hline
\end{tabular}

The following table reflects the demographic picture of the sample that participated and successfully completed the Community Survey.

Exhibit 3: Demographics for Community Survey Participants $(n=100)$

\begin{tabular}{|c|c|c|c|c|c|c|c|c|}
\hline \multicolumn{2}{|c|}{ Age } & \multicolumn{2}{c|}{ Gender (\%) } & Education (\%) & \multicolumn{3}{c|}{ Employment (\%) } \\
\hline $\begin{array}{c}\text { Mean age } \\
\text { (yrs) }\end{array}$ & $\begin{array}{c}\text { Largest } \\
\text { represented age } \\
\text { group }\end{array}$ & Males & Females & GED or higher & $\begin{array}{c}\text { Total } \\
\text { employed }\end{array}$ & $\begin{array}{c}\text { Full- } \\
\text { time }\end{array}$ & $\begin{array}{c}\text { Part- } \\
\text { time }\end{array}$ & Other \\
\hline 43.6 & 35-44 year olds & 39.0 & 61.0 & 80.0 & 75.0 & 71.6 & 13.5 & 14.9 \\
\hline
\end{tabular}

Administration of the survey. Two interviewers were trained to administer this survey to the 100 adult tribal members orally and face-to-face. Ultimately, with the exception of one survey administered by a member of the evaluation team, all the useable surveys were conducted by one interviewer. Survey participants were read a disclaimer form, and once they agreed to participate in the survey, this form was given to the participant. Other demographic information was sought, including year of birth, gender, education level, employment, and number of children living at home. No other identifying information was sought. The interview took 45-60 minutes to administer. It was typically conducted in the individual's home in an area that was private and comfortable for both the person being interviewed and the interviewee. Interviews were conducted in English, which was appropriate and acceptable for this community. All participants were compensated for their participation with a \$20 gift card to WalMart at the completion of the survey.

Quality Control of Data. Interviews were piloted and reviewed. Subsequent to pilot testing, all surveys were reviewed by an evaluation team member for completeness and accuracy of entry. To maintain the high standard that was required for the administration of this detailed survey, the evaluation team decided to employ only the more senior interviewer as this individual was experienced, thorough, comfortable with the interviewing process, and knowledgeable about the community. Data was entered by the data manager on the evaluation 
team (D.C.W. Lopez), and quality control checks were done throughout the process of imputing the data.

II.5.2) Focus Groups. Six focus groups were conducted at two points in time: 18-19 July 2006 and 18-20 September 2006. The focus groups questions were open-ended and addressed knowledge and impact of the CMAD Initiative; issues or problems with the Initiative; how the community viewed its actions; the importance and inclusion of a cultural perspective (traditional healers and others) in implementing various aspects of the CMAD Initiative; and how the Initiative has affected work and networking capabilities, policy making decisions, and/or treatment. Participants were also asked to think about what they would like CMAD to address and about their perceptions and definitions of some of the service barriers they may be experiencing (clients, community, and/or youth). There were six different sets of questions reflecting the type and level of interaction the population of each group would have with CMAD or with its activities. Each set included 9-10 questions. All questions followed the format from general to specific and reflected an open-ended approach that encouraged discussion. The focus groups were: policy makers, service providers, youth, adult clients and family members, traditional healers, and community members. Originally only five focus groups were proposed, but after meeting with the EOC and the CMAD coordinator, the evaluation team decided a group of community members who are rarely heard from was warranted (community members’ focus group). All questions were reviewed by each member of the EOC, individually and as part of the group. The EOC gave final approval of the questions on 13 January 2006.

One of the reasons the focus group format was chosen was because it has been used with considerable success with American Indians (see e.g., Devlin, et al. 2006; Severson and Wilson Duclos 2003; and Poupart and Becker 1997). Focus groups offer a means to explore thoughts and views contextually in an open, non-threatening environment. The group session permits deep discussion and exploration of an interpretation of an issue, and how it is understood and incorporated into, e.g., the daily functioning of a program or department or the daily life of a community member. The focus group method allows the evaluation to obtain a more nuanced understanding of an action, situation, or attitude than is usually available in a quantitative survey. This data both complements and provides a means to test the validity of the survey results while also providing for a detailed understanding of specific topics. This format is culturally appropriate for the Lummi people as it reflects traditional ways for communicating. The focus 
group also allows individuals to express themselves in their own words, placing situations and occurrences within the unique situations of the individual respondents.

All focus groups and the single interview session were conducted on-site at Lummi by two members of the evaluation team, both trained moderators, who oversaw and ensured the focused flow of discussion on the defined questions.

Criteria for participation in the focus groups. Each focus group was held with a different group of community stakeholders who either held specific positions or jobs in the community, e.g., service providers or policy makers; represented a specific age group (youth) or category of individuals who could speak to certain issues, e.g., traditional healers or adult clients; or were members of an often unrepresented group (community minorities). In addition to the focus groups, the evaluation team conducted an interview session with two traditional providers who preferred this format. These two individuals were interviewed together using the same questions employed in the focus group for traditional healers. All but a couple of the participants in the focus groups were tribal members. Although most participants lived on the Lummi Reservation, a few were known to live off it.

Sample size. Forty-seven adults and youth participated in the focus groups. An ideal size for a focus group is between 10 and 12 individuals. The size of the six focus groups ranged from 5 to 11 participants. The following represents the breakdown by number and gender for each focus group:

- Traditional Healers (TH)
o Focus group
4 females, 3 males,
o Interview
1 female, 1 male
8 females, 3 males
3 females, 5 males
3 females, 6 males
3 females, 2 males
4 females, 1 male

- Adult clients (AC)

- Youth (Y)

- Service Providers (SP)

- Policy Makers (PM)

- Community members (CM)

Sampling strategy. The sampling strategy was purposive to ensure representation of appropriate stakeholders for each group. The sample for the service providers, policy makers, youth, and community groups was chosen by the EOC membership and the CMAD Coordinator. Because of issues of confidentiality, the participant list for the youth was compiled by the 
coordinator and counselors of the Y.E.S.S. program, which provides prevention services to youth and family members. These designated individuals took on the responsibility of contacting the individuals. This same method was used to compile and recruit participants to the adult client group. In the latter case, a counselor contacted the individuals. Although there was a list of participants for the traditional healers group, the research team used a more informal method of recruitment. The CMAD Coordinator arranged for the evaluation team member conducting the focus group to meet with the Lummi Cultural Commission during their regularly scheduled meeting in lieu of holding a separate traditional healers focus group. The CMAD Coordinator and the UA evaluator felt this group would be appropriate as many of the individuals on the Cultural Commission were also on the list of traditional healers that was generated by the EOC.

Conducting the focus groups. All focus groups occurred in surroundings that ensured privacy and confidentiality. This was made possible with the cooperation of the Employment and Training Center, which provided rooms for conducting four of the focus groups (policy makers, service providers, youth, and community members). The traditional healers group was held in the Lummi Indian Business Council conference room, and the adult client group was conducted in the C.A.R.E. treatment conference room. All consenting processes occurred just prior to the start of the groups with the exception of the youth group session, in which all participants were required to come with signed parental /participant consent forms. Participants were handed copies of the focus group questions to refer to throughout the process. The focus groups took from 90-120 minutes to conduct, depending on the length and time participants took to discuss the questions. All the focus groups were openly audio taped with full knowledge and agreement of the participants. In addition to taping, the moderators took notes throughout the session. All participants were provided with snacks and were compensated for their time and effort. Because the service providers and policy makers were paid employees of the Lummi Nation, they received prints of paintings done by Northwest Indian artists. All other focus group participants received \$20 gift cards to WalMart at the conclusion of the session.

II.5.3) Secondary data collection. The evaluation team also collected data used for a variety of purposes, e.g., reimbursement, by the different tribal units. This data was collected from November 2006 through June 2007. With this form of data collection, the evaluators were able to relate changes on multiple objective factors to the intervention and its impact. To isolate key areas to collect data, the evaluation team used the Comprehensive TEPEE Strategy (renamed 
Shxwolewen in Salish) used by the CMAD Initiative to identify the five ongoing needs addressed in the Lummi Nation’s BJA's IAS A DP grant. These five areas were treatment (including aftercare), law enforcement, prevention, education, and employment. In addition tribal health data were collected to assess the health of the community in relation to alcohol and drug related diseases and conditions. Because employment has not yet been addressed through the CMAD Initiative, this data was not collected. Other data collected were meeting minutes, progress reports, and media reports.

Mode of data collection. Evaluators used record abstraction to collect relevant data. This sometimes came in the form of relevant data pulled from specific reports from tribal units. Producing the data needed for analysis was challenging for some of the units to supply. It was not always clear to unit heads what could be shared and what should not be shared with the evaluators. Constraints on the time of the units and a personnel shortage made it difficult for them to get data into an analyzable form. This problem was exacerbated by the fact that some of their data was in hard copy form. Because of the aforementioned reasons, some units had data backlogs that put an additional strain on their ability to provide this information. Also, because of a lack of funding, there were software needs which further inhibited the ability of units to provide as complete a story as they might otherwise have wanted to provide. Nevertheless, even with these constraints, there was support and significant compliance with the evaluation team's requests. The CMAD coordinator was particularly helpful in explaining the need for the data and putting the prestige of the Office of the Chairwoman behind the request. Similarly, the Lummi Tribal Vital Statistics Office was helpful in sharing all pertinent data and directing the evaluators to the appropriate individuals. Finally, almost all units provided requested relevant data. The Lummi Nation is in the process of trying to develop a viable infrastructure that can respond to the needs of data sharing between units while at the same time maintaining needed confidentiality.

Study population. The study population for this portion of the evaluation was the entire community served by the Lummi Nation that has used treatment, prevention, housing, or education services or has been subject to or prosecuted by Lummi Nation law enforcement. Because of the means by which the data is collected and managed by the different tribal units, there could be non-enrolled tribal members in the record extraction.

Type of data collected. Data was sought from the following sources: 


\section{Exhibit 4: Sources for secondary data collection}

Type of Data

- Treatment

Outpatient(youth and adults)

Inpatient (youth)

Off-site services

- Arrests

- Prosecution

Drug-related crimes

Drug-related exclusions

Probation

- Prevention

Child Protective Services

Youth Outreach

Youth and family programs

Safe House (youth, mental health)

- Education

- Housing

- Health

\section{Source}

1) Lummi C.A.R.E. Outpatient 2002-2005 Treatment Admissions (2006).

2) DASA Target data, 2005-2006 (2007).

3) Suboxone clinic client data (Medicaid report) 2007.

1) Se>Eye>Chen Monthly Youth Treatment Report (2007).

Unavailable

1) Report of crimes monitored by CMAD, LNPD, 2006-2007 (2007).

2) Total cases monitored by CMAD, 2003-2005, Prepared by Lummi Tribal Office of Vital Statistics (LTVS) from data submitted by LNPD (04/06/2006).

3) Crime in Washington: 2005 Annual Report. Washington Association of Sheriffs and Police Chiefs, Washington State Crime Statistics (2005).

Civil Court Statistics for the Years 1996 to 2005 Report, LN Tribal Court, n.d.

1) Exclusion Orders in Place Report, provided by the LN Prosecutor's Office (Last updated 2/28/07).

2) Lummi Nation Summary of Exclusions Prepared by LTVS (07/20/2006).

Unavailable

Family Social Services Report (04/28/2006).

1) Youth Outreach Annual Reports, 2004, 2005 (n.d.)

2) Youth Outreach Annual Reports, 2005 (n.d.)

LN Y.E.S.S. 2006 Data Report (2007). LN Y.E.S.S.Medicaid Report (2006).

1) LN Safe House Final Report, 2004 (2005).

2) LN Safe House Final Report, 2005 (2006).

Lummi and Whatcom County school demographics and adequate yearly progress performance measures (2006).

Transitional Recovery Report, Lummi Housing Authority (08/2007).

Lummi Health Clinic Report of ICD-9 Codes for Alcohol and other drug related diagnoses. (04/27/2007) 
II.5.4) Legal Review. A detailed historical review was conducted on the interrelationship of federal, state, and tribal law and how this complex interplay impacts Indian reservations in their dealing with drug-related crimes. This review was conducted from February - April 2007, and with slight revisions completed in May 2007. This component of the evaluation was added to the original evaluation plan to examine and contextualize the complex situation and issues Indian communities face when they are dealing with a problem that has such strong outside influences as drug use, e.g., drug trafficking and drug law enforcement. Although the review addresses the situation through a global perspective as this problem is experienced by all tribes to some level, it also specifically addresses the unique situation of the Lummi Nation which, as a border tribe, is continually struggling to control drugs on its reservation. To conduct this review extensive historical research was done into the legal legacies of the past as well as the current state of federal and state laws and their impact on the ability of tribes to control drugs on their lands (See Appendix B for a copy of this paper).

\section{II.6) Methods of Data Analysis.}

This evaluation called for multiple data sources and incorporated both qualitative and quantitative approaches. Because much of what was studied was part of process evaluation, most of the analysis and related statistics were relatively straightforward, i.e., numbers and percentages. The data analysis plan linked the evaluation questions with the data collection to produce both descriptive data, and where appropriate, inferential data. Data sources such as that produced by structured questionnaires were set up for quantitative analysis while data from focus groups and other observational and informal interviews were subject to qualitative analysis and triangulated with the quantitative data. The use of multiple data sources was critical in confirming or strengthening accuracy of the findings.

Available quantitative data, e.g., from the tribal court, the police, and treatment, was -as mentioned earlier-- collected from data systems from which data could be drawn, e.g., dates and types of incidents such as alcohol-related crime or drug trafficking. Few departments had data systems and therefore data extraction was used.

Because many of the programs involved in the CMAD Initiative are in the early implementation phase and because the sample sizes are small, the data did not lend itself to complex statistical analysis other than descriptive data. The descriptive data helped provide an abbreviated profile of the programs and their activities. Unfortunately, most of the data from the 
programs did not yield enough data to characterize relationships between different aspects of the programs or between programs.

Descriptive data did provide a means for analyzing the results from the community survey to characterize relations between different variables. This was done by cross tabulation and correlation. EXCEL, ACCESS, and SPSS were used to conduct these and other descriptive statistical analyses. To analyze the qualitative data from the focus groups, the evaluation team used a thematic approach. "Don't know" responses were not options presented to participants in the community survey; however, on occasion a respondent would answer with the comment "I don't know." When a sizeable number of these comments were given, they were reported; otherwise, they were removed from the analysis." Prominent themes were pulled from each focus group, and these were then compared against one another to discern commonalities and differences of perceptions, attitudes, and reactions. This data was then looked at in relation to the quantitative data generated by the community survey to assess if themes evident in the focus groups supported the quantitative findings revealed by the survey. 


\section{III) DETAILED FINDINGS}

Results of the evaluation of the Lummi Nation CMAD Initiative are presented in response to each defined goal listed in the Lummi Nation's funded proposal to the Department of Justice/Office of Justice Programs-BJA-IASAD program. Data will be drawn from the community survey, focus groups, and secondary data collection.

One hundred respondents participated in the community survey. Of that number, 61 were females and 39 were males. Average age of the respondents was 44 years (range: 73-19), and the average length of residence in the community was 37 years. Sixty-five percent of the respondents had children under the age of 18 years old living at home, and approximately 75 percent of the respondents were employed.

Six focus groups and one interview session were conducted in which a total of 47 people participated. Of that number, 26 were female and 21 were male. None of the focus group participants were interviewed for the survey.

\section{III.1) Goal 1: To increase the identification, apprehension, and prosecution of those engaged in illegal drug and alcohol transportation, distribution, or use.}

To address this goal, the evaluation team looked at a number of factors: 1) the raising of awareness of the drug problem in the Lummi Nation and among the other Coast Salish tribes; 2) how the drug problem and law enforcement efforts are perceived in the community and 3) the level of impact these efforts have had on the perception and actual reduction of alcohol and drug related crimes in the community.

\section{III.1.1) Raising awareness in the community and among Northwest Coast Salish Tribes}

- Were methods used to raise awareness about drug problems in the community successfully employed?

First, it was important to discern if the Lummi community had ever heard of the CMAD Initiative. Of those surveyed, 73 percent indicated they had heard about it, and of those who had, 58 percent indicated its purpose was to fight drugs and alcohol problems (34\%), mobilize the community around the drug problem (13.5\%), and increase awareness of substance abuse problems in the community (10.8\%).

CMAD has used several methods to increase awareness about the drug problem in the community. The CMAD Coordinator and other CMAD members have given multiple presentations over the course of the funding period. The evaluation looked at tribal and inter- 
tribal presentations from September 2004 to August 2006 to assess the number, types, and groups the presentations were offered to. This time period was chosen because it provided continuous data for two consecutive years. The presentations were given to the Lummi community and to specific community stakeholders by the CMAD director, coordinator, and various members.

Exhibit 5: CMAD Lummi Nation Presentations

\begin{tabular}{|c|c|c|c|c|}
\hline Time period & $\begin{array}{c}\# \\
\text { Events }\end{array}$ & Event & Group & $\begin{array}{c}\# \\
\text { Attending }\end{array}$ \\
\hline $9 / 1 / 2004-2 / 28 / 2005$ & 1 & - Coast Salish Gathering II & $\begin{array}{l}\text { Regional tribes including } \\
\text { Lummi Nation }\end{array}$ & $\mathrm{n} / \mathrm{a}$ \\
\hline 3/1/2005-8/31/2005 & 5 & $\begin{array}{l}\text { - Drug and alcohol discussion } \\
\text { - Coast Salish Gathering III } \\
\text { - CMAD Presentation } \\
\text { - CMAD Presentation } \\
\text { - CMAD Presentation }\end{array}$ & $\begin{array}{l}8^{\text {th }} \text { graders, Tribal School } \\
\text { Regional tribes including } \\
\text { Lummi Nation } \\
\text { Ventures Group } \\
\text { Ventures Group } \\
\text { Ventures Group }\end{array}$ & $\begin{array}{r}\mathrm{n} / \mathrm{a} \\
200 \\
\mathrm{n} / \mathrm{a} \\
\mathrm{n} / \mathrm{a} \\
\mathrm{n} / \mathrm{a}\end{array}$ \\
\hline 9/1/2005-2/28/2006 & 1 & - Coast Salish Gathering IV & $\begin{array}{l}\text { Regional tribes including } \\
\text { Lummi Nation }\end{array}$ & 200 \\
\hline 3/1/2006-8/31/2006 & 2 & $\begin{array}{l}\text { - CMAD Presentation } \\
\text { - CMAD Presentation }\end{array}$ & $\begin{array}{l}\text { Lummi Housing } \\
\text { Commission } \\
\text { Employment and Training } \\
\text { Center }\end{array}$ & $\begin{array}{l}14 \\
15\end{array}$ \\
\hline
\end{tabular}

A total of nine presentations (28\% of all presentations) were given in the Lummi community over this two year period. This also includes the three Coast Salish Gatherings for other Coast Salish tribes hosted by CMAD and held on the Lummi Nation.

An additional method used by CMAD to increase community awareness about its drug problems was the increased attention given to the policy of exclusion, particularly as it relates to drug related crimes. After five years in which there were no drug-related crime exclusions, the Lummi Nation reinstituted the process by which the tribal judge has the option to banish offenders for certain crimes (Native American Rights Fund, 2007). Through exclusion, which is an act of traditional justice ((Native American Rights Fund, 2007; see also Ross, 2007), an individual is exiled from the reservation and loses all tribal benefits (including rights related to hunting, fishing, education, and health care) (12 Lummi Nation Code of Laws, 2007). The Exclusion Committee-a body created by the Tribe’s government-is responsible for creating the policies associated with exclusion, but the tribal court decides who to exclude based upon the evidence provided in court (Personal communication, R. Doucet, 2007). After five years, an excluded individual is typically permitted to apply for reinstatement (Ross, 2007). The threat of this traditional method of justice at Lummi and its planned and actual implementation has been 
addressed extensively in the press, both nationally (e.g., NY Times) and locally (e.g., Bellingham Herald). One such article in the Seattle Post-Intelligence (May 19, 2003) covered the situation of a Lummi tribal member facing exclusion, addressed the conflict of instituting traditional justice, and discussed the "shame" it brought to the family.

Increased awareness of the drug problem in the community was also measured through tribal media coverage. The tribal newspaper, Squol Quol, is a monthly publication that regularly runs articles about the services available in the Lummi Nation that address drug addiction in the community. Over the course of six site visits (November 2005, January 2005, March 2006, April 2006, May 2006, June 2006, and July 2006), the evaluation team reviewed copies of the newspaper for mention of drug prevention, treatment, or drug-related arrests. All six issues had at least one item addressing one of these problems. The newspaper also printed a listing of drugrelated arrests that included type of offense, date of the offense, and individual in question (allowed through Resolution \#99-110 of the Lummi Indian Business Council: “Tribal publication of Drug and alcohol-related arrests, indictments and case outcomes”). These listings did not appear every month.

As part of addressing the problem of illegal drug use and drug-related crimes, it was also important to know if there was an increased awareness of the drug problem in the community. Data from multiple sources (media coverage, policy decisions, community survey, and the multiple focus groups) were used to assess if awareness was raised about drug abuse and drugrelated crimes. This data was important for gauging how much the community acknowledged the problem and the extent of its interest and involvement in mobilizing to reduce it.

- Was awareness raised about drug problem in the community?

First the evaluation had to determine if drug and alcohol use were considered a problem by the community. To find this out, participants in the community survey were asked to identify "one major problem facing this [Lummi] community." 
Exhibit 6: Lummi people view drugs and alcohol as major community problems, 2006

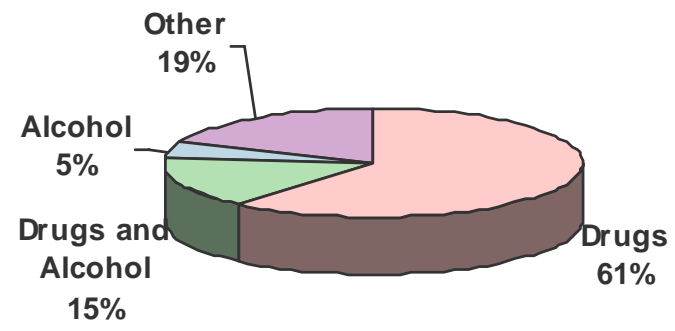

As Exhibit 6 shows, 81 percent of all respondents identified drugs, drugs and alcohol, and alcohol as major community problems, with 61 percent of respondents specifically identifying drugs as a major problem in the community. Only 19 percent of the respondents identified anything other than drugs and/or alcohol as a major problem.

Exhibit 7 further demonstrates how seriously drugs are considered a problem in the Lummi community.

Exhibit 7: Drug abuse is considered a very serious problem in the community, 2006

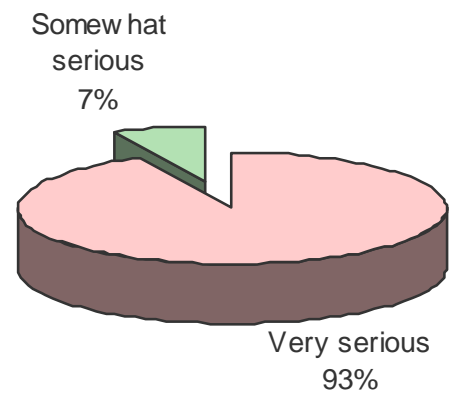

The community members clearly think drugs are a problem for the Lummi Nation, with 100 percent feeling it is a "very serious" and "somewhat serious" problem, and 93 percent of those surveyed feeling it is a "very serious” problem. When asked if the community is seriously addressing this problem, 46.3 percent of those who had responded that drugs and/or drugs and alcohol were a problem answered “yes.” Exhibit 5 provides the breakdown of this response by gender. 
Exhibit 8: Seriously addressing problem of drugs, drugs and/or alcohol by gender

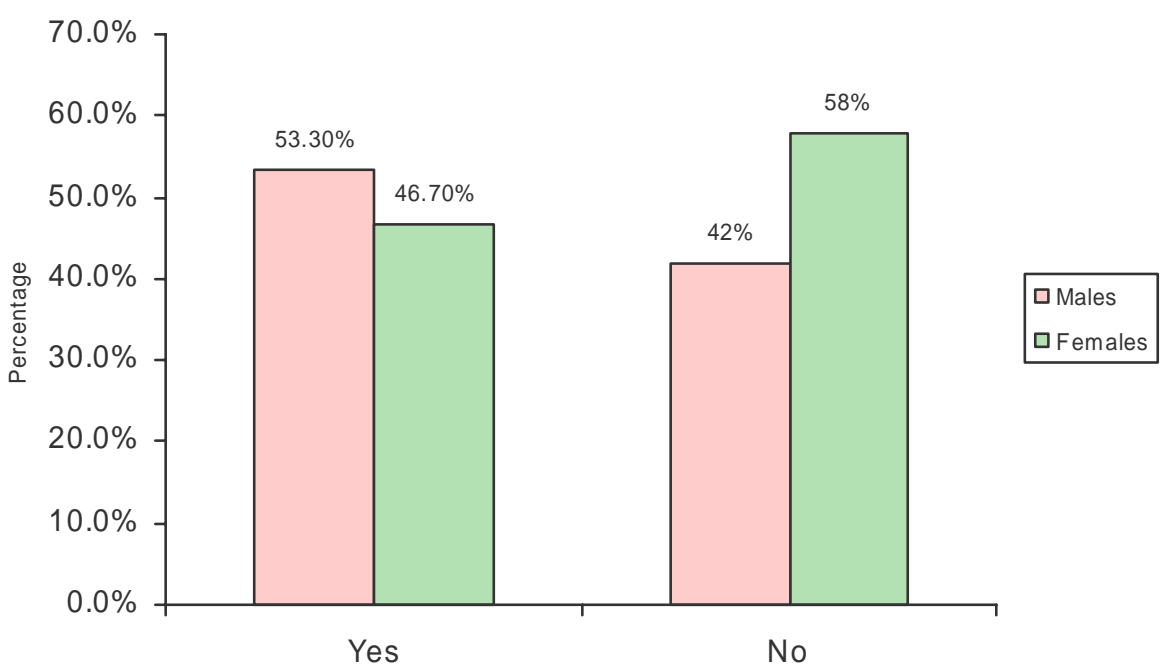

As the above graph shows, men more than women feel the problem is being addressed seriously, 53.3 percent (16) to 42 percent (21). No differences were discerned based on age.

The impact of drugs was felt at different levels by community members. Some focus group participants saw drugs as a community problem: "I like pull into the store and there's a drug deal going on, somebody buying a bottle for a teenager. It’s just everywhere; drugs and alcohol are everywhere.” For others it was seen as a family problem: "It is probably happening in all of our families. ...We're working on our family, that's the way we see it. ...You start with yourself, you start with your family.” And for many it was an individual problem of conflict and stress: “...there are people in families who are heavy users and sellers, and then there’s those, on the other hand, who are fighting it, and they are in the same household.”

Members of the focus groups also addressed the CMAD Initiative and community awareness about drugs and drug-related crimes. This was discussed at length in the service providers' focus group. One participant in the focus group explained that during the early stage of the Initiative, there were people in the community who were unaware they were doing anything wrong in selling drugs: "A couple of the people that got caught for selling, I think one of the comments that a person made was she didn't know that it was a bad thing. She was just, I think, thought she was doing a service to the community by selling drugs.” This perception was reiterated by another participant who felt that “...Some of the dealers...didn’t realize until it was 
too late that what they were doing was not only against the law, but a crime against their own people. They didn’t realize it.”

Respondents also saw the raising of awareness about the drug problem as synonymous with CMAD: “...the purpose [of CMAD] was to raise the level of awareness.” Yet, not all saw it so clearly, with some seeing it tied to their own growth: "we have improved in our courage to be able to face these things. I don't know if that's CMAD, I don't know if that was a result of that or if CMAD has helped us to find critical ways to do better.” For this participant, CMAD may not have been the cause of this new awareness, but it was a means for learning how to do things better.

CMAD's role with regard to substance abuse was viewed positively by many focus group participants. Policy makers commented on the progress that has been made: "We've made a lot of substantial progress with regards to the awareness of drug issues, and the alcohol issues..." and "I do think that CMAD really did throw a lot of light on some of these concerns, and put a lot of resources into some of these concerns that otherwise wouldn't have gotten them.” A community member reinforced the positive message, noting the difference in how things were handled in the past compared to now: "Some of our abuse issues are on the table, as opposed to being hidden... many years ago that would never have happened. So I think that's real progress, to be able to say we have a problem and it's tied to some of our addiction issues.” Finally, reflecting on the enormity of the problem, one elder from the traditional healers group acknowledged that “CMAD wasn't supposed to be the cure-all [for our drug problems].”

In summary, results show the utilization of multiple avenues to raise community awareness of the drug problem. It is an issue that has received extensive coverage in the medianationally, locally, and tribally_and has been addressed through presentations to key community stakeholders and youth. Respondents both to the community survey and in the focus groups see the problem as serious because it affects their lives in multiple ways.

- Did the CMAD Initiative increase awareness of drug problems among other neighboring tribes?

To assess if there has been any increase of awareness of drug use and drug-related crimes among neighbors as a result of the CMAD Initiative, the evaluation team looked at the number and kind of presentations given and meetings held with neighboring tribes about the CMAD 
Initiative and related projects. The following table presents an outline of CMAD intertribal events and presentations for the period of September 2004 through August 2006.

Exhibit 9: Regional Intertribal Presentations

\begin{tabular}{|c|c|c|c|c|}
\hline Time period & $\begin{array}{c}\text { \# } \\
\text { Events }\end{array}$ & Event & Location & $\begin{array}{c}\text { \# } \\
\text { Attending }\end{array}$ \\
\hline 9/1/2004-2/28/2005 & 1 & - Coast Salish Gathering II & $\mathrm{n} / \mathrm{a}$ & $\mathrm{n} / \mathrm{a}$ \\
\hline 3/1/2005-8/31/2005 & 3 & $\begin{array}{ll}\text { - } & \text { Inter-Tribal Restorative } \\
& \text { Justice Group } \\
\text { - } & \text { Coast Salish Gathering III } \\
\text { - } & \text { Hearts of Fire Gathering }\end{array}$ & $\begin{array}{l}\text { LN, Bellingham, WA } \\
\text { n/a }\end{array}$ & $\begin{array}{r}\mathrm{n} / \mathrm{a} \\
200 \\
425\end{array}$ \\
\hline 9/1/2005-2/28/2006 & 5 & $\begin{array}{l}\text { - International Grandmothers' } \\
\text { - } \text { Conference } \\
\text { - NASA/Tribal Conference } \\
\text { - Squamish First Nation } \\
\text { - } \text { Meeting } \\
\end{array}$ & $\begin{array}{l}\text { n/a } \\
\text { Quinault Tribe, } \\
\text { Ocean Shore, WA } \\
\text { Blaine, WA } \\
\text { n/a } \\
\text { Squamish First Nation, } \\
\text { N. Vancouver, BC, Canada }\end{array}$ & $\begin{array}{r}223 \\
\mathrm{n} / \mathrm{a} \\
\mathrm{n} / \mathrm{a} \\
200 \\
\\
60\end{array}$ \\
\hline $3 / 1 / 2006-8 / 31 / 2006$ & 5 & $\begin{array}{l}\text { - } \text { State of WA Men’s Health } \\
\text { Conference } \\
\text { - } \text { BJA IASAD Regional } \\
\text { Roundtable Training } \\
\text { - } \quad \text { Elders Panel for Juvenile } \\
\text { Justice } \\
\text { - Colville Tribal Drug } \\
\text { Awareness Conference }\end{array}$ & $\begin{array}{l}\text { Yakama Nation, Yakima, } \\
\text { WA } \\
\text { Squaxin Island, Skokomish, } \\
\text { WA } \\
\text { Tulalip Tribes, (Tulalip } \\
\text { Tribal Court) WA } \\
\text { Colville Tribes, Nespelem, } \\
\text { WA }\end{array}$ & $\begin{array}{r}75 \\
\mathrm{n} / \mathrm{a} \\
20 \\
120\end{array}$ \\
\hline
\end{tabular}

Out of a total of 30 presentations given over the two year period, 14 were to regional tribal communities. These presentations were delivered by the CMAD director, coordinator, and/or members. Presentations addressed the work CMAD was doing and collaborative intertribal efforts it was spearheading, e.g., the Restorative Justice Center that will serve the eight Coast Salish communities in Northwest Washington. The Coast Salish Gatherings, which were hosted by CMAD, brought together adults and youth from the Lummi Nation and other Coast Salish tribes to address the impact of drugs on their communities and particularly their youth. Results, including the number and diversity of those present at these gatherings and meetings show continued interest in collaboration (e.g., brought together eight tribes that support the development of a regional tribal Restorative Justice Center), concern (e.g., Tulalip elders are interested in looking at the next step regarding juvenile justice in their community), and continued involvement (e.g., Confederated Tribes of the Colville want to have Lummi CMAD back for further discussion regarding implementing CMAD in their community). 


\section{III.1.2) How the drug problem and law enforcement efforts are perceived in the community}

- What is the prevalence of the drug problem in the community?

Using a Likert scale ranging from "big problem" to "not at all a problem" respondents to the community survey were asked to assess how large a problem each of the following drugs were in the community. The following graph (Exhibit 10) outlines this data.

Exhibit 10: Percentage of drugs considered a big problem for Lummi Nation, 2006

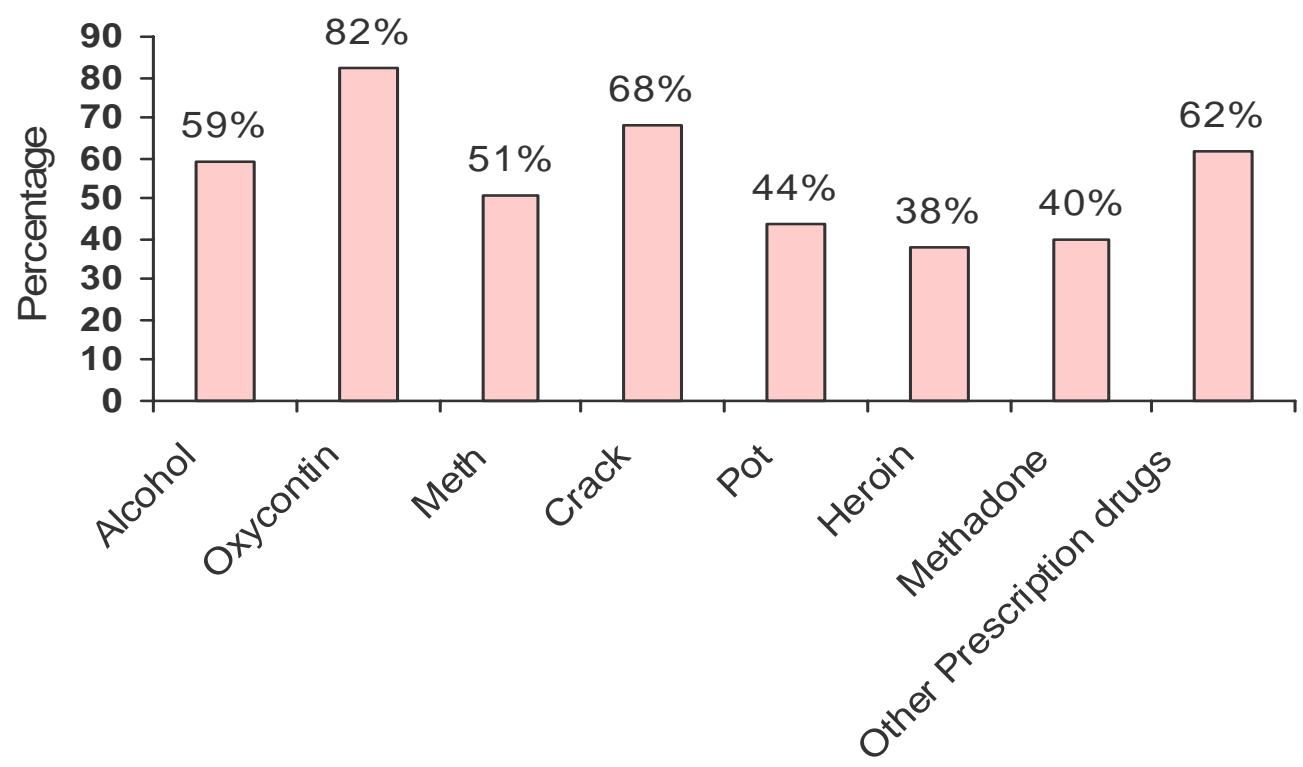

As Exhibit 10 shows, Oxycontin (commercial name for oxycodone) is considered a "big problem” by 82 percent of those responding to the survey. Crack cocaine is next in prevalence with 68 percent of respondents viewing it as a "big problem." Third in order of cited frequency was "other prescription drugs" (62\%). Of all the drugs seen as a problem, prescription drugs accounted for two out of the three most frequently mentioned drugs considered a "big problem" in the community.

Participants were also asked to assess how big a problem ("big problem," "small problem," or "almost no problem) certain drug-related activities were in the community.

Exhibit 11: Most frequently cited "big problems" in the community

Problem

- Drug use

- Drug dealers operating in the community

- Burglary and other property crimes

- Neglect and abandonment of dependent children

- Interruption of regular school attendance
$\%$ of Respondents

$95 \%$

$93 \%$

$91 \%$

$76 \%$

$72 \%$ 
As Exhibit 11 illustrates, the top three of the five problems most cited by respondents were drug use (95\%), drug dealers operating in the community (93\%), and burglary and property crimes (91\%). These responses cross gender and are close to universal for the respondents for these three areas of concern. Gender differences play more of a role in how the latter two items, “neglect and abandonment of dependent children” and "interruption of regular school attendance,” are seen. Approximately 85.3 percent of the 61 female respondents felt "neglect” was a big problem compared to 61.5 percent of the 39 male respondents. Similarly, although not with as dramatic a difference, females more than males felt "school attendance" issues were a "big problem” (77.1 \% compared to $64.1 \%)$.

Based on the above data, drug dealing is a major focus for community members. Using a Likert scale from "very powerful” to "not at all powerful," the survey asked tribal members to assess the influence outside drug connections have today on the community compared to three years ago.

\section{Exhibit 12: How powerful are outside drug connections compared to 3 years ago?}

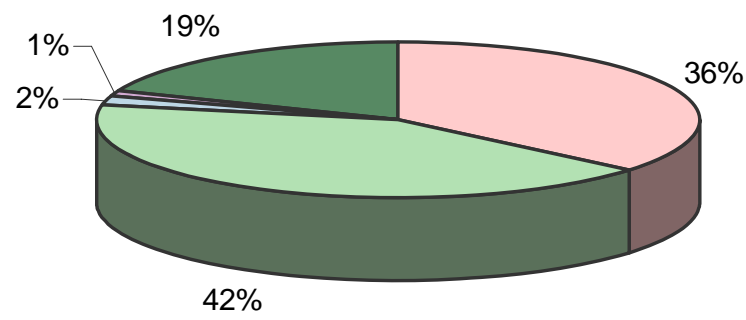

\section{Very powerful $\square$ Powerful $\square$ Not powerful $\square$ Not at all powerful $\square$ Don't know}

Consistent with previous data from this survey, 78 percent of respondents interviewed for the community survey viewed outside drug connections as "very powerful” and "powerful.” Yet, while only 3 percent of respondents viewed these drug connections as "not powerful and "not at all powerful,” 19 percent of the tribal members surveyed indicated “don’t know” as their response. When looking at drug connections and perception of safety compared to three years ago, 90 percent of respondents who indicated they feel much less safe compared to three years ago also indicated they feel outside drug connections today are "very powerful” compared to three years ago. 
- $\quad$ How accepted are drugs in the community?

While there was a consistent pattern of non-acceptance of drug use and drug dealing throughout the different focus groups, participants in the adult clients group addressed this subject at length. Members of this group generally felt that substance abuse was increasing, especially among the younger persons of the community and that this was not desirable ("I think it’s worse. I think the age group is getting younger...early teens.”). A second participant pointed to the kinds of drugs available as explanation for why things are worse: “...I think that the newer drugs that are available to our kids has really affected things that are going on in this community.” Yet the problem of youth drug use was also connected to cross generational perpetuation of the problem. As one focus group member noted, "You know, our community didn't get like this overnight, and its going to take more than just...CMAD, even the Council to throw money at it to change it back...I was thinking a lot of it is generational...maybe three generations affected with alcoholism and drugs.” As the focus group members saw the problem both affecting the young and evident across generations, so they also wanted everyone to be accountable for their behaviors: “They [referring to the Lummi Business Council members] need to be drug tested like everyone else...Even our police need to be drug tested.” Yet, as one member of the service provider focus group pointed out, community members working in prevention, enforcement, and treatment can and do face a painful conundrum when family members are among those who are using and/or dealing drugs: "You've got people who are using and selling (to) their relatives and people who are fighting against it, and the guys want to stop it but they don't want to harm family members who are actively participating...people are torn between turning people in and identifying them.”

- How well are the police and prosecution able to handle alcohol and drug problem in the community?

To measure the effectiveness of the police and the tribal court in addressing alcohol and drug problems in the community, the evaluation team assessed community perceptions of effectiveness in handling the problem and outcomes from personal interaction. In addition the evaluation team reviewed reports of arrests, prosecutions, probationary data, and exclusions. Finally, level of satisfaction was reviewed.

Effectiveness against alcohol-related crimes. Participants in the community survey were asked to assess how good a job the police were doing in handling alcohol-related crimes, 
including reducing underage drinking and reducing the sale and use of illegal drugs in the community. Exhibit 13 represents respondents' answers to how they felt the police was doing handling alcohol-related crime.

Exhibit 13: How good a job are the police doing at handling alcohol-related crime?

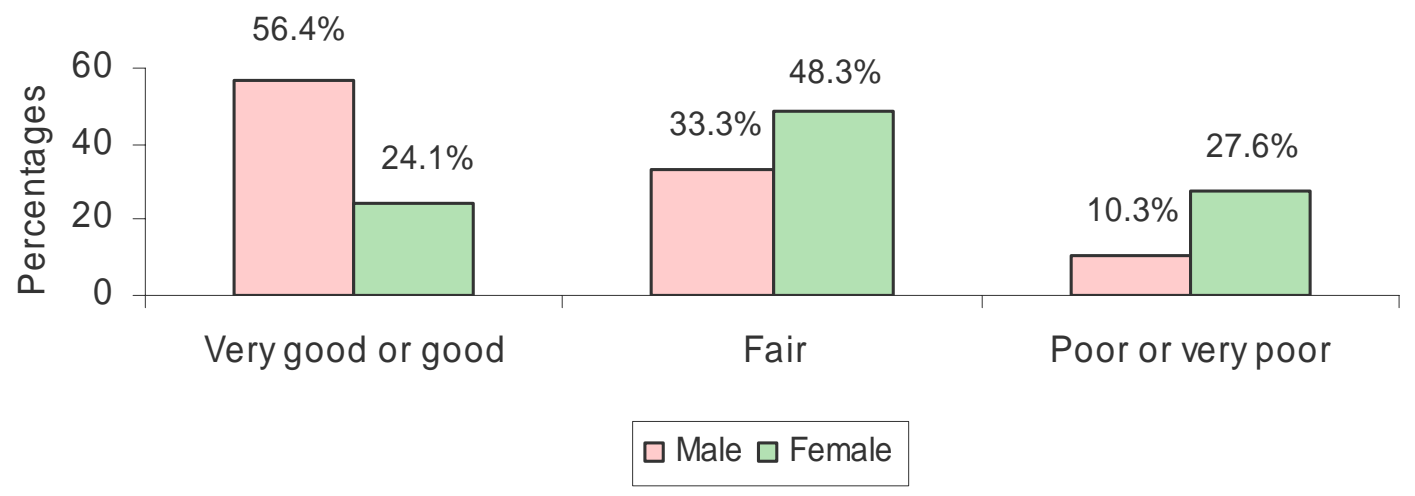

As the above graph shows, more respondents felt the LNPD is doing a "very good" and “good” job (36\%) than a "poor” or “very poor” job (20\%), although most respondents' answers fell into the category of "fair" (41\%). When broken down by gender, there is a split in response with more men feeling the police are doing a "very good" and "good" job than women and in inverse proportion, more women feeling the police are doing a "poor" or "very poor" job at handling alcohol-related crime.

Most frequent reasons given by those who indicated some dissatisfaction with the way alcohol crimes were handled were (1) poor response, (2) understaffed and/or underfunded, and (3) reluctance to interfere with alcohol parties.

Participants were also asked to compare how the tribal police were doing in reducing underage drinking in the community today compared to three years ago (prior to the CMAD Initiative). Most respondents saw little change, with 59 percent of those responding it was “about the same,” yet 22 percent thought it was “better.” Only 9 percent felt it was “worse.” There were no major differences between men and women responding to this question.

Participants in the community survey were also asked to assess how good a job the prosecutorial division of law enforcement was doing in handling alcohol-related crimes. Exhibit 11 represents respondents' answers to this question. 
Exhibit 14: Effectiveness of alcohol-related crime prosecutions by gender

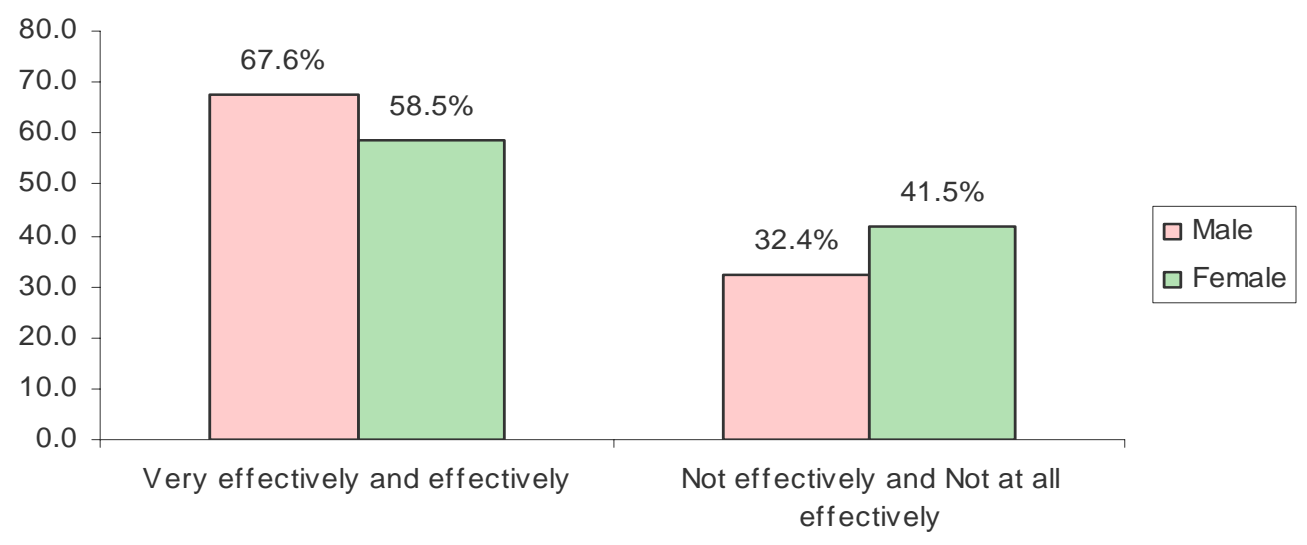

As the above chart demonstrates, respondents feel the prosecution of alcohol-related crimes in the community is more effective than not effective. Of those responding to this question, 62.2 percent felt alcohol-related crimes were prosecuted "very effectively” and "effectively."

Effectiveness against drug-related crimes. To understand how the community felt about the police's effectiveness in reducing the sale and use of illegal drugs, the evaluation team asked participants to assess how the situation is now in comparison to three years ago. Exhibit 12, below, presents how good a job the respondents feel the LNPD is curently doing in reducing drug-related problems.

Exhibit 15: How good a job are the police doing in reducing sale and use of illegal drugs?

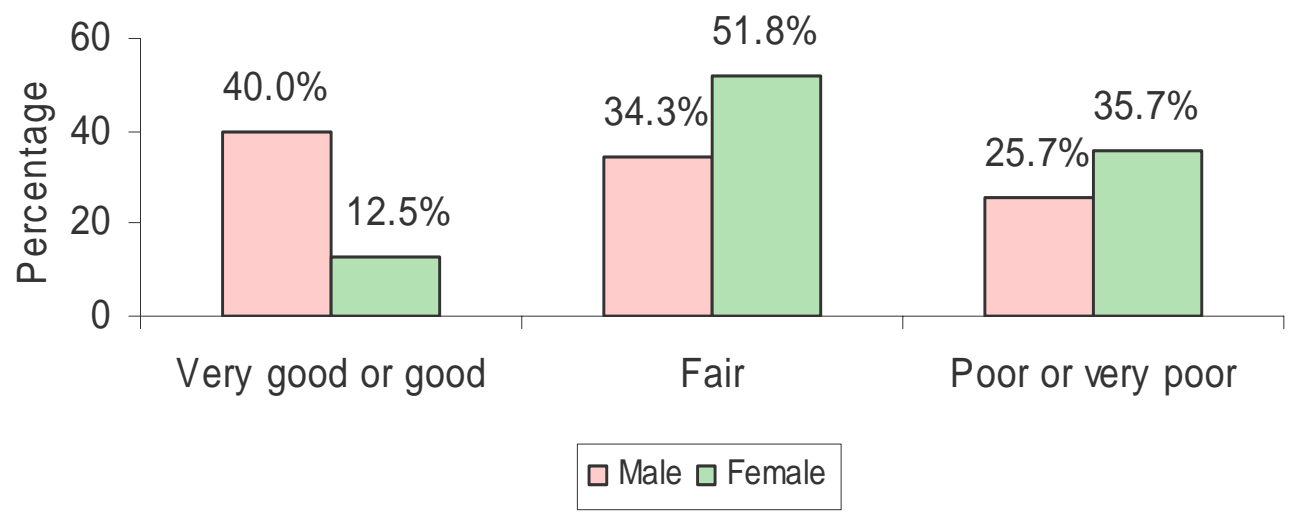

Exhibit 15 shows a notable difference between how men and women responded to this question. Men, much more than women-40 percent to 12.5 percent or a factor of three times greater-felt the police were doing a "very good" and "good” job in reducing the sale and use of 
illegal drugs in the community. Women’s responses primarily fell into the "fair" and the "poor" or "very poor" category compared to responses from men.

Of those respondents who indicated "fair," "poor," or "very poor" for how tribal police were doing their job to reduce the sale and use of drugs, many of them $(n=70)$ responded with detailed answers addressing the causes for why they thought the police's ability to address this issue was less than adequate. The following exhibit represents the most frequently cited causes:

Exhibit 16: Reasons for dissatisfaction with police's job to reduce sale and use of drugs

\section{Reason}

- $\quad$ Police were underfunded/understaffed

- Out of control problem

- Lack of timely arrest and/or investigation

- Lack of effective means for police to handle drug problem
\% of Responses

$20 \%$

$17 \%$

$10 \%$

$10 \%$

Community members felt that additional police manpower would help the community deal with the drug problems more effectively. As one respondent noted: "Not enough help. They are doing their share. They need more help and training."

In comparison to three years ago, the majority (59\%) of the community members responding to the question "Compared to three years ago, how are the police doing in reducing the sale and use of illegal drugs" indicated "about the same level.” Approximately 28 percent felt the police were doing "better" now.

As with the police data on the sale and use of illegal drugs, data on the effectiveness of drug related crime prosecutions show a split response by gender (see Exhibit 17).

\section{Exhibit 17: How effectively do you feel drug related crimes are being prosecuted?}

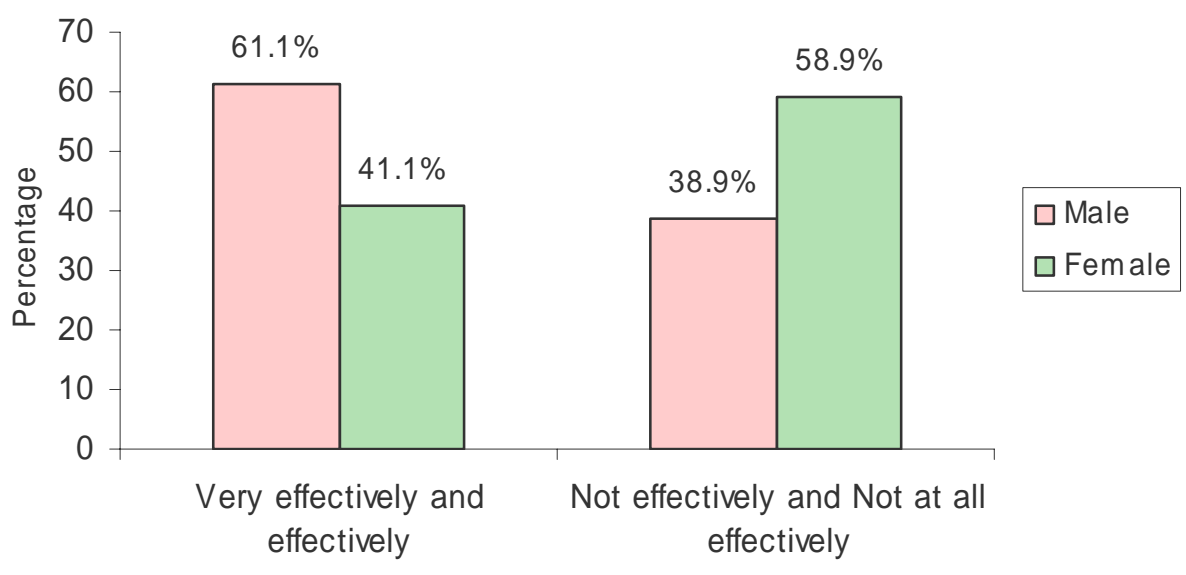


Exhibit 17 shows the men's response to be a virtual mirror image of the women's responses. Of those who answered this question, more men than women felt crimes were "very effectively” and "effectively” being prosecuted. Conversely, more women than men felt the crimes were "not effectively" and "not at all effectively" prosecuted.

As mentioned earlier, the tribal judge can, if he or she so deems fit, invoke exclusion as a form of punishment for a drug offense. Exhibit 18 presents the results from a question that asked community members about how well they saw this method working in reducing drug-related crimes.

\section{Exhibit 18: How well is exclusion working to reduce drug related crimes?}

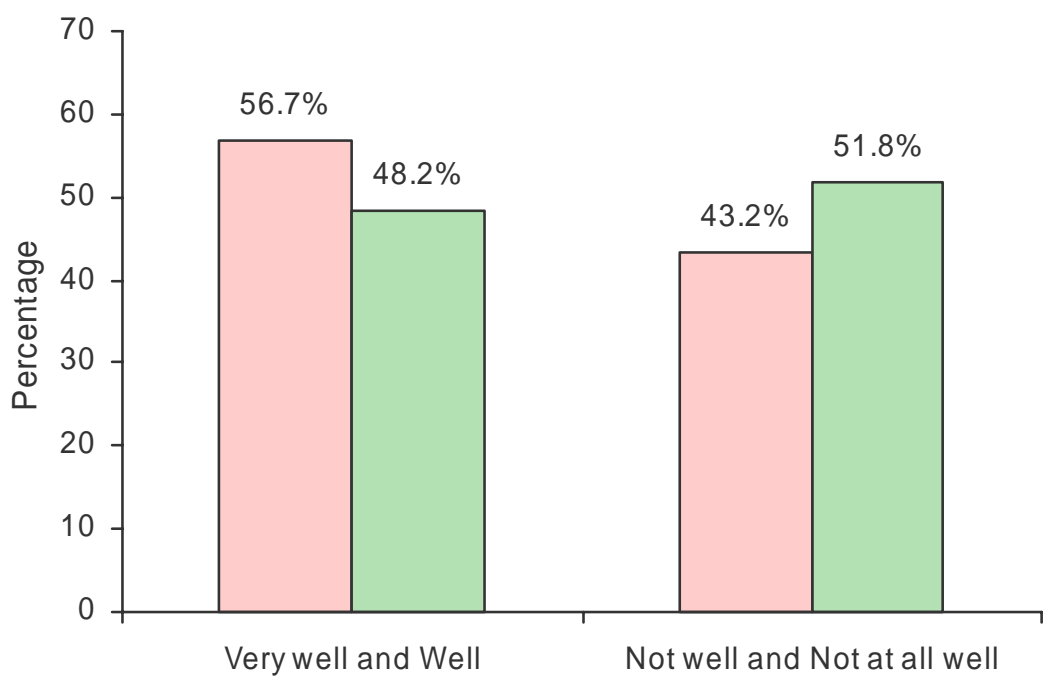

\section{$\square$ Males $\square$ Females}

As before, the community members were split in their response. Approximately 52 percent of all individuals responding to this question felt exclusion was working "very well and well” in reducing drug related crimes. Yet, while more men than women felt it was working well, this gender difference was only eight percentage points.

Exclusion was frequently addressed in the focus groups in which the role and effectiveness of the policy and its implementation were discussed. In one focus group (CM), participants closely echoed the feelings expressed in an earlier cited news report (Seattle Post Intelligencer): "If you banish a tribal member, then they lose contact with their family, and that destroys the structure of that family....And how can you combat the problem, you know, how do you make them pay or be responsible for their actions if they don't have consequences....” 
Participants in another group went further in their analysis: “...They can't stand the idea of having their being stripped of being an Indian, being kicked off the reservation. That's the one thing they fear.” (SP) Another participant agreed adding: “...if you get banished, you don’t belong anywhere.” Here, tribal members are articulating what they see as the biggest fear, that of losing their cultural identity.

A major component of dealing with drug-related crimes is reducing the number of drug dealers in the community. The apprehension and reduction of drug dealers in the community has been a major thrust of the Lummi Nation Police Department, e.g., the department has a full-time detective dedicated to addressing these issues in the community. The problem of drug dealers in the community was specifically addressed in the community survey in which respondents were asked to reflect on how they felt about the situation. Exhibit 19 shows how community members see the effect of the efforts of law enforcement to rid the community of drug dealers.

\section{Exhibit 19: Perceived situation regarding drug dealers in the community}
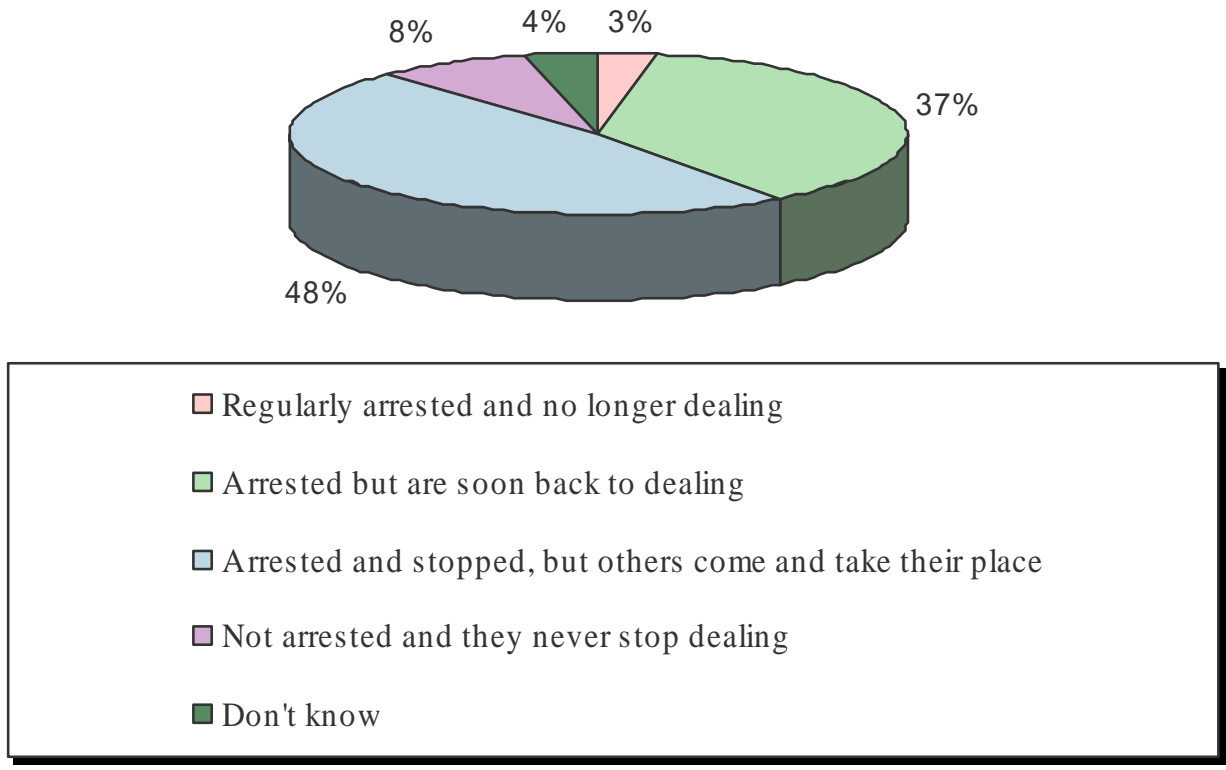

As Exhibit 19 shows, community members’ responses center on two kinds of situations, one in which the drug dealers are "arrested and stopped, but others come and take their place" and the other in which the drug dealers are "arrested but are soon back to dealing.” Both represent a cyclical pattern in which the police remove the drug dealers, but they return or others 
come to fill the gap. Focus group members were able to draw out some of the nuances of the issue, although they expressed a similar pattern as the survey respondents. One focus member noted: “They're trying to get a handle on the pushers... They never seem to make any headway. They arrest some people, then somebody else comes in and takes their place.” These sentiments were echoed by participants in another focus group of community stakeholders (PM). For example, one participant in this group saw the process in which dealers are removed and replaced by new ones as a "vacuum that sucks other dealers in.” Yet, while some community members spoke of the frustration of not being able to arrest the drug dealers ("These drug dealers know, and they know how to get away from the law, they know every step”), others who deal directly in enforcement and policy felt that while they have tried to reduce the number of drug dealers, it is unclear if those efforts have had an effect on drug dealing: "I don't know that there's been a reduction in the amount of drug dealing overall. There has been an increase in the prosecution. Like I said, it's hard to know what that means.”

\section{III.1.3) Impact of law enforcement efforts on the perception of change and reduction of alcohol and drug related crimes in the community}

- Has the drug problem in the Lummi community changed compared to three years ago?

Community's perception of change. Overall, tribal members felt some changes have occurred both for the "better" and for the "worse." The following table outlines the most frequently mentioned problems perceived as worse compared to three years ago by percentage of respondents who cited it.

Exhibit 20: Most frequently cited problems in the community that are getting worse compared to 3 years ago.

\section{Problem}

- Drug use:

- Burglary and other property crimes:

- Drug dealers operating in the community:

- Neglect and abandonment of dependent children:

- Interruption of regular school attendance:
\% of Respondents

$69 \%$

$55 \%$

$52 \%$

$44 \%$

$43 \%$

Five of the six most cited items seen by respondents to the community survey as getting worse are the same items most cited for being big problems in the community. Drug use was most often cited as a "big problem” and getting “worse” compared to three years ago.

There are also areas that community members see as better compared to three years ago. Exhibit 21 presents the four most cited problems in which respondents see improvement. 
Exhibit 21: Most frequently cited problems in the community that are getting better compared to 3 years ago.

\section{Problem}

- Drunk and disorderly conduct:

- Violent crime (shooting, assaults):

- Gang activity:

- Drug dealers operating in the community:
\% of Respondents

$23 \%$

$22 \%$

$22 \%$

$13 \%$

The data presented in Exhibit 21 show community members seeing positive change in the areas of drunk and disorderly conduct, violent crimes (e.g., shootings and assaults), and gang activity, but less positive change in the area of drug dealers operating in the community. There was no noteworthy difference by gender in these responses.

To put some of this data in context, it should be noted that for this random sample of 100 community members, 46 percent had been victims of crime between the years 2002-2006. The following Exhibit details the four most frequently cited reasons respondents called the police during this time period. However, because the survey was conducted in 2006, results for that year could be representing only partial data.

Exhibit 22: Crimes reported from 2002-2006 to Lummi Nation Police Department by tribal members participating in community survey.

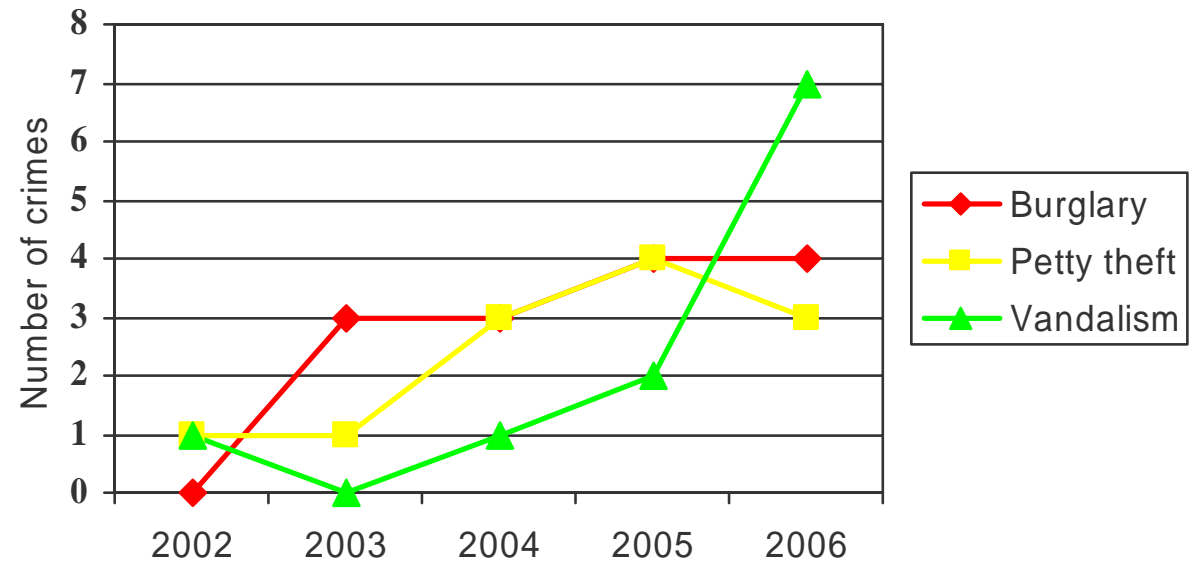

The above numbers accounted for 37 of the 68 crimes (54.4\%) respondents said they reported to the police.

Reported data: changes in arrests and prosecutions. While this is a formative evaluation, it was important to assess if program and department data are being collected in the most 
informative way possible and if that data is conveying a picture reflective of the proposed objectives of the CMAD Initiative.

The following table presents data reported to the Lummi Tribal Vital Statistics Office by the Lummi Nation Police Department for 2003-2006.

Exhibit 23: Alcohol and drug-related crimes, 2003-2006

\begin{tabular}{|l|r|r|r|r|}
\hline & $\mathbf{2 0 0 3}$ & $\mathbf{2 0 0 4}$ & $\mathbf{2 0 0 5}$ & $\mathbf{2 0 0 6}$ \\
\hline Drugs & 136 & 93 & 134 & 78 \\
\hline Assault & 259 & 263 & 259 & 212 \\
\hline Disorderly Conduct & 135 & 116 & 145 & 123 \\
\hline Burglary & 92 & 50 & 112 & 133 \\
\hline Theft & 299 & 277 & 349 & 288 \\
\hline $\begin{array}{l}\text { Consumption/Possession of Alcohol by a } \\
\text { Minor }\end{array}$ & 60 & 58 & 66 & 57 \\
\hline
\end{tabular}

Source: Lummi Tribal Vital Statistics compiled from data submitted by LNPD, 4/5/2006 and 4/6/2007

The above data shows no consistent trends either of increasing or decreasing. Most of the data shows a cyclical pattern. This is evident for crimes associated with drugs, theft, disorderly conduct, and burglary. Consumption and possession of alcohol by a minor shows a stable pattern. Burglaries appear to be increasing (43\%) and assault appears to be showing a decrease (18\%) from 2003-2006. Because the numbers are not broken down by age, repeat arrests, type of drug crime or theft (e.g., grand theft and petty theft), it is not possible to determine if, or how many of, the arrests or violations were re-arrests or re-citations of the same individuals or types of crimes for which the individual was arrested.

To determine if there were any changes in prosecutions for drug-related offenses, the evaluation team examined (Exhibit 24) court data. The following table represents the data received from the court.

Exhibit 24: Criminal Court Cases: Adult and Juvenile Drug Offense 2002-2005

\begin{tabular}{|l|r|r|r|r|}
\hline & 2002 & 2003 & 2004 & 2005 \\
\hline Criminal Drug Offense & 98 & 170 & 187 & 146 \\
\hline Juvenile Drug Offense & $*$ & $*$ & 40 & 26 \\
\hline
\end{tabular}

Source: Civil Court Statistics, 1996-2005

Because the data was undifferentiated by type of crime, number of cases successfully prosecuted, and recidivism, it is not possible to determine if prosecutions show a decline or increase in drug-related prosecutions for adults. While the number criminal adult drug offenses show a decline from 2004 to 2005 it will be necessary to have aditional data points to ascertain a true decline. Similarly, the juvenile data is equally inconclusive for the same reason. 
The only court related data made available that specifically addressed drug trafficking was the exclusion data. The following exhibit represents numbers of exclusions from 1994-2006 for drug-trafficking.

Exhibit 25: Drug Trafficking Exclusions: 1994-2006

\begin{tabular}{|l|c|c|c|c|c|c|}
\hline & \multicolumn{2}{|c|}{$1994-1999$} & $\begin{array}{c}2000- \\
2005\end{array}$ & \multicolumn{2}{c|}{2006} & Total \\
\hline & $\mathrm{M}$ & $\mathrm{F}$ & & $\mathrm{M}$ & $\mathrm{F}$ & \\
\hline Lummi Tribal Member & 2 & 4 & 0 & 0 & 0 & 6 \\
\hline Non-Lummi U.S. Indian & 1 & 0 & 0 & 1 & 0 & 2 \\
\hline Non-Lummi Canadian Indian & 0 & 0 & 0 & 0 & 2 & 2 \\
\hline Non-Indian & -- & -- & 0 & 1 & 2 & 3 \\
\hline TOTAL & 3 & 4 & 0 & 2 & 4 & 13 \\
\hline
\end{tabular}

Source: Lummi Prosecutor’s Office, February 2007

The number of drug-trafficking exclusions increased 600 percent from 2000 to 2006, with all six exclusions occurring in 2006. The number of exclusions for the year 2006 represents almost half of all drug-trafficking exclusions for the 12-year period, 1994-2006. All of the 2006 exclusions were non-Lummi compared to the exclusions that occurred from 1994-1999 in which six of the seven individuals who were excluded were enrolled Lummi tribal members. Overall, both for 2006 and for the years 1994-1999, more females were excluded for drug trafficking than males.

\section{III.2) Goal 2: Reduce and organize and educate to prevent the number of highway fatalities and injuries caused by alcohol and drug use.}

The LNPD has been working in collaboration with the Washington State Patrol to reduce the number of highway fatalities and injuries caused by alcohol and drug use. They have worked with these agencies to institute drug and alcohol traffic stops to help curtail accidents resulting from driving under the influence. One member of the Lummi police noted that because of the increased awareness of the tribe's efforts through CMAD and the media attention it has received about the drug and alcohol problems on the reservation, the State Patrol wanted to get involved "because their biggest concern is drunk drivers." The feeling is that they are getting more involved in a supportive way and, in turn, the Lummi police have been able to use the State Patrol's technical expertise in investigating and addressing serious traffic accidents. Similarly, the education process has been two way. Both law enforcement agencies at the county level and the state level were unaware of the work LNPD has been doing in traffic enforcement. This would include information on numbers of drunk drivers arrested, speeding citations, etc. Because of recent meetings and discussions with these law enforcement agencies, they are now sharing 
this kind of information, which was previously unavailable to them (personal communication, LNPD official, 2006).

Exhibit 26 presents data on moving violations reported to the Lummi Tribal Vital Statistics Office by the Lummi Nation Police Department for 2003-2006.

Exhibit 26: Moving violations, 2003-2006

\begin{tabular}{|l|r|r|r|r|}
\hline & $\mathbf{2 0 0 3}$ & $\mathbf{2 0 0 4}$ & $\mathbf{2 0 0 5}$ & $\mathbf{2 0 0 6}$ \\
\hline Citations for DWI & 56 & 118 & 78 & $\mathrm{n} / \mathrm{a}$ \\
\hline Accidents resulted in injury & 10 & 10 & 8 & $\mathrm{n} / \mathrm{a}$ \\
\hline Fatal motor vehicle accidents & 1 & 2 & 0 & $\mathrm{n} / \mathrm{a}$ \\
\hline
\end{tabular}

Source: Lummi Tribal Vital Statistics compiled from data submitted by LNPD, 4/5/2006 and 4/6/2007

There were no fatal motor vehicle accidents in 2005 and a slightly reduced number of accidents resulting in injury. While there is a decline in citations for DWIs from 2004 to 2005, there was still a 39 percent increase in DWIs from 2003. However, because data was not available for 2006, it is not possible to clearly state any patterns for any of the three areas for which data were collected.

\section{III.3) Goal 3: Expand Lummi Nation partnerships with federal, state, and local law enforcement agencies consistent with existing law enforcement issues through formal MOUs.}

The Lummi Nation Police Department currently is collaborating with federal, state, the local county sheriff's office, and other tribal police departments in the region on several projects. Through collaboration and contacts with Immigration and Customs Enforcement, the Lummi police have been able to track and cut off drug smugglers crossing the Canadian border and heading towards the Lummi Nation (LNPD, personnel personal communication, 2006). At the federal level the department has worked with the FBI on issues of law enforcement related to drug trafficking. Currently, there are no partnerships developed internationally. Yet, there has been mutual education occurring. In November 2005 the LNPD Chief of Police along with several CMAD members presented the CMAD Initiative to the Squamish First Nation in Vancouver, British Columbia. At that time considerable information was shared with the local law enforcement agents from West Vancouver regarding methods used to curb drug use and trafficking and the kinds of regulations and controls available to the different law enforcement departments to address these problems in their respective regions. 
As mentioned above, at the more local level the LNPD is collaborating with the Washington State Patrol and Whatcom County’s Office of the Sheriff on traffic drug and alcohol stops to help curtail accidents resulting from driving under the influence and to share data and technical expertise. The Lummi Nation Police Department is also engaged in coordinating its drug trafficking investigations with the Whatcom Regional Drug Task Force and other regional tribal agencies (LNPD, 2006). Similarly, the Lummi Police have been working collaboratively with the Snohomish County Sheriff's Office in finding adequate and appropriate space to create the Restorative Justice Center for American Indians. The Center, which will also require the support and collaboration of other Coast Salish tribal communities and police, will address those individuals who have committed violations that bring a sentence of one year or longer. The center and the social and spiritual services-e.g., mental health and substance abuse counseling and sweats — will be offered and used to help tribal members transition out of prison (see below for further discussion). Discussions and presentations to Coast Salish tribes and their law enforcement agencies have been ongoing (see below for a detailed discussion on the progress of the center).

At this time, no memorandums of understanding (MOU) have been signed between the Lummi Nation Police Department or the Lummi Indian Business Council and any federal, state or local law enforcement agencies. Nevertheless, a network has developed by which information and expertise is shared in the areas of alcohol and drug use to reduce traffic accidents and fatalities, drug trafficking, and recidivism rates, and to support wellness and recovery among incarcerated American Indians.

\section{III.4) Goal 4: Increase access points to contact Lummi Nation law enforcement and provide information about crimes and criminal activity.}

The LNPD has made a concerted effort to enhance the use of "9-1-1" for emergencies and cases in which community members feel something suspicious may be occurring. This information is placed in monthly reports in the Squol Quol, the tribal newspaper (e.g., "If you see anyone around your home or neighbor's home that does not belong there, please call 9-1-1 immediately and an officer will be dispatched to investigate”) and in small billboards throughout the reservation. As part of its planned strategies to provide quick and enhanced access to the police, CMAD was supposed to create an "800" number. This was not done, but there was discussion at a CMAD meeting (CMAD Meeting Minutes for March 23, 2006) that a better use 
of tribal resources might be to use an existing hotline for this purpose. It is not known if this has occurred. An attempt was made to set up a Neighborhood Watch Group at the different housing developments. After two attempts in which no one attended either of the scheduled meetings, organizers abandoned this method of mobilizing community members. There were several activities planned to increase police exposure and accessibility in the community: (1) the police were planning to hire an additional patrol officer to cover the different housing areas (currently the police department has a 20-member force including chief of police, lieutenant, drug detective, two support personnel, and a school resources officer), (2) police would provide information to the community about laws and ordinances, (3) community meetings would be held to listen and respond to expressed concerns (LNPD 2006).

- How responsive do community members see the Lummi Nation Police Department responsiveness to their concerns?

Participants in the community survey were asked to rate how responsive the police department was to the community’s concerns (see Exhibit 27).

\section{Exhibit 27: In general, how responsive is tribal police department to the community's concerns?}

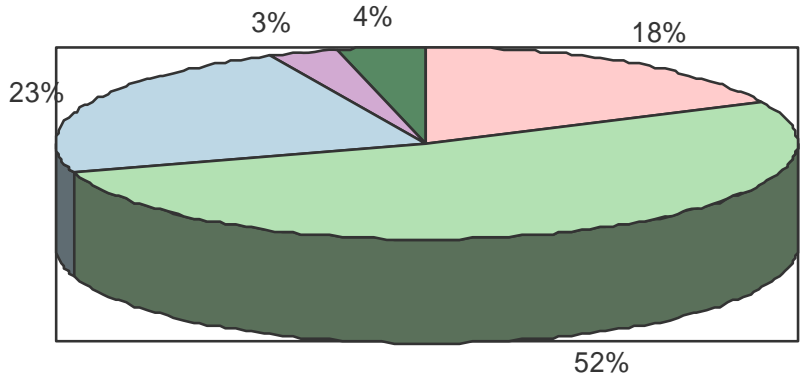

$\square$ Very responsive

$\square$ Somewhat responsive

Somewhat unresponsive

$\square$ Very unresponsive

$\square$ Don't know

As the above chart shows, 70 percent of respondents felt the police have overall, been "very responsive” and "somewhat responsive."

The police were perceived as either less than effective or hamstrung by circumstance by participants from several focus groups. One member stated that “...the way I see things work is that they would have to hire Indian policemen out of away from here, so they can't be in with the people that are here...They can’t be related,... a little bit of nepotism going on with the cops.” A policy maker's perception was that "when CMAD first started...I was on the Council then, and 
there was a lot of action taken. We had a list of eight drug houses...and busted one, to my knowledge. I don’t know how many we’ve busted since then but I don't think we've done much.”

Adult clients commented on the seeming lack of interest of police in responding to substance abuse issues. "I would like to see less drug and alcohol activity going on there...And what, call the cops every time we see somebody driving by? What do they do? They don't do nothing.” Another participant noted, "I see a lot of drug activity going on, and their (police) eyes are closed to it...."

A service provider placed the substance abuse issue within a broader perspective, emphasizing the role of the community in apprehending drug dealers “...it's not just a police problem. The community's involved, they have the eyes and the ears...we rely on the community to help us with information and it's participating.” This individual also pointed out the collaborative relationship that is developing with outside law enforcement agencies (State Patrol and Office of Sheriff of Whatcom County) in dealing with substance abuse and related crimes: “And so the State Patrol has been getting more and more involved with the tribe...it's been involvement in a positive way.... The Sheriff...wants to do everything he can to support the tribe’s efforts in the way of combatting drugs and alcohol.”

- How far has the Lummi Nation progressed in developing a community justice program and facility?

In 2002 the Lummi Nation began developing the concept plan for a regional tribal restorative justice center that would address the needs of the Pacific Northwest tribal communities and Indian inmates. The current problem is seen as multifold, as it includes community crime problems, safety iaauwa of people and property, limited access to county jails, inability to hold people accountable, crime-related substance addiction, questions about the relevance of a "tough love” approach, and a belief in the need to introduce Indian culture and values into rehabilitation. The Nation envisions that the corrections facility will be based on a restorative justice model, be overseen by a consortium of tribes, and provide a full range of integrated corrections, treatment, recovery, and skill building services and programming to Native offenders. The facility is designed to be for both male and female Coast Salish people who are incarcerated and have been sentenced out of tribal courts (James 2005). The Chief of 
Police and his Lieutenant sit on the advisory committee that is heading efforts to create the restorative justice center.

The Lummi Nation is currently engaged in ongoing discussions with law enforcement professionals and local public officials in working out a viable solution. CMAD members have presented the plan at meetings (e.g., Inter-Tribal Restorative Justice Group) to Coast Salish tribes. The advisory committee for the restorative justice center is currently looking at facilities to house the inmates (what was originally seen as a possible facility has now been deemed, under careful review, to be inappropriate.) There are many issues to be addressed before the center can be realized, among them the kinds of case management activities necessary to service the residents and to ensure a provider's time is utilized effectively and efficiently.

The current plan is to seek funding to further develop the plan for the center. There are currently no MOUs signed between any of the designated Northwest tribes (Lummi, Nooksack, Samish, Sauk-Suiattle, Stillaquamish, Swinomish, Tulalip, and Upper Skagit) although dialogue surrounding the Restorative Justice Center and the need to address the drug and alcohol abuse and related crimes have been ongoing through Coast Salish Gatherings and through individual presentations to tribes, e.g., Elders Panel for Juvenile Justice in Tulalip. This project is currently in its planning phase.

\section{III.5) Goal 5: Plan, develop and implement a holistic treatment model consistent with the alcohol/substance abuse needs of Lummi youth, adults, and families.}

To measure the level of development and implementation of a holistic treatment model, the evaluation team needed to address several factors: coordination of agencies working on drugrelated issues in the community, development of new treatment strategies, use of available resources, and satisfaction of the community with the treatment being offered and its availability. In addition, it is relevant to assess the role of parallel treatment offered from traditional healers and how it fits into treatment options and as far as possible, to assess treatment and health program data for any changes in use of drugs and alcohol in the community.

- How have treatment options changed for adults since the CMAD Initiative has been in effect?

Lummi C.A.R.E., which provides outpatient substance abuse treatment to the Lummi community, has a long history (dating back to the 1960s) in the community. It currently has eight counselors, is situated in the Lummi Nation, and offers group session treatment therapy to adults 
and youth. Most clients served by C.A.R.E. are court ordered or referred to treatment from Family Social Services. Adults receive 72-hours of treatment that includes accudetox-overseen and administered by a physician certified in accudetox therapy_-and 10-person group counseling sessions. Acudetox, a detox method that employs acupuncture, is accepted by clients and found to have no cultural barriers to its implementation. It is a relatively new offering and is provided by the resident addictive medicine physician. According to the director of C.A.R.E., it is now requested by some clients. (Inpatient care is only available off-site for adults, e.g., St. Joseph's Hospital for short-term inpatient care [under 30 days].) Aftercare consists of 26, one-hour sessions over the course of 26 weeks.

Additional outpatient treatment is offered through the newly opened Suboxone Clinic. The development of the clinic and the choice to use suboxone rather than the more traditional medication treatment of methadone was discussed, reviewed, and developed not only with C.A.R.E. staff, but also with the full consultation and input of the CMAD team who addressed, over the course of several months the pros and cons of this method of treatment (see e.g., CMAD meeting minutes, March 23, 2006; April 6, 2006). Since April 2007, the daily number of adults seen by the clinic has grown from three individuals the first day to 65 individuals by the end of the fourth week. Clients are provided with the medication, suboxone, which allows the person to function without withdrawal symptoms or the debilitating effects of methadone. Suboxone is an opioid medication approved for the treatment of opioid dependence. Its primary active ingredient is buprenorphine, an opiate with limited effects compared to oxycodone or heroin. The clinic provides medical oversight by a physician certified in the administration of this drug and behavioral therapy conducted by trained substance abuse counselors (currently drawn from the staff of C.A.R.E. counselors). The clinic also offers culturally traditional methods of healing. The treatment starts out intensively with dosage once a day, and then, depending on the individual's progress, is reduced to a maintenance regimen of three times a week. The plan is to eventually wean the client off of suboxone after two years. Currently plans are being developed to include transitional help and employment training as part of a holistic treatment modality. Based on informal interviews with the director of the clinic and the CMAD coordinator, the clinic is having a very positive effect on those who are enrolled in it. They believe it is providing people who could not otherwise succeed through treatment programs a means to reshape their lives in a positive way. 
- $\quad$ How have treatment options changed for youth since the CMAD Initiative has been in effect?

Youth receive out-patient care-as they have before the CMAD Initiative — in the form of group counseling sessions through C.A.R.E. New since the implementation of the CMAD Initiative, and often credited to the work of CMAD, is the Home of Healing Spirits (Safe House). This facility provides a temporary structured and safe environment for youth who do not have a stable home. The usual stay in the Safe House, which previously had ten beds but now has six (reduced to stay in compliance with Washington State regulations), lasts approximately two weeks. If a youth creates a problem at the Safe House, he or she is sent to detention. Approximately 95 percent of youth recommended to stay at the Safe House are tribal court mandated because of neglect or abuse by adults or because of violence perpetrated by the youth. If placement in the Safe House is unsuccessful, e.g., the youth is providing "dirty” drug tests (e.g., urine analysis) and/or is disruptive, the youth is reassessed, and if necessary, is sent for a minimum of 60 days to Pioneer Center, an off-site inpatient facility in Sedro Woolley, WA.

Also under C.A.R.E., but separate from the outpatient facility, is Se $>$ Eye $>$ Chen, which offers in-patient treatment for Lummi youth and for other American Indian youth living in Northwest Washington State. Se>Eye>Chen was, as one focus group member called it, “a dream with no backing” before CMAD came into being. The facility serves adolescents, 14 to 18 years of age, and provides chemical dependence education, case counseling, mental health counseling, and cultural education and experiences. It has been in existence since April 2005. Se>Eye>Chen is not a lock-down facility.

In addition to the above treatment options, adults and youth are offered the opportunity to include traditional healing in their care. There are traditional healing services administered through the Shaker Church, traditional winter dancing that lasts until April in the Smokehouse, and other traditional Lummi spiritual healing methods.

- Since the inception of the CMAD Initiative are there changes in the numbers of people going through treatment and the kinds of treatment services being offered?

The following graph represents the number of admissions for C.A.R.E.outpatient treatment for the years 2002-2005. 


\section{Exhibit 28: Lummi C.A.R.E. Outpatient Treatment Admissions, 2002-2005}

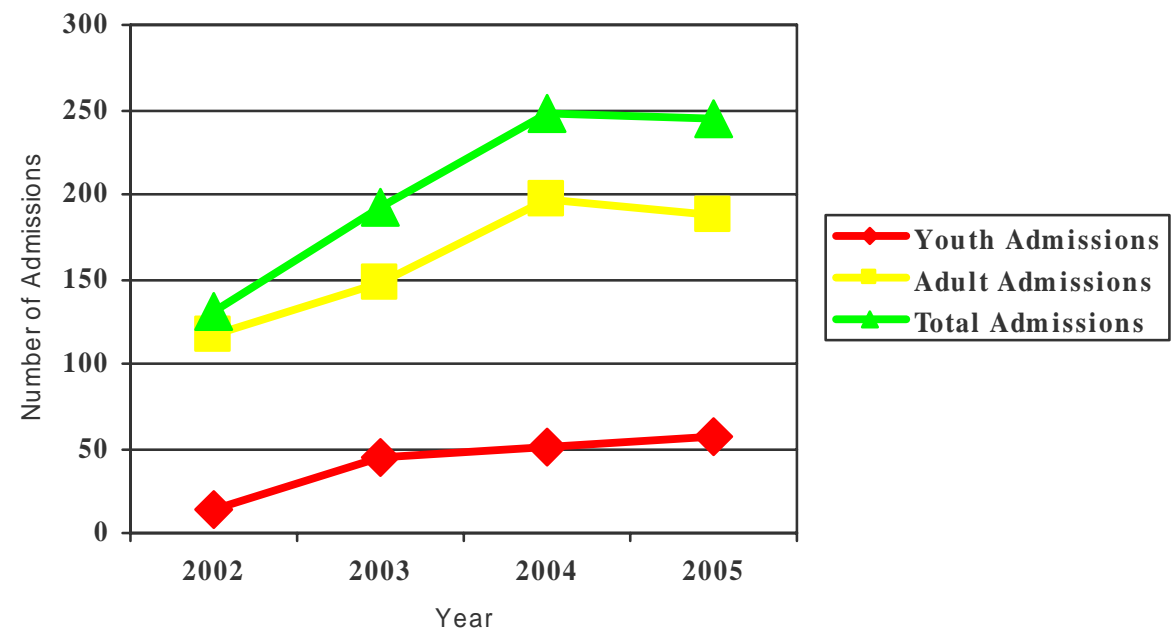

Source: Lummi C.A.R.E. Brief Summary of Outpatient Treatment 2002-2005 Admissions, Lummi Tribal Vital Statistics Office, 2006.

Exhibit 28 shows a gradual although small continuous rise for youth admissions into treatment. It also shows a reduction in adult admissions from 2004-2005. More data points will be needed to determine if this is a trend. While this data is helpful for an overall picture, it does not provide enough information to determine if treatment has reduced the number of individuals abusing substances. Data that would help in this determination would include a breakdown of youth and adult numbers by month, number successfully completing treatment, and number of individuals who have relapsed and are repeating treatment. It is also not evident if this data includes people receiving treatment in off-site facilities such as jails.

Of those officially admitted into treatment, alcohol admissions for adults declined from 69.2 percent of all adult admissions in 2002 to 63.3 percent in 2005. Yet, during that same time period there was a steady increase in admissions for "other" substances (defined as cocaine, heroin, meth, other opiates, and Oxycontin/ oxycodone) from 13.7 percent of all adult admissions in 2002 to 29.3 percent in 2005. This represents a 244 percent increase (16 to 55) in admissions for “other” drugs for this time period.

Marijuana remains the most prevalent drug of abuse for youth at admission, although the number of youth admitted with this as their primary drug of abuse has declined from 57.1 percent in 2002 to 50.9 percent in 2005 . As with the adults, there is a steady although smaller increase in admissions for “other” substance use: 14.3 percent of all youth admitted in 2002 to 
19.3 percent in 2005. Based on comments from the adult client focus group, this increased prevalence for the "other" category is what they see too. When asked what kinds of drugs young people were using, four of the six respondents indicated "pills," “oxys” or "they're selling the crack to get the oxy.”

Lummi youth served by $\mathrm{Se}>$ Eye $>$ Chen. Exhibit 26 presents client data on admissions and completion of services received at $\mathrm{Se}>\mathrm{Eye}>$ Chen over the first year of its existence. Because data was collected and recorded monthly, we were able to look at the first half of the year in comparison to the second half.

\section{Exhibit 29: Se>Eye>Chen Client Data, April 2005-March 2006}

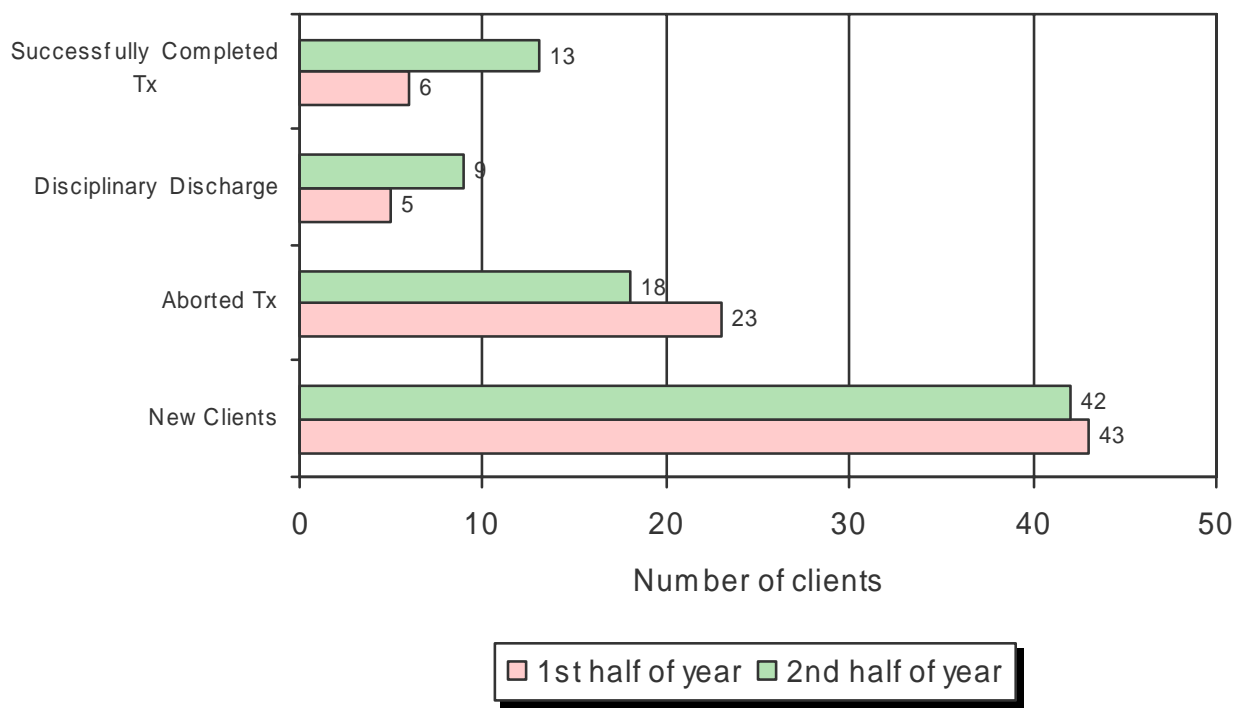

(Source: Se>Eye>Chen Report to Tribal Vital Statistics Office, 10/26/06)

As Exhibit 29 shows, while the actual number of new clients has stayed relatively stable, the number of successfully completed treatments has increased by over 100 percent from the first half of the year to the second half, while the number of aborted treatments has dropped by slightly over 20 percent. While these numbers are quite good, there has also been an 80 percent-albeit the numbers are very small—increase in disciplinary discharges. The one major difficulty the center appears to be experiencing is retaining Lummi youth long enough for them to complete the program. As one focus group member noted, “they don't stay...because they know the reservation, because it's not a lock-down facility. They can walk, and they walk....it's 
just too tempting for the Lummi kids to walk up and talk to family members or community members whom they know, and then go.”

Coordination with other services. In addition to the treatment it provides, C.A.R.E. also trains Tribal Drug Court personnel. Individuals learn how to manage cases and what they have to know regarding treatment, legal ramifications, and requirements. The training is approximately 4.5 days in length, given over a 4-week period.

Additionally, the Youth Outreach Program-in existence since 1993, but now subsumed under the Youth Enrichment and Social Services (Y.E.S.S.) Program-provides intake and referral, tracking, participation in treatment plan development, case management activities, and other services consistent with individuals’ needs. The Youth Outreach Program works with schools, child protective services, juvenile justice, Lummi medical and mental health services, and C.A.R.E (Lummi Youth Outreach Report 2005).

Changes instituted since CMAD Initiative. Based on interviews held with CMAD members, who included those in substance abuse, law enforcement, prevention, and housing, stakeholders identified the following changes that resulted as a consequence of the CMAD Initiative:

- Increased visibility of C.A.R.E. The director of C.A.R.E. notes there was a sudden large, influx of people who volunteered for treatment when the news about the community reinstituting the exclusion policy became known.

- Voiced mental health needs of the community in a larger forum.

- Increased budget for substance abuse treatment. C.A.R.E. has increased the size of its mental health team, doubling the number of counselors from four to eight.

- Incorporated new methods into substance abuse treatment, e.g., acudetox, a detox method that employs acupuncture.

- Opened an in-patient youth treatment facility (Se>Eye>Chen) in April 2005.

- $\quad$ Opened a Suboxone Clinic in April 2007.

Utilization of available resources. Available resources have been used in developing and implementing new treatment services. The community has made use of the physician they have on staff, whose specialty is addiction medicine. This individual has fulfilled multiple roles and, with key stakeholders, has overseen the development of Se>Eye>Chen and the Suboxone Clinic. 
He also oversees and administers acupuncture as part of the acudetox treatment. Other personnel who have been used in the expansion of treatment options are the counselors who are providing their services to the Suboxone Clinic. Finally, existing structures have been used and retrofitted for these two facilities.

- How satisfied is the community with the availability of treatment services?

Community members were asked about the availability of alcohol and drug treatment services for adults, youth, and families to ascertain their level of satisfaction with these services. Exhibit 30 presents those findings.

Exhibit 30: Satisfaction with substance abuse treatment availability
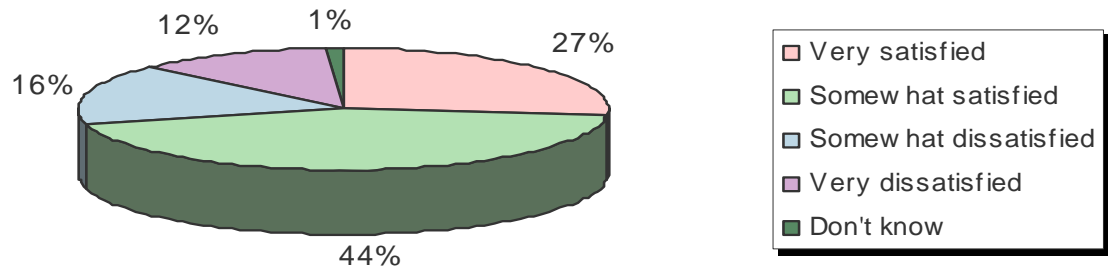

As the above exhibit shows, 71 percent of respondents were "very satisfied" and "somewhat satisfied" with the availability of treatment services. All those who indicated some level of dissatisfaction where asked to comment on what they thought was wrong or needed improvement. The most cited comment was that treatment is inadequate to meet needs (17.6\%). Representative comments included such responses as: "Not giving them enough time for treatment” and “We don't have 24/7 someone at C.A.R.E. program.” The second most cited concern was that the wait for getting into treatment was too long. Typical comments reflecting this response were: "Takes too long for bed date and some programs are too slow for response times" and "Programs need to be made available immediately." The third type of comment was centered on the need for aftercare (12.2\%). Here typical responses included the following: "No support system for when you get out of treatment for jobs...." and "We don't have a halfway house for people coming out of treatment. They need more support.” As the above comments 
show, respondents wanted longer treatment programs with quicker and on demand access as well as more support through aftercare to stabilize recovery and daily lives.

Focus group comments were generally positive regarding Lummi C.A.R.E. This was particularly noteworthy for the adult client group, the one group that had the most direct and recent contact with its outpatient program. Their comments addressed the quality, longevity and continuity of the care and the role of family in that care. "[Services are]...helpful, very helpful!" “And I'm getting the help I need... and it's the help of Lummi C.A.R.E., and I'm worth it.” Another person stated she had been seeing a counselor for ten years and felt she was "very helpful. I have a problem; she doesn't hesitate for us to come in.” Another participant was pleased with the inclusive nature of the counseling: "All of us, my two granddaughters and my son and I are both in counseling, all of us...”

Several participants across the groups felt there was a need for more services, from pretreatment to longer treatment programs to a holistic model that extends through aftercare. One participant questioned the ability of the present system to address the readiness of individuals to go into treatment: "The C.A.R.E. Program, you have to be in the C.A.R.E. Program to get services. Now what if they're not ready to go there yet?” Another participant felt services should be extended to include inpatient care and aftercare ("I think they're lacking one thing, and that's the intensive inpatient. ... They need a, when they come out of treatment, a recovery house, so they can come back into the community...there's no safety net”), while another participant voiced the need for a longer treatment program ("Sure, the C.A.R.E. Program is there, but 30 days ain't enough when you send them out...It gotta be over 200 days”). One policy maker, commenting on the cyclical nature of the current situation, suggested an extended treatment program as a possible response to this problem: "People are getting treatment and they're going right back [into drugs].... They're not lasting...they need long-term treatment.”

Frustration was expressed regarding the character of some of the participants in the C.A.R.E. Program. On participant stated that, "People that are in addiction are very smart, oh yes. They find ways to come over here to get what they need. And that's like they're pulling the wool over our eyes again, and so I hope that's the goal of CMAD, so we can get people what they need but also on the way to recovery... because it's frustrating. It's like we're knitting a blanket and pulling it out at the bottom at the same time." An elder made the point that, "We need to make it a dry reservation.” 
Other participants advocated for consulting and including the advice of clients and former clients in developing more appropriate services. A policy maker stated “...maybe change the mission of CMAD a little bit back to where we listen to the real stories of people [who have gone through it].” An adult client reflected a similar sentiment in his comment on instituting changes in treatment delivery: “...somebody that’s never done it and haven’t gone through it can’t be making decisions on how to change it, long-range.”

Services were addressed which related indirectly to drug issues. For instance, homelessness was viewed as resulting from an attempt to curtail addiction. This was a particular concern of those participants in the community members' focus group. One participant pointed out that:

“They [CMAD]...think that they addressed the drug problem by UA-ing everybody. In order to get a house they have to have a clean UA. And so that causes the problem...they try to keep the housing projects clean....and that doesn't give them [those with positive UAs] anywhere to go. And so they become either homeless or living in tents or they're living with relatives.” This sentiment was similarly voiced by another participant who felt that “... it [CMAD] does create a barrier to our families that are into drugs and alcohol as it makes them be forced out of housing....” Another person proposed a way in which to address homelessness: “...because there's more and more people falling into that category...Housing should take it upon themselves to build a safe home housing project for the homeless people and make a program working with them to make them more responsible to be home owners and home renters.” Another participant felt the needs of single head of households should be addressed: "Housing should provide a big building where single parents...can get a place to take care of their children and feel comfortable.” The needs and concerns of these kinds of issues has, as one member of the policy maker focus group noted, affected the way the Housing Department works, turning it “...into a social service, is what housing is.”

Other tangential issues mentioned to treatment and recovery were the need for reliable transportation to get to jobs and treatment and rehabilitation (“... Instead of having just one bus, I think we need four or five buses”) and free daycare for those in job training and rehabilitation ("Daycare is available for them, but they can’t afford to put their baby in there unless the training's going to pay for that stage....”). Possibly the comments of one focus group participant 
sum up the overall feeling addressed by the above concerns and frustrations, “...I think it's more the system ....There's a lot of people trying to get clean, and they can't get through the system. They can't get through the red tape....”

While community members are satisfied with the treatment care they are receiving and that has been expanded for youth, they would like to see changes or increased emphasis placed on the following:

- Lengthen duration of treatment program

- Have on-reservation adult treatment facility

- Have better outreach to those in need

- Increase funding and personnel for treatment

- Address generational issues

- Provide more aftercare support including housing, employment, and transportation

Finally, the evaluation wanted to determine if there were any changes in alcohol and other drug related diagnoses over the time period the CMAD Initiative has been in effect. The following exhibit provides data received from the Lummi Health Clinic on number of clinic visits by most frequent alcohol and other drug-related diagnoses (based on ICD-9 codes).

Exhibit 31: Changes in health conditions:

Number of clinic visits for frequent alcohol and other drug diagnoses

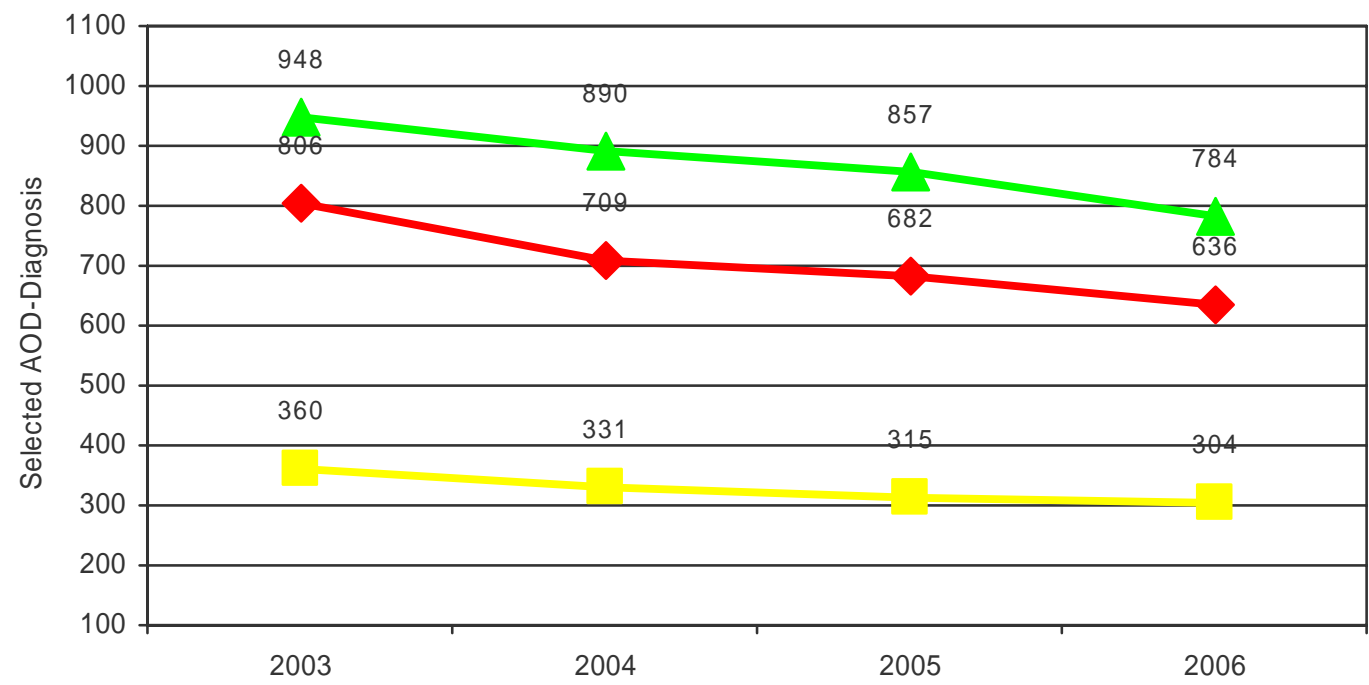

Alcohol dependency syndrome $\longrightarrow$ Drug dependency $\longrightarrow$ Alcohol and drug abuse

Source: Lummi Health Clinic, 3/27/2007 
The above data shows a 17.3 percent decrease in alcohol and drug abuse, a 21.1 percent decrease in alcohol dependency, and a 15.6 percent decrease in drug dependency for individuals seen at the Tribal Health Clinic. Although these are all positive trends, the information is limited because it does not include data from non-tribal health and mental health care providers. This data from outside sources was unavailable to the evaluation.

\section{III.6) Goal 6: Provide active and consistent coordination of the treatment, enforcement, and support services needed by Lummi Nation youth, adults, and families.}

- How well are agencies able to coordinate their efforts to enhance services to the community?

Several program directors have identified areas in which they see greater coordination among programs and departments as a result of involvement in CMAD. Drawing from their annual reports, they include the following areas:

- Increase of collaboration between related departments with overlapping concerns, e.g., C.A.R.E. and Tribal Drug Court in referrals and staffing, and housing and TANF to assist people in transition and to share resources.

- Create a task force to address a problem, e.g., develop policy and guidelines for transitional housing. In this case representatives from housing, family services, and employment and training work together to address issues and strategies for developing housing plans.

- Develop plans that incorporate the input and collaboration of multiple services (LNPD, Tribal Drug Court, C.A.R.E., Employment and Training, and Y.E.S.S. to develop and implement the Restorative Justice Center.

- Develop plans that incorporate the input and collaboration of the Housing Department, Y.E.S.S. Program, Employment and Training Center, and C.A.R.E. in the development and implementation of Recovery and Transitional Homeless Housing.

- Establish a collaborative relationship between Y.E.S. and Se $>$ Eye $>$ Chen personnel prior to opening of the treatment center via the CMAD process.

- Provide informative meetings/workshops, e.g., process-mapping meetings, in which members examine their programs and look at ways to streamline processes and increase communication across groups. 
As mirrored through the focus groups, collaboration or the lack of it, is not seen the same across all segments of the Lummi community. Presenting a less positive perception on how well programs in the community are working together, an elder sums up several persons’ perspectives from the traditional healers’ focus group: “Programs here don’t work together....it takes five programs within the community to help one person and three from the outside...to help one person....I don't see that it is working.” Another member of this group states, “Others come, sober up for a while, then go off again because of the way things are here. We don't have the people working together here. We don't have the people in programs working together. That's one of the biggest things." In this case the person is connecting the failure of people to stay off of drugs with an absence of coordinated programs. On the other hand, service providers perceived collaboration in a more positive light, as exemplified by the following comment from one of the focus group members: "The community as a whole is also more aware of options for healing and recovery because of CMAD. Not only has CMAD linked everybody together and formed programs like Se>Eye $>$ Chen but, because the word is out, committee members are now aware that resources are available.” In almost direct opposition, this individual is stating that because of the collaboration there was success in forming a viable program.

A sense on the part of some participants in the focus groups pointed to the elevation of CMAD from a community base to more of a bureaucratic base. One participant felt that "community mobilization seems to be diminished whereas six or seven years ago it was absolutely a community movement and now it becomes more of an administrative or political government kind of movement." A policy maker commented that "CMAD was a Council initiative, and I think that sort of had a double-edged sword effect. It reduced the amount of community input .... There was more staff input...” Another participant from this group felt that there was “....a shifting perception of the Council's interest as a whole in CMAD. Because of the change in chairmanship..." Yet, participants could also cite accomplishments of CMAD that pointed to collaboration both between tribal entities and non-tribal entities. A view of one person was that CMAD had a role in aiding the children's cause with regard to substance abuse issues: "One of the great things that came out of the CMAD meeting when we were talking about the children's code was a statement of children’s rights.” The Lummi Tribal Police outreach to the State Patrol and the Whatcom County Sheriff's Office was noted as a fine example of 
collaboration in that the State Patrol and the Sheriff were not aware of "the preventive effort that we were doing in police work...so they were pleasantly surprised”...[and are] getting more and more involved with the tribe."

In a desire to get a better handle on how well the efforts that are being put into place are working, the policy makers discussed at length the need for evaluation and accountability to the community. One stated that "I am not aware of any evaluating process. Our departments are basically evaluated in the whole community.” Another said "I think it would be very helpful to have an evaluation that makes sense to the community...they want to know...we're spending umpteen million dollars and what do we get?” A frank statement from one policy maker was that "I don't like evaluations.... I run from evaluations...that's what a politician does....We run from evaluations, but it won’t improve anything if we keep doing that.” One participant commented "And so an evaluation process is not to go around pointing fingers at people....keep doing things that are working and stop doing things that aren't.... Look for other ways that might work. And if we get better incrementally every year, we could become more and more effective as time goes by, using a proper evaluation system.” Based on these comments there was acknowledgement of a need for reassessment, willingness to take the risk to hear if things were not working, and a desire to use the evaluation as a collective tool to improve on what they would learn.

Mental health and prevention services: Youth Enrichment and Social Services Program (Y.E.S.S.). The Y.E.S.S. Program is a comprehensive case management program within the Department of Family Social Services. It was spearheaded and developed in 2004 through the CMAD Initiative. Its mission is to implement safe and affordable social service and educational programs for Lummi children, youth, and their families. The program provides youth outreach services (in operation since 1993 but now subsumed under the Y.E.S.S. Program), counseling services, a summer school program, assistance for athletic activities and events, cultural activities, parent education and support, and an Angel Tree at Christmas. It currently has eight mental health counselors who provide support and services to the Tribal School. It has a full time speech and language pathologist on staff for Head Start and contracts with occupational and physical therapists to be in compliance with federal guidelines. Mental health services are offered through school based counseling at Lummi Head Start and Lummi Nation Schools, by 
means of individual and group therapy sessions, delivered in and outside the office; through family therapy, and through home visits.

- $\quad$ How satisfied is the community with the availability of prevention services and activities?

Participants in the community survey were asked to assess their satisfaction with the availability of a variety of programs and activities offered in the community for youth. Using a scale from “very satisfied” to “very dissatisfied,” community members responded in the following way:

Exhibit 32: How satisfied are you with the availability of sports, recreation, enrichment opportunities, after school activities, spring break, etc.
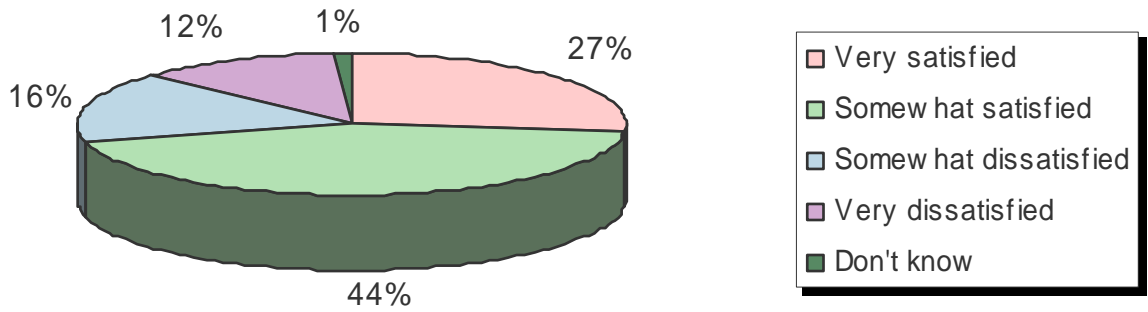

As the above exhibit shows, 82 percent of respondents were "very satisfied” and "somewhat satisfied” with the availability of youth oriented activities. Level of satisfaction was more fully addressed through the focus groups in which participants addressed how activities, or the lack of them, are impacting the lives of the youth of the community.

Youth focus group participants were generally satisfied with the activities and services provided by Lummi. With regard to the Y.E.S.S. program, one participant commented that, "Pretty much if you ask them for help, they help you, and they seem to be on top of things whenever I look around, so yeah, it’s great.” Another stated that “There are real good counselors there. They give real good advice." The Y.E.S.S. Program was also viewed as "helping organize youth sports go out into tournaments...pay their fees... whether it's softball, basketball, and I've seen them help other families.” With reference to the Canoe Journeys, which is seen as 
a traditional path to healing, the consensus was that the journeys can be "awesome” and helpful to the youth and those over the age of 18 as well. One participant stated that when some troubled youth went on the Journey, "that it did change their lives...it changed their way of thinking, to be out of the gang-related things....” The act of canoe pulling was seen, as one participant put it, as giving “...us a real sense of family.” The youth also appreciated the canoe pulling experience in that it gave them "teachings...from the elders, the real sense of family and friends..." Over all they felt that "People like are there more for you.... So they're always trying to find out stuff for us to do...just trying to keep us busy, checking up on us, making sure we're doing all right.” For many, it became an extension of or substitution for their family within which they felt welcomed and comfortable.

Participants in the community members' focus group expressed the need for more youth services and activities. One commented, "What I would like to see is an AlAnon group starting for our youth." Another suggested "that CMAD implement more of those [summer events]...to invite youth to, encourage them to stay clean and sober, to celebrate that with them, rather than always focusing on the bad things." One participant cited traditional activities as desirable: "We had them when I was a kid. They were Coast Salish dancers and songs, and we don't have those anymore.”

Some adult clients were positive about the ways in which youth issues were being addressed, given the fact that they saw the substance abuse problem among youth increasing and involving younger and younger persons. One participant commented that "the treatment programs...what they're working on in dealing with younger children, and that's where I see quite a bit of improvement in.” Another participant in this group pointed out the dichtomy from how things previously were to the services that exist now for youth: “...if I was brought into treatment center as a youth...it could have made a difference in my life. I probably wouldn’t be sitting here today. I think that's just really cool that they're getting the youth into treatment as they're younger, as soon as it starts....” Some of the participants in this group were not as positive in their assessment of the services and programs available to youth. One participant felt “there's not enough support and activities for youth...no building or community center for them, for games and activities on the weekend. A lot of what I hear is that there is no money. And there's no real activity like outside the reservation for them. Like for them to pick them up and bring them to the movies or something.” Another respondent questioned the importance tribal 
officials are giving the issue: “...because right now they [Lummi Indian Business Council] say our children are our priority, but they won't put the money into it.”

Because the Y.E.S.S. program is relatively new, there is little comparative data that could be compared from one year to the next to convey the impact of the program. The following exhibit presents the unduplicated encounters reported to Medicaid for the years 2004-2006. Based on the Lummi Nation's BJA Indian Alcohol and Substance Abuse Demonstration grant proposal in which it states, "almost all of the [Lummi] youth are eligible for services reimbursed through the Medicaid Program” (Lummi Nation 2003: 19), the following chart is a snapshot of the number of individuals receiving mental health services through Y.E.S.S. from 2004-2006 as reported to Medicaid.

\section{Exhibit 33: Youth Enrichment and Social Services: Unduplicated encounters reported to Medicaid, 2004-2006}

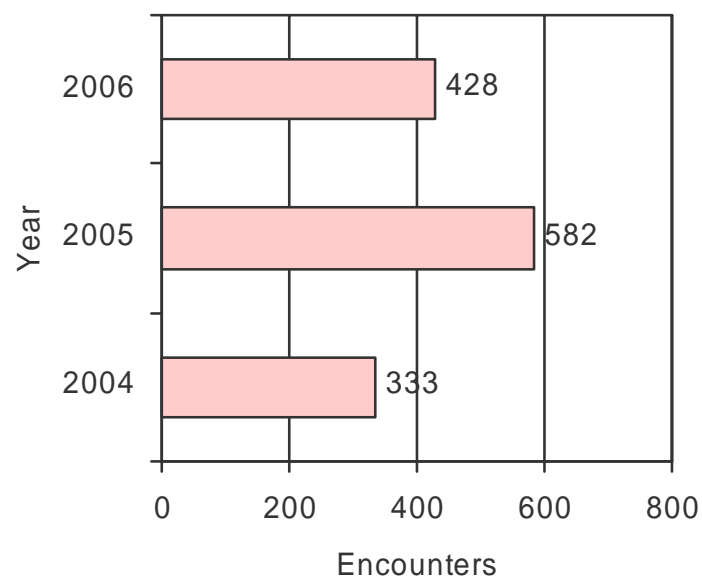

Source: Lummi Nation Youth Enrichment \& Social Services, 2006-2007, Squol Quol, May 2006)

- How effective is the Home of Healing Spirit or "Safe House"in reducing alcohol and drug use and related crimes among Lummi youth?

The "Safe House" was opened in 2004 under the supervision of the Y.E.S.S. Program. As of 2006, the program was removed from under Y.E.S.S. and is now directly under Family Social Services. The facility provides a safe and structured environment for Lummi children and youth 365 days of the year, twenty-four hours per day. The House originally maintained ten (10) beds but is now down to six to comply with Washington State regulations. It receives referrals from the following tribal sources: Tribal Court, Children and Family Services, Y.E.S.S. (including Youth Outreach), Youth Recreation, and Lummi C.A.R.E. As part of its staffing, the Safe House 
coordinator regularly participates in monthly meetings with Juvenile Justice, the Child Protective Team, and CMAD to assist in developing tailored comprehensive plans for the youth residing there. Approximately 95 percent of the residents at the Safe House are tribal court mandated because of neglect or abuse by adults or because of violence perpetrated by the youth (Barrie, personal communication 2005). A child could also be recommended for the Safe House by a mental health counselor, or if 13 years and older, through self-referral.

While residing at the Safe House, youth are assisted in many life domain areas, including independent living skills, money management, completion of probation requirements, and education. They are provided with transportation to variety of appointments and cultural events and have access to participation in sports and other extracurricular activities (Lummi Nation $\left.2005^{\mathrm{a}}\right)$.

Youth perceptions of and experiences with the Safe House were positive. One participant commented that "It provides you a safe place to stay when parents are fighting and drinking." Another stated, "I feel comfortable there...not having to watch kids. Because I always watch kids when I'm at home with my mom... when I'm there I don't have to watch anybody except myself.” Additional comments included, “At the Safe House it's more, better being there than at home...I still can barely take care of my own baby because I have to take care of my mom's babies. So it's more stressful on me when I move home, so I'd rather be in the Safe House.” Another youth stated that being at the Safe House “...helped me out on this process where I wasn't [in] a good place.... They helped me and got me on my feet.” As the comments indicate, the Safe House serves as a respite from stress, fear, and excessive responsibility while providing the youth with the time and place to refocus and to take care of themselves ("I don't have to watch anybody except myself”).

Over the three year period from 2003-2005, the Safe House has admitted 165 youth— 2003: 24, 2004: 83, and 2005: 58 (Safe House Final Report 2005). Data was not available for 2006. While this program appears to be filling a need in the community, data was not yet available that could connect residency at the Safe House with reduced juvenile drug use and drug related crimes.

- Have other programs or services been developed to reduce the risk of youth to use alcohol and drugs and be involved in alcohol and drug related crimes? 
As part of prevention, education was one of the five areas identified by the CMAD proposal that needed to be addressed. Education was addressed in part by the Y.E.S.S. program. Subsequent to writing its proposal, the Lummi Nation and specifically CMAD, moved to address low school attendance at the tribal school and unsupervised youth. (As of 2004-2005, the absenteeism rate for grades 1-8 at the Lummi Tribal School was 8.85 percent, the highest rate in the state of Washington and 22 times higher than the state rate of .4 percent (Valz and Bellaw 2006). (In addition, 77 percent of those responding to the community survey identified "interruption of regular school attendance as a "big problem" in the community.) The Y.E.S.S. program accomplished this by developing a plan to provide dormitory housing for $5+$ days per week and supportive services for Lummi students from grades 7-12 in need of this kind of environment. This project, called the Youth Leadership Academy, is planning to pilot this wraparound intervention of services with approximately 20 youth (10 girls and 10 boys). It will incorporate professional counseling and physical and speech therapy plus tutoring as part of this care. While not geared specifically to youth with special needs, it will include and provide services for those individuals. The facility is currently under construction (J. Folsom, personal communication, October 2007).

\section{III.7) Goal 7: Plan, develop, and implement transitional housing for clients.}

Currently, the transitional recovery program is in place although on-site transitional housing is not. The transitional recovery program was designed to assist individuals in their first year of recovery by helping them secure transitional housing in a clean and sober environment.

The Transitional Recovery Program, which was developed as part of the CMAD Initiative, was designed to provide transitional off-reservation housing for Lummi adults and emancipated youth in their first year of drug and/or alcohol recovery (Lummi Housing Department, 2006). The program, which is the only such tribal program serving American Indians in Northwest Washington State, provides housing assistance with clean and sober housing rental assistance vouchers for units not within any other Lummi Housing program. It pays the deposit and rent for up to six months for qualified individuals, including their domestic partner and/or any minor children for which the applicant has custody (Lummi Housing Policies and Procedures, Chapter 10: Transitional Recovery Program). The program is limited to 10 individuals at any one time. To ensure the living arrangement is appropriate, the following procedures are in place: 
- Background checks are made on landlords to determine whether their rental units are located in a safe, clean, and sober environment and whether the types of housing they have available, i.e., if it is for individuals and not families or is a facility that only accepts women or only men.

- Clients must agree and sign a contract that they will participate in monthly home visits, random drug testing, and a treatment program.

A person can be dropped from the program for one or more of the following reasons: criminal charges, positive drug test, or eviction. The following client data is for the years 20052006. Because the program had a slow start (many social service providers were unaware of it at the beginning), the number of clients using the program was very small at the beginning. In 2005, only one person (with one child) received assistance, and that individual did not succesfully complete the program. In 2006, 18 individuals (with 13 children) received assistance. Of that number, nine successfully completed the program and nine did not. Data for 2007 (January-August) currently shows 19 individuals (with 13 children) receiving assistance during the first eight months of the year. Of that number, six individuals are still in the program, six successfully completed the program, and seven did not successfully complete the program.

In addition to the traditional recovery program, the Housing Department has been working for the last two years on obtaining approval from the Housing Commission for the development of an on-site Recovery and Transitional Homeless Housing unit or units. This process has involved finding an appropriate site on the reservation and developing the policies by which the program would be implemented. Because this process involves coordinating multiple facets of recovery, program development has brought together the Housing Department, Y.E.S.S. program, Employment and Training Center, and C.A.R.E. into the discussion and planning of this project (Transitional Housing Meeting Minutes, 11 April 2006). On-site transitional housing is currently in the planning stage of development.

\section{III.8) Goal 8: Plan, develop, and implement a subsidized employment program for clients.}

Approximately 60 percent (59.8\%) of those responding to the community survey were "very satisfied” and "somewhat satisfied” with job opportunities in the community. However, based on Transitional Housing meeting minutes and responses in the focus group discussions, there is considerable need for financial support in the community, particularly for those seeking transitional housing. Focus group comments indicate an increase in interaction between 
Temporary Assistance for Needy Families (TANF) and housing. This may have been enhanced by the recent movement of the Employment and Training Center, including TANF, to Social Services. Currently, there is nothing being addressed regarding rehabilitation of traffickers to gainful employment although there are plans for this to occur for those in treatment (see discussion on Suboxone Clinic). The Lummi Nation was recently awarded a six million dollar grant from the Northwest Area Foundation to improve economic development in the Lummi Nation. The plan outlined by the Nation in its report to the foundation (Lummi Nation 2005 ${ }^{b}$ ) included a specific objective to provide education and employment opportunities to support those in recovery. It is unknown if this is in the planning stage.

\section{III.9) Dissemination Activities}

Since 2004 the CMAD Initiative has given many presentations to the Lummi Nation, Coast Salish tribes, and other tribes. These presentations have been to both small groups and conferences. The following exhibit represents the presentations given over the two year period from September 2004 to August 2006. The list was drawn from the presentation log completed by the CMAD coordinator at the request of the evaluators.

Exhibit 34: CMAD Tribal and Intertribal Presentations (9/1/2004-8/31/2006)

9/1/2004-8/31/2005 Presentations/Events

- Lummi Nation 4

- $\quad$ Regional Intertribal with Lummi Nation community 5

- $\quad$ Non-regional, Intertribal 3

$\begin{array}{ll}\text { Total } & 12\end{array}$

9/1/2005-8/31/2006 Presentations/Events

- Lummi Nation 1

- Regional Intertribal with Lummi Nation community 2

- Regional Intertribal without Lummi Nation 6

- $\quad$ Non-regional, Intertribal 9

$\begin{array}{ll}\text { Total } & 18\end{array}$

- $\quad$ CMAD Hosted/Co-Hosted Event (included in above count) 6 
As evidenced by the above data, there were multiple presentations and events given by the CMAD Coordinator and other CMAD members on topics that varied from a specific project, e.g., the Restorative Justice Center, to disseminating information on the development and progress of the CMAD Initiative and how it can function in a community. The number of given presentations increased by 50 percent over the period September 2004 to August 2006. The increase was seen primarily in the area of non-regional, intertribal presentations. Overall, the CMAD Initiative hosted six events during this two year period of which three were the Coast Salish Gatherings described earlier. The presentations were well received, with the presenters often commended by audiences and workshop trainers.

The Lummi community, however, is to a small degree conflicted in how they regarded these events. This conflict is exemplified by the few comments focus group participants' made about these activities. A couple of participants in the traditional healers group voiced concerns that CMAD needed more of an inner directed Lummi focus. "They put these big things on, conferences and so forth, and pull in other people from other places, and our people here that need help are still out there,” commented one. This sentiment was echoed by another elder, “And I see them having all these banquets. What good is that? That's [not]...taking some of these kids off the streets or these drug sealers off the street...” An adult client made a similar observation, “...I see them going on trips and organizing this and organizing that in many different places. I think they need to start by sticking around here for a while and really taking a look at their own people.” However, a participant in the community member focus group saw things differently: "I hear our CMAD Director is traveling and presenting and spreading the word to our neighbors, which I don't criticize. I think that that's imperative, that we have a model that's working, that we share it with our neighbors.”

\section{III.10) Technical Assistance Data System Findings}

\section{III.10.1) Lummi Family Social Services}

Most of the information for this department is kept in paper files, with data aggregated into Excel sheets as reports to the Lummi Tribal Vital Statistics Office.

\section{III.10.2) Lummi Nation Police Department (LNPD)}

The Lummi Police use CRISnet RMS, a system developed several years ago for multiagency use. The LNPD uses Crystal Reports system to pull information regarding calls and 
arrests from the data base system. Crystal Reports requires that new report programs be written every time someone needs data. CRISnet does not have the ability to provide UCR type data such as the number of arrests by type, age, and month.

The Tribal Courts use the Full Court database system and would like to able to talk to the police system. Specifically, the courts would like to be able to link the original charges to the court results and outcome resolution. This would enable them to report outcome resolution back to the community, i.e., number of people with specific charges by outcome resolution (jail, probation, etc.)

The Police Department is looking at other systems to use for data collection. Funding will be needed to purchase a system that can integrate with the Tribal Courts’ Full Court system.

\section{III.10.3) Lummi C.A.R.E.}

C.A.R.E. uses TARGET, which is also used by the State of Washington for reporting data, for all of their admission information. The Lummi Tribal Vital Statistics Department obtains summary information from TARGET about the number of admissions. The numbers submitted to the State are drawn from group counseling sessions. Group members sign in at sessions, and group leaders submit a weekly activity report. Some individuals, they reported, are not entered into the TARGET system (e.g., those just dropping in, or those receiving services not reimbursable by the State). The numbers reported do not always reflect actual numbers served as they do not account for walk-ins, home visits, jail visits, hospital visits, and interventions, all of which are not recorded in TARGET. It might be useful to have a system in which each of the counselors/group leaders record their activities and attendance electronically, but that would require more time and equipment than C.A.R.E. currently has available.

\section{III.10.4) Se $>$ Eye $>$ Chen}

The Se $>$ Eye $>$ Chen facility was opened on April 14, 2005. All data for this youth in-patient treatment center is in the TARGET system. It is used to compile monthly reports on numbers of clients being served along with basic demographic information. In addition to this data, Se>Eye $>$ Chen also maintains full paper files on the youth that they serve. All of the data (mental and physical health) they need to track and treat their clients are contained in those files. 


\section{III.10.5) Lummi Housing Department}

Currently all work orders are entered into an Access database so that Lummi Housing can tell the amount of money spent per house and per work order. Other information, including the number of inspections, number of evictions, and number of houses occupied, is entered into an Excel spreadsheet. They update the household information annually unless a situation changes, at which point they review it the day the situation occurs. They have heard of a records management system to keep all their records together that will allow them to scan old documents into files as well. This system costs $\$ 20,000$ and would allow them to have all of their information in one location. Outside funding is necessary for this purchase.

Lummi Housing would like to conduct urinalysis for drug testing locally. They are currently taking people into Bellingham to do this, which is costly in time and money. They would like a local business created at Lummi to do this as they are currently spending more than $\$ 50,000$ outside of the community to do the drug testing. While other departments might want other information from the drug testing, Housing wants to make sure the only information they receive is whether or not the result from a test was "positive" or "negative." They do not want to know the amounts or types of drugs found.

\section{III.10.6) Court and Probation}

The Courts are using the Full Court system to enter all of their data. Full Court uses an Oracle back-end and a Crystal Reports system for reporting. This would allow the LNPD to bridge to the court data if they have a system that uses Oracle. The Full Court system has a good ability to pull up data about a specific case and individual. The Courts would like to see the Probation Office use this system, and they are currently trying to get another license so that the Probation Office can also use the Full Court system so that they can look at compliance information. Up until very recently, probation officers maintained only paper files; they are now in the process of entering their files into the Full Court system. The judge would like to be able to report on the effectiveness of the system (repeat offenders, lost to follow-up, etc.). Probation officers want to determine measures of success and variables associated with success and failure.

\section{III.10.7) Summary and recommendations}

Each agency has a different system for handling their data. Both C.A.R.E. and Se $>$ Eye $>$ Chen use Washington State’s TARGET data system for reimbursement of client 
services. The TARGET data system is used by the Lummi Tribal Vital Statistics Office to obtain general demographic information on the clients receiving services.

Overall, the court and treatment information systems are more than sufficient to collect and utilize all of the data available to them about the individuals in their system. Several other agencies would like to have an easier way to collect their data so that doing reports would be faster to produce. The vast majority of the agencies do not seem interested in an integrated system where all of the data is centrally located. Lummi Housing for example, wants to know if a drug result is positive or negative, but does not need to know any additional information beyond that. Police would like to link to the court and probation data, which will be possible if they pick any system with an Oracle back-end. The courts would like probation data, but they are not interested in other information as it would not be helpful to them. Overall, the agencies need to develop specialized systems that work well for them to provide aggregate data, but they are not interested in a centralized system where all information on a specific individual is available.

The Director of the Department of Information Technology has been asked by the tribal council to address different issues regarding each department and to work on developing a centralized system for Lummi. He will need additional funding and assistance to meet the information needs of the Lummi agencies. 


\section{IV) ANALYSIS AND DISCUSSION}

\section{IV.1) Evaluation Focus}

This NIJ funded evaluation was a formative assessment that focused (1) on whether or not the Lummi CMAD Initiative was being developed and meeting the goals and objectives the Lummi Nation set out in its BJA/IASAD proposal, and (2) if the model had application for other tribal nations confronting similar public safety issues related to alcohol and substance abuse. As part of this process, the evaluation team from the UA proposed to partner with the Lummi Nation CMAD Initiative and its EOC to ensure the evaluation process was sensitive to the tribal environment while being conducted within a framework that was scientifically rigorous.

By employing a community-based participatory evaluation, which included the community and key stakeholders at all levels of its development, implementation, and analysis, we were able to create a detailed, ethnographic picture of the CMAD Initiative and how it is perceived at different levels of interaction. Through this primary data collection and subsequent analysis, a multifaceted picture of progress and challenges emerged. The following are the major findings from the evaluation.

\section{IV.2) Awareness of drug problem in the community}

Through multiple media and work-related efforts, meetings, and events, the CMAD Initiative raised awareness of the dangers of drug use, the legal consequences of drug trafficking and use, and the notion that neither will be considered acceptable in the Lummi Nation. This latter point is critical because, according to multiple accounts of community members, this was not always the case. It is this heightened awareness of the hazardous impact of drugs on the community, the family, and the individual that both increased support for law enforcement action and increased the critical awareness of actions or inaction of law enforcement. Currently, there is frustration with the prevalence of drugs and the openness and ubiquity of drug trafficking in the community. Nevertheless, even with this frustration there is the awareness that the CMAD Initiative has been responsible for raising the consciousness of the community about the problem. Community members correctly associate CMAD with fighting drugs and/or alcohol in the community. However, even though this association is made, many Lummi who were surveyed or who participated in the focus groups did not know what CMAD could and could not do as an entity. A more complete understanding of CMAD was found among the service 
providers and policy makers, individuals directly involved in CMAD through its meetings and/or task forces.

\section{IV.3) Perception of drug problem: now and compared to three years ago}

Drug availability and use continue to impact the community. Focus group members detailed how it affects their families and presents a particular challenge to those who are directly addressing the problem as service providers, policy makers, and law enforcers. As noted, having family members involved with drugs presents a unique and powerful stressor on these practitioners, sometimes drawing them in opposing directions of loyalty. While the desire to take care of one's own family is evident and often practiced, family members who take on caregiver roles for children of drug users or the drug user him/herself experience the effects on a daily basis of an added emotional burden.

Oxycontin is seen as the biggest drug problem at Lummi, followed by crack cocaine, other prescription drugs, and alcohol. The abuse of this prescription drug was also the impetus for creating the CMAD Initiative in 2002. It is evident from the data that this problem remains the most critical drug concern facing the community. From the perspective of the community, it is a problem that has not diminished over the last three years.

As drugs are considered big problems by community members, so also are drug use and drug dealers. Almost all of the respondents indicated these latter two concerns were major problems in the community. Of those who thought outside drug connections were "very powerful” compared to three years ago, 86.1 percent thought Oxycontin was a "big problem.” Similarly, of those who felt "much less safe" as compared to three years ago, 90 percent also felt drug connections were "very powerful” compared to three years ago."

\section{IV.4) Law Enforcement}

While it is clear from the data that the community sees the drug problem as getting worse and issues of safety as rising, it was also important to evaluate their perceptions of the effectiveness of 1) the Lummi Police in reducing alcohol and drug related crimes, and 2) the Lummi Tribal Courts in prosecuting these crimes. Overall, both the handling and prosecution of alcohol related crimes were viewed by community members as handled better by the police and prosecuted more effectively than were drug-related crimes. 
Within both areas the evaluation team found a gender split, with men more than the women viewing the police as doing a better job and the courts as being more effective. This gender difference was particularly pronounced in the area of drug-related crimes in which there was 28 point difference between the percentage of men (40\%) and women (12.5\%) who thought the police were doing a "very good" or "good" job in this area. This gender difference was less pronounced for the prosecution of alcohol and drug crimes.

These striking results were analyzed multiple ways to determine why this gender difference existed. First, we looked at the possibility that women might be home more and therefore witness to more drug activity during the day. However, based on the data from the community survey, the percentage of women working outside of the home was virtually the same percentage as the men: 75 percent and 74 percent, respectively. Similarly, of the women employed, 76 percent indicated they were working full time. Next, we looked to see if there was any relationship between gender and whether or not these individuals had a child living at home with them by how the respondents felt the police were handling alcohol and drug crimes. Findings showed virtually no difference between women with children at home and women without children at home: 7.7 percent of women without children at home compared to 9.3 percent of those with children living at home thought the police were doing a "very good" or "good” job handling drug related crimes. AS with alcohol related crimes, there was also a similar small differential in response with 21.4 percent of the women without children and 25 percent of the women with children at home indicating the police were doing a "very good" or "good" job in this area.

Men’s responses were more varied. Those with and without children at home were in relative agreement about how good a job the police were doing handling alcohol related crimes: 57.9 percent of the men without and 55 percent of the men with children at home thought the police were doing a "very good” or "good” job. However, with respect to drug related crimes, 47.4 percent of men without children and 28.6 percent with children at home felt the police were doing a "very good" or "good" job in this area. While this result suggests that the handling of drug related crimes is seen as less effective by both men with children at home and all women, it still does not explain why it is considered so much less effective by women other than that Lummi women may be more skeptical or pessimistic than Lummi men in their view about change. 
Changes were made both in the exclusion policy practiced by the Lummi Nation and the aggressive public stand the tribe took towards ridding the community of drugs and drug trafficking. This approach brought considerable attention, both from within and outside the Lummi Nation, about its situation and the tough approach it promised to take towards drugrelated crimes. The enforcement of this policy for drug trafficking has only started to be employed again in 2006 after a hiatus that lasted five years, from 2000-2005. It has not been used as a punishment for drug-related crimes against Lummi tribal members since 1999, which is prior to the CMAD Initiative. However, there is considerable discussion and concern about the exclusion policy in the community, with tribal members split on its effectiveness as a deterrent. Virtually half of the respondents to the community survey feel the practice of exclusion was going well, and approximately half felt it was not going well. This finding was corroborated through the focus group data, which detailed this ambivalence: support for punishment yet concern for the person's loss of identity and separation from family. While it is not possible to determine if the exclusion policy is having an effect on drug trafficking, it may in fact be premature to expect a reduction in drug trafficking as an effect of this policy because (1) no tribal member has been excluded for drug trafficking since the policy was revised, and (2) the view remains that new drug dealers continually replace ones that have been arrested. At this point, it is having its largest impact in the discussion it has generated in the community and in the notion that there is a more serious and life altering punishment at the disposal of the courts than a year in jail for drug dealing.

The development of the Regional Tribal Restorative Justice Center for inmates remains in the planning stage as barriers to finding an appropriate site and to building a facility meeting code requirements continue to challenge the realization of this multi-tribal rehabilitation detention facility. This facility is a collaborative effort that requires the input and commitment of seven other tribes in the region. The Lummi Police Department has met with the key tribal and non-tribal entities, and presentations have been given in which the reception has been positive for the development of the Consortium. As of this date, no MOUs have been signed. Although there is support for this type of center at Lummi, it is unclear how long it will be before this objective can be realized. The Lummi Nation is currently considering applying for a planning grant to help support the development of a plan that will work for all eight tribes. 


\section{IV.5) Treatment availability and options}

The availability of treatment services was largely seen as favorable by respondents to the survey and by focus group members directly involved in receiving the services. There were comments regarding desired improvements, but these were centered on having treatment be longer and accessibility to treatment increased. Focus group members wanted to see more in the prevention services available to young people of the community. The CMAD Initiative has put considerable effort into increasing treatment options and prevention services. C.A.R.E., which provides treatment services for the Lummi community, now offers acudetox to clients, has an inpatient facility for youth (Se>Eye>Chen) that opened in 2005, and offers a maintenance program (Suboxone Clinic) that opened in 2007 for adult clients for which behavioral therapy is not enough. The CMAD Initiative encouraged and brought in consultant experts in the area, who supported the collaborative work of CMAD members (chemical dependency faculty from the Northwest Indian College and the resident physician in addictive medicine) in the planning and designing of the treatment program. Work in all these new services were developed under the supervision of the medical doctor. Their implementation has helped the Lummi Nation move towards realizing a holistic treatment modality.

The inpatient youth facility, $S e>E y e>C h e n$, has shown positive results in the number of youth successfully completing treatment over the first year of its implementation. It also has shown a decrease in the number of cases that were aborted. There still remains the problem of Lummi youth leaving the program prematurely. This behavior has been attributed to some extent to the ease of leaving the facility. Because it is not a lock-down facility, other methods have been employed to encourage completion, e.g., safety, constancy, and the compassion of the staff. More data will be necessary to determine if these methods are affecting the retention of Lummi youth.

Establishing the Suboxone Clinic moved from the development stage to completion in less than two years. There was considerable input from CMAD in choosing the appropriate maintenance program. The program, which is only months old, is already popular with the clients it is serving, with the numbers being served increasing steadily. The clinic plans to expand its services to include weaning clients off of suboxone, employment training, education, housing options, and ultimately stabilization of the client. These approaches need to be coordinated with the different departments and are currently in the planning stage. 
Of all aspects of treatment implementation, implementation of aftercare services seems to be the greatest hurdle to overcome. This was evident in the comments made in the focus groups, responses to the community survey, meeting minutes, and informal interviews with staff. For example, on-site transitional recovery housing has not received approval of its policy and procedures from the housing commission. Nevertheless, the off-site transitional recovery program continues to increase the number of individuals in recovery it is serving. In 2006, half of the 18 clients successfully completed the assistance program, allowing them to have subsidized housing for six months in a designated off-site facility. Data from 2007 (up to August) shows that of the 19 individuals enrolled in the program, six have already completed the program and six are still in it. This program had a slow start in 2005 but appears to be increasing the number of clients served with each passing year.

Employment efforts, other than instituting a drug-free policy for all tribal departments, have not received as much attention as the other areas of the CMAD Initiative's agenda. This may alter with the recent change in which the Employment and Training Center was placed under Family and Social Services.

\section{IV.6) Youth Prevention Services}

Youth prevention services were considered an important issue for community members, particularly for participants in the adult client focus group during which members emphasized the need for these services to stop the cycle of drug use in the community. It was the overriding topic of the youth focus group, whose members detailed the importance of these services in providing recipients with emotional and mental support, practical services, and a sense of purpose and family through participation in their sponsored programs. Through the efforts of the CMAD Initiative, strides were made in enhancing and consolidating prevention efforts. In 2001 the Y.E.S.S. Program (formerly referred to as Youth Recreation) was reorganized and renamed. It drew together multiple youth-related programs under one umbrella, thereby centralizing services that included counseling and youth outreach services - the latter of which reached out to community members in multiple social service, treatment, enforcement, and educational programs. As with many programs that are part of the CMAD team, data is not yet in a form that can adequately assess this program’s progress. Nevertheless, the breadth of activities and programs offered through the Y.E.S.S. Program appear to address several educational, social, 
emotional, and mental needs, all of which support healthy, non-drug involvement of youth and their families.

The Safe House (House of Healing Spirit) for youth (grades 7-12), formerly under the auspices of the Y.E.S.S. Program, has been in existence since 2004 and is another program that connects its inception to the work of the CMAD Initiative. Both from personal testimony of youth who have taken advantage of this program and discussions with its director, the safe house provides a structured environment for youth to focus on redirecting their lives, particularly in the area of school, and giving them the coping skills to enable this to happen. While it is unclear from the data reported whether or not the Safe House is having an impact on specific segments of the youth population it serves, e.g., those youth not on probation versus youth on probation, the qualitative data supports the notion that the shelter and the services it provides are helping the young people better cope with very difficult and stressful life situations.

\section{IV.7) Education}

Currently the CMAD Initiative is working on implementing the Youth Leadership Academy. This ambitious project has been developing over the last two to three years, and as of 2007 has been restructured to begin as a smaller pilot project that will initially serve 20 students, one-sixth of the originally proposed enrollment. The project, which entails developing a dormitory for $7^{\text {th }}-12^{\text {th }}$ graders adjacent to the Lummi Nation Schools campus, would also provide multiple educational, social, mental health, and cultural services to young people from across the academic spectrum who are at risk for high absenteeism or who would educationally benefit from this type of environment. This type of program would necessitate considerable coordination and continued commitment of multiple departments to implement it successfully. The project would include ample funding to provide at the very least housing for no less than five days per week and staff to provide services, supervise the students, and oversee the running of the facility. Work on the academy is steadily progressing. The project has been approved by the Education Commission and is currently under construction (J. Folsom, personal communication, 10 October 2007).

As the above discussion shows, considerable work was done in the implementation of treatment programs, yet for some of the other programs outlined in the CMAD proposal, considerably more collaboration with multiple departments and/or agencies is required. For these more complex efforts, which require a high level of coordination, commitment, and direction by 
all parties involved, barriers (e.g., MOUs, locations, implementation plan) have prevented their completion.

Overall, the participatory evaluation model provided a means for community stakeholders to become directly involved in the evaluation process. CMAD members and the CMAD coordinator partnered with the evaluation team in all the elements of the conception, development, implementation, and analysis of the evaluation. They were extremely supportive and helpful in overcoming many logistical hurdles throughout the two year process. The model was effective in increasing the knowledge of stakeholders about the benefits of evaluation and the need for the collection of specific information within defined formats to be able to assess progress. There was clear interest among stakeholders in conducting internal evaluations of their programs. The ability to conduct such evaluations is limited only by technical expertise and software needs of the different departments. .

\section{IV.8) Replication and dissemination to other tribal nations}

CMAD members, particularly the project director and the program coordinator, have presented the CMAD model through many venues, including workshops, intertribal conferences, and events. These presentations have provided inspiration and given hope to many tribes who see the holistic approach the Lummi are using as innovative, appropriate, and audacious. The presentations have been frank in addressing both the difficulties and successes of the approach. Participants in these conferences and events, based on the feedback the CMAD Initiative has shared with the evaluation team and through one-on-one informal discussion with other Coast Salish people, applaud the work done by the Lummi and respect the challenges they have had to overcome. For many attendees, the situation the Lummi people are facing is similar to their own. The Shxwolewen model is seen as incorporating most, if not all, the services available on other reservations. While it is easy to saythat sharing the model is premature because all components of the model are not yet fully implemented, the evaluation team observed that the Lummi did not solicit this sharing process but were asked by others to speak about the CMAD Initiative. The model is not being presented yet for replication but rather for collaboration and inspiration. As such, these presentations are serving an important purpose for the American Indian community at large. Nevertheless, it is also important to note that the Lummi community would benefit from more direct participation and feedback on progress. Therefore, a renewed emphasis should 
probably be placed on communicating more with the community to both inform and increase involvement and support of the people.

\section{IV.9) Limitations of findings}

The above study was a formative evaluation. As such, it never aimed to provide a total picture of the impact of the CMAD Initiative. Furthermore, our findings were limited by the data we expected to find but were not available in a way that we could use. For example, because data were non-specific regarding criminal activity for particular drugs, nothing could be said about the effectiveness of the enhanced efforts to reduce drug related crimes in the community. Were these efforts targeting the individuals who needed to be targeted? How effective were collaborations with other tribal and non-tribal law enforcement departments in apprehending outside drug connections? With the exception of one or two reports, the secondary data received from programs were limited by time and the constraints of the systems and personnel in place. Data that was collected for multiple purposes, e.g., for reimbursement or for an ad hoc report, contained specific information that had gaps or was confusing. In some cases programs were too new to have any viable data. In other cases programs were still in the process of entering raw data into electronic databases. Finally, several programs were short staffed or missing key personnel, creating both a backlog and an inability to access data. Similarly, the evaluation could not obtain data from non-tribal programs. These factors limited our ability to document change or correlation between factors, e.g., arrests, recidivism, and treatment.

\section{IV.10) Dissemination}

Dissemination will take the form of publications in refeered journals. Specifically, papers will be written on lessons learned, to be developed in conjunction with the evaluators of the SissetonWahpeton Oyate Tribe demonstration project. In this paper we will address the issues and modifications that were necessary in conducting the CBPE and what they mean for evaluation in Indian Country. This paper will be submitted to American Indian Quarterly. A second paper, to be submitted to the American Journal of Evaluation, will address the process necessary to adapt and work through the different cultural perspectives that are interacting in CBPE in Indian Country. The third paper, to be submitted to Criminology and Public Policy, will examine gender dichotomy in respondents'views on crime, criminal behavior, and related public policy, 
what generates those perceptions, and how these views are implicated in perceived changes in the community after four years of implementation of the CMAD Initiative.

\section{V) CONCLUSION AND IMPLICATIONS OF FINDINGS}

Overall, the CMAD Initiative has put into place or is working to implement many of the components it indicated it would address in its Indian Alcohol and Substance Abuse Demonstration proposal. It has made a significant impact on the consciousness of community members about drug use and alcohol and drug related crimes and has alerted many tribal communities, through presentations, to a new broad, holistic method for tackling those problems. Community members do not see the same impact of the CMAD Intiative on the drug and alcohol situation as those who work directly in the area. This is not an unexpected result as most community members do not see the collaborations or the work that goes into arrests, prosecutions, or program development. What community members see is the continual presence of drugs in and around their homes. This apparently has not changed enough to produce a "noticeable difference" in these areas. With that said, alcohol abuse and related crimes are seen as better handled by the police and prosecuted more effectively by the courts than drug use and drug related crimes. Similarly, alcohol treatment numbers have shown a decline over the years as have car fatalities. Of all the problems facing the community, drunk and disorderly conduct was cited most frequently by respondents as declining compared to three years ago. Other declines have been seen in the number of assaults committed over the years of the project. There have been increases in problem areas that show that considerably more work needs to be done, e.g., in illegal prescription drug use and in drug trafficking. There has also been a sharp increase in the number of burglaries committed in the community, an indicator of the prevalence of drug use.

Because secondary data could only provide a small picture of the effect of the increased efforts in law enforcement, treatment, and prevention, the evaluation team suggests that further attention be placed on internal evaluation of programs, including designing appropriate data collection methods for monitoring programs; training and/or hiring personnel to oversee and handle data within departments, including cross training within departments; and designing a method for data sharing of key data sets across departments. The Lummi Nation has both an Information Technology Department and an Office of Tribal Vital Statistics with trained personnel who could, with the input of a task force, be instrumental in designing and 
implementing a data sharing program and the development of databases for program evaluations. These individuals could also research appropriate software and review it for the departments. It is also important that the community be informed through presentations to groups, at community events, and through work with young people, e.g., in schools, about the changes in the community, the work that is being done, and the services available. While this has been doneand CMAD should be commended for its efforts-more work in this area is suggested as a means to draw in and encourage further involvement from the community.

Additionally, the CMAD Initiative has not yet been able to develop formal external MOUs with other Coast Salish tribes and law enforcement agencies. The concern about the flow of drugs and drug traffickers into the community is still a major issue for the Lummi people. Obtaining MOUs would be an important step towards addressing this problem.

Finally, for much of the life of the initiative, there has been a strong identification of the program with key individuals, its champions. For some this strong identification and the loss of its project director, and more specifically the power of the office he held, has been seen as impacting the effectiveness of the Initiative in being able to engage stakeholders. For others, the strong identification with the Office of the Chairperson brought attention and a sense of mission to activities. For example, exclusion was addressed openly and treatment options were increased. Community members could see or anticipate direct application and consequences from drug and alcohol use and from related crimes in the community because of the importance the issues were given by the chairperson as he sought media attention to expose the problem and proposed ways to address it. While the regular presence and hands-on approach of the former Chairman at CMAD meetings enforced a sense of urgency, importance, and commitment at a critical point in time-as did his expert use of the media-it is not necessarily wrong or inappropriate for another leader to see his or her role differently and still be effective. Many new programs and services have been developed over the tenures of both chairpersons. Collaboration efforts continue and the Youth Leadership Academy, which has taken several years to formulate, is being constructed. This could only have happened with considerable coordination and collaboration among departments and agencies and the support of the administration. In addition, the current Chairwoman, Ms. Evelyn Jefferson, is encouraging more involvement of the community, e.g., the next Coast Salish Gathering will be focused on the Lummi community with direct invitations 
delivered to the entire community. This approach suggests a concerted movement to draw in and obtain community involvement.

The CMAD Initiative has attempted a very innovative and intense approach to reducing alcohol and drug related crimes in the Lummi Nation, and for that alone it should be commended. From what this evaluation could measure, the CMAD Initiative addressed a singularly important and critical problem in the Lummi community. Both by its methods and the validation it has received from other tribes, it is a culturally appropriate method that draws in key departments and programs to address the problem. It has also benefited from the dedication of key stakeholders. Because so many of the programs fostered under the initiative are new, it is not clear whether they are successful. Only additional, careful internal evaluation and monitoring can assess their effectiveness.

Whether this methodology can be replicated in other tribes depends as much on the individual tribes as the feasibility of the plan. For example, tribes will have to assess if they have the critical mechanisms and personnel in place, and if not, how they will make modifications and remain true to this holistic perspective. They will also have to assess the level of readiness of the community to address the problem, determine who and how leadership for such an effort will be identified, and determine whether or not the resources are available to help make it happen and to assess what is accomplished.

Finally, whether CMAD stays in its present form or takes on a new set of related issues and/or a new configuration, the work it has begun certainly merits continuation. 


\section{REFERENCES}

American Indian Health Committee for Washington State (2003). Working together to build a Healthy future: 2003 American Indian Health Care Delivery Plan. Washington State DOH.

Barrie, K. Personal communication, 11/8/2005.

BJA Funding Focus (2003). Successful treatment and drug courts. BJA Annual Report: FY 2003. Office of Justice Programs: USDJ.

BJA. (2007). BJA Fact Sheet: Indian Alcohol and Substance Abuse Program Overview. Washington D.C.: Bureau of Justice Assistance

Campbell, D.T. and Fiske, D.W. (1959). Convergent and discriminant validation by the multitrait-multimethod matrix. Psychological Bulletin 56: 81-105.

Denny, C.H., Holtzman, D., Cobb, N. (2003). Surveillance for Health Behaviors of American Indians and Alaska Natives from the Behavioral Risk Factor Surveillance System 1997-2000. MMWR 52(SS07): $1-13$.

Devlin, Heather, Roberts, Martha, Okaya, Amy, and Iang, Yen Moua (2006). Our Lives Were Healthier Before: Focus Groups with African American, American Indian, Hispanic/Latino People with Diabetes. Health Promotion Practice 7 (1): 47-55.

Duffy, M.E. (1987). Methodological triangulation: A vehicle for merging quantitative and qualitative research methods. Journal of Nursing Scholarship 19 (3): 130-133.

Dunworth T and Mills, G. (1999 June). National Evaluation of Weed and Seed. Research in Brief. National Institute of Justice: U.S. Dept. of Justice.

Edwards R. W. P, Jumper-Thurman, P., Plested, B. A., Oetting, E. R., and Swanson L. (2000). Community readiness: Research to practice. Journal of Community Psychology, 28(3):291307.

Guba, E. (1981). Criteria for assessing the trustworthiness of naturalistic inquiries. Educational Communications and Technology Journal 29 (2): 75-91.

Guillory, B.R., Willie, E. and Duran, E. (1988). Analysis of a Community Organizing Case Study: Alkali Lake. J. Rural Community Psychology. 9(1):27-36.

(IHS) Indian Health Service (2004). Trends in Indian Health 2000-2001. Washington D.C.: Government Printing Office: USDHHS. Indian Health Service. 
James, G. (2005). Regional tribal restorative justice center: A concept overview. Unpublished paper, March 1, 2005.

James, G. (2007). Regional Tribal Restorative Justice Center: A concept overview. Lummi Nation: Internal report (slide presentation).

Jumper-Thurman, J., Plested, B., Edwards, R.W., Foley, R., and Burnside, M. (2004).

Community readiness: The journey to community healing. In: Nebelkopf, E., and Philipps, M. (Eds.) Healing and Mental Health for Native Americans; Speaking Red. Walnut Creek, CA: Alta Mira Press.

Kershaw, S. and Davey, M. (2004, January 18). Plagued by drugs, tribes revive ancient penalty. New York Times. http://www.nytimes.com/2004/01/18/national/18BANI.

Lei S. (2005 May). Program is “uniquely Lummi.” NWIC Monthly. 2(5): 7.

Lummi Nation (2003). Community Mobilization Against Drugs (CMAD) proposal submitted to Bureau of Justice Assistance (BJA). Unpublished manuscript.

Lummi Nation (2005). Promoting prosperity: Lummi Nation ventures program. Report presented to the Northwest Area Foundation on December 22, 2005. Unpublished manuscript.

Lummi Police Report (2006). Lummi Nation Police Report-Statistics Fact Sheet. Unpublished manuscript.

Lummi Nation Youth Enrichment \& Social Services 2004-2006. (2006 May). Squol Quol.

Lummi Housing Department 2006. (2006 June). Monthly Report. Squol Quol.

Lummi Nation Police Department. (2006 April). Lummi Nation Police Department Monthly Report. Squol Quol.

Lummi Nation Housing Department. (2006 April 11). Transitional Housing Meeting Minutes. Unpublished manuscript.

Lummi Office of Tribal Vital Statistics. (2006 April 5). Crimes Monitored by CMAD compiled from data submitted by LNPD (2003-2005).

Lummi Office of Tribal Vital Statistics. (2006). Lummi C.A.R.E. Brief Summary of Outpatient Treatment 2002-2005 Admissions. Unpublished manuscript.

Lummi Nation Police Department. (2007). Crimes Monitored by CMAD compiled from data submitted by LNPD, 2006-2007. Unpublished manuscript.

Lummi Health Clinic. (2007 April 27). Lummi Health Clinic Report of ICD-9 Codes for Alcohol and Other Drug Related Diagnoses. Unpublished manuscript. 
This document is a research report submitted to the U.S. Department of Justice. This report has not been published by the Department. Opinions or points of view expressed are those of the author(s) and do not necessarily reflect the official position or policies of the U.S. Department of Justice.

Lummi Nation. (2003). Lummi Nation s Community Mobilization Against Drugs US Department of Justice/ Office of Justice Programs-Bureau of Justice Assistance Indian Alcohol and Substance Abuse Demonstration Program Grant Proposal. Unpublished manuscript.

Lummi Nation. (2005a) Safe House Home Of Healing Spirits Holistic Lummi Treatment Project Final Progress Report, 1 H79 TI13605-01 TI-H79/TCE 2005. Unpublished manuscript.

Lummi Nation. (2005b) Promoting Prosperity: Lummi Nation Ventures Program. Report presented to Northwest Area Foundation. Unpublished manuscript.

Magrath, M. (2006). Se $>$ Eye $>$ Chen Report to Lummi Department of Tribal Vital Statistics, October 26, 2006. Unpublished manuscript.

Mapes, L. V. ( 2003, August 10). A tribe desperate to survive considers banishings its own. Seattle Times.

Mapes, L. (2005, December 2). Lummis enlist fire, an old ally, as they battle scourge of drugs. Seattle Times.

May, P.A. (1995). The Epidemiology of Alcohol Abuse among American Indians: The Mythical and Real Properties. The IHS Primary Provider. 20(3): 41 - 50.

McKinney, S. and Melton, A. (2005). Evaluability assessment: Lummi Nation's Community Mobilization Against Drugs Initiative. Office of Justice Programs: USDJ.

National Center for Health Statistics. (1999). Alcohol Consumption by State, Race/ethnicity, Sex, and Age, 1997-1999. U. S. National Vital Statistics System: National Vital Statistics Reports.

Noe, T., Fleming, C., and Manson, S. (2004). Reducing Substance Abuse in American Indian and Alaska Native communities: The Healthy Nations Initiative. In: Nebelkopf, E., and Philipps, M. (eds.) Healing and Mental Health for Native Americans; Speaking Red. Walnut Creek, CA: Alta Mira Press.

Northern Economics, Inc. (2005). Lummi Nation workforce skills inventory and analysis: Final report. Prepared for the Lummi Development Authority and Lummi Indian Business Council. Anchorage, AL and Bellingham, WA: Northern Economics, Inc.

Oetting, E.R., and Beauvais, F. (1989). Epidemiology and Correlates of Alcohol Use among Indian Adolescents Living on Reservations. In: Alcohol use among U.S. Ethnic Minorities, NIAAA Research Monograph No. 18. Rockville, MD: U.S. Public Health, pp. 239.

Oetting, E.R., Donnermeyer, J. R., Plested, B. A., Edwards, R. W., Kelly, K. and Beauvais, F. (1995). Assessing community readiness for prevention. International Journal of Addictions 30(6): 659-683. 
Perry, S.W. (2004). American Indians and Crime: ABJS Statistical Profile, 1992 - 2002._ Office of Justice Programs: U.S. Dept. of Justice. (NCJ 203097).

Plested, B.A., Jumper-Thurman, P., Edwards, R.W., and Oetting, E. R. (1998). Community Readiness: A Tool for Effective Community-Based Research. The Prevention Researcher_5(2): 57.

Poupart, John and Becker, Tracy (1997). Communications and relationships between reservation American Indians and Non-Indians from neighboring communities. American Indian Policy Center.

Roehl, J.A.R., Huitt, R., Wycoff, M. A., Pate, A., Rebovich, D., and Coyle, K. (1996 October). National Process Evaluation of Operation Weed and Seed. Research in Brief. National Institute of Justice: U.S. Dept. of Justice.

Ross, L. (2004). Native Women, Mean-Spirited Drugs, and Punishing Policies, Social Justice. Vol. 31 (No. 4).

Safe House Final Report. (2005). Excel spreadsheet. Unpublished manuscript.

Seelau, R. (2007). Fighting the good fight: An analysis of how the law interacts with border reservations and the war on drugs. Tucson, Arizona: University of Arizona, Native American Research and Training Center, Internal Report.

Severson, Margaret and Duclos, Christine Wilson (2005). American Indian suicides in jail: Can risk screening be culturally sensitive? Research for Practice.

http://www.ncjrs.gov/pdfiles1/nij/207326.pdf .

Shukovsky P. (2002, November 15). 10 ${ }^{\text {th }}$ drug arrest of year at Lummi Nation. Seattle Post Intelligencer. http://seattlepi.nwsource.com/local/95736_lummi15.shtml

Shukovsky, P. (2003, May 19) Drug dealers face banishment: Lummi Tribe gets tough with new rules to fight narcotics. Seattle Post-Intelligencer.

Spicer, P., Beals, J., Mitchell, C.M., Novins, D.K., Croy, C.D., Manson, S.M., The AI-SUPERPFP Team. (2003). The Prevalence of Alcohol Dependence in Two American Indian Reservation Populations. Alcohol Clin. Exp Res._27(11): 1785-1797.

Substance Abuse and Mental Health Services Administration. (2000). Summary Findings from the National Household Survey on Drug Abuse, 1999-2000. Rockville, M.D.: Office of Applied Studies, SAMHSA: USDHHS.

Telephone Interview with Hon. Randy Doucet, Chief Judge of Lummi Nation Tribal Court (April 30, 2007). 
Twelve Lummi Nation Code of Laws §§ 1-5 (Native American Rights Fund, 2007) (available at: http://narf.org/nill/Codes/lummi/12exclusionsupp.pdf).

Valz, E. and Bellaw II, TJ. (2006). Lummi and Whatcom County school demographics and adequate yearly progress performance measures. Lummi Department of Vital Statistics, Community Research Office, Bellingham, WA.

Vital Statistics and Community Research Office. (2006). Lummi Nation.

Walker, R. (2003, August 17). Lummi gaming raises money to fight substance abuse. Indian Country Today.

Wallace, L.J.D., Sleet, D. A., and James, S. P. (1997). Injuries and the Ten Leading Causes of Death for Native Americans in the U.S.: Opportunities for prevention. The IHS Primary Provider_22(9): 140- 145.

Washington, D. (2005). Community Mobilization Against Drugs (CMAD) initiative. Lummi Nation General Council Meeting, August 8, 2007.

Washington State Agencies. (2005). Crime in Washington: 2005 Annual Report. Washington State Agencies Uniform Crime Report: Criminal Justice Information, Support Staff. Washington Association of Sheriffs and Police Chiefs. 


\section{APPENDICES}

\section{Appendix A: Logic Model}

Appendix B: Fighting the Good Fight: An Analysis of How the Law Interacts with Border Reservations and the War on Drugs (Historical/Legal Report) 
This document is a research report submitted to the U.S. Department of Justice. This report has not been published by the Department. Opinions or points of view expressed are those of the author(s) and do not necessarily reflect the official position or policies of the U.S. Department of Justice.

APPENDIX A: LOGIC MODEL 
This document is a research report submitted to the U.S. Department of Justice. This report has not been published by the Department. Opinions or points of view expressed are those of the author(s) and do not necessarily reflect the official position or policies of the U.S. Department of Justice.

LOGIC MODEL FOR EVALUATION OF LUMMI NATION'S COMMUNITY MOBILIZATION AGAINST DRUGS (CMAD) INITIATIVE

\begin{tabular}{|c|c|c|c|c|c|}
\hline \multirow[t]{2}{*}{ Inputs } & \multirow[t]{2}{*}{ ACTIVITIES } & \multirow[t]{2}{*}{ OUTPUTS } & \multicolumn{3}{|c|}{ OBJECTIVES } \\
\hline & & & Process & Impact & Outcome \\
\hline 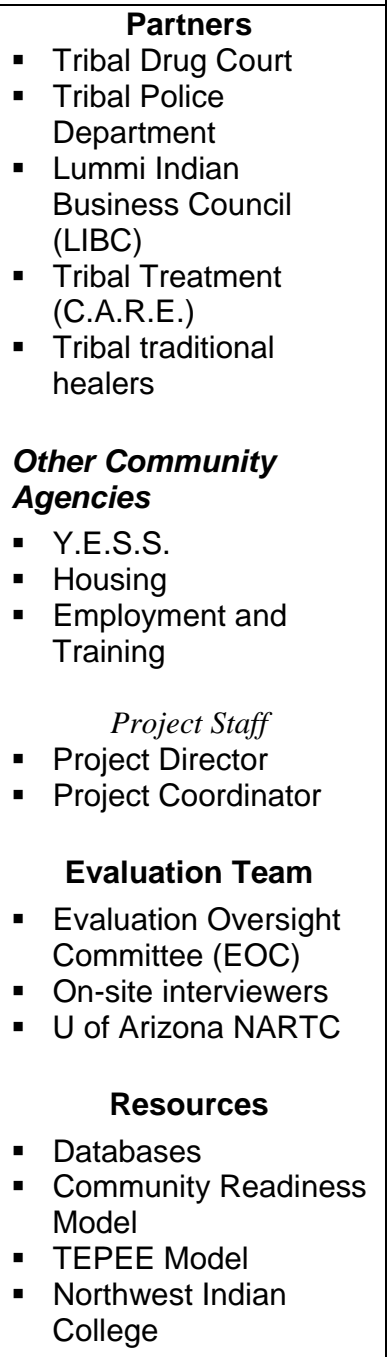 & 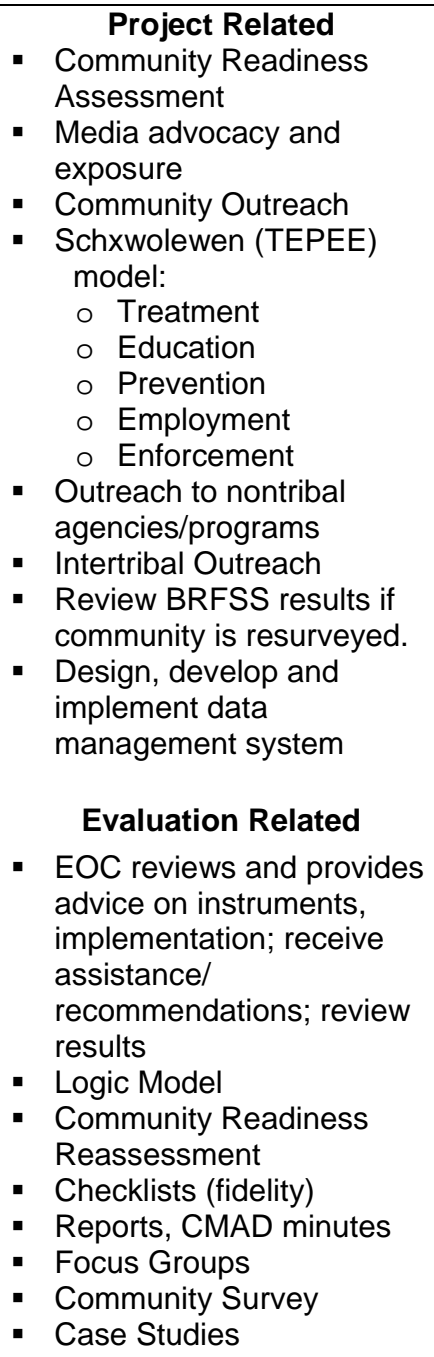 & 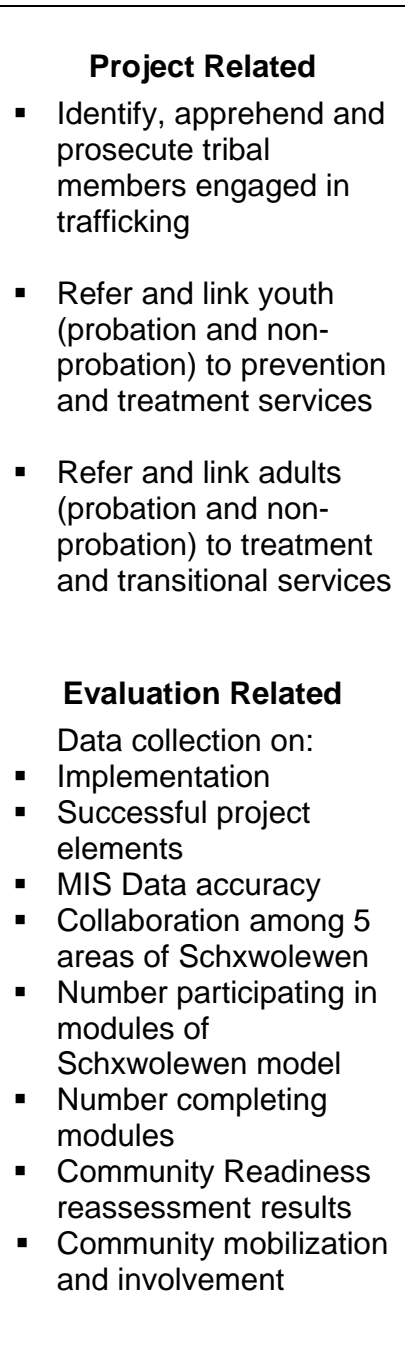 & $\begin{array}{l}\text { - Increase awareness of drug } \\
\text { problem in the community } \\
\text { - } \begin{array}{l}\text { Increase awareness of drug } \\
\text { problem among other } \\
\text { neighboring tribes }\end{array} \\
\text { - Encourage replication of } \\
\text { strategies in other tribes } \\
\text { - Greater coordination of } \\
\text { agencies working on drug- } \\
\text { related issues in community } \\
\text { - Better use of resources } \\
\text { - Policy development to } \\
\text { address substance abuse } \\
\text { related crimes }\end{array}$ & $\begin{array}{l}\text { - Decrease re-offense rates } \\
\text { - Decrease DUls } \\
\text { - Decrease acceptance of } \\
\text { drugs in community } \\
\text { - Decrease drug-related } \\
\text { disorder and addiction } \\
\text { rates } \\
\text { - Decrease youth using } \\
\text { drugs or drinking } \\
\text { - Increase rehabilitation of } \\
\text { traffickers to gainful } \\
\text { employment } \\
\text { - Increase rate of } \\
\text { employment } \\
\text { - Enhance healing in } \\
\text { community } \\
\text { - Increase number in } \\
\text { recovery in transitional } \\
\text { housing } \\
\text { - Increase number in } \\
\text { recovery being trained or } \\
\text { employed } \\
\text { - Increase use of resources } \\
\text { and staff }\end{array}$ & $\begin{array}{l}\text { - Sustainability of } \\
\text { CMAD Initiative } \\
\text { - Data-driven } \\
\text { programs and } \\
\text { policies } \\
\text { - Decrease illicit drug } \\
\text { trafficking } \\
\text { - Decrease drug- } \\
\text { related criminal } \\
\text { arrests } \\
\text { - Decrease arrests } \\
\text { and prosecutions for } \\
\text { drug-related } \\
\text { offenses. } \\
\text { - Increased } \\
\text { community } \\
\text { participation in the } \\
\text { Schxwolewen } \\
\text { strategy. } \\
\text { - Dissemination of } \\
\text { CMAD strategy } \\
\text { intertribally. }\end{array}$ \\
\hline
\end{tabular}




\section{APPENDIX 2: Historical /Legal Report \\ Fighting the Good Fight:}

An Analysis of How the Law Interacts with Border Reservations and the War on Drugs 
Fighting the Good Fight:

An Analysis of How the Law Interacts with Border Reservations and the War on Drugs

Prepared for the Native American Research and Training Center

by

Ryan Seelau

Spring 2007 


\section{The Introduction}

"You can no more win a war than you can win an earthquake." ${ }^{\mathrm{i}}$ Although these words were not spoken about the United States' "War on Drugs," they seem applicable. After generations of drug abuse and more than 25 years of fighting the War on Drugs, America's drug problems simply will not go away. New laws are passed, but drugs remain. New officers are put on the streets, but drugs remain. New crime-fighting technologies are developed, but drugs remain.

Indian tribes struggle with illegal drugs as much as, or in many cases more so than, the average community. And although the media loves to sensationalize the use of drugs on reservations, actual statistics on the topic are hard to come by. ${ }^{\text {ii }}$ In recent months, the media has focused yet again on Native Americans and the War on Drugs. Specifically, recent articles in both the New York Times and the Seattle Times discuss border tribes and how the reservations these tribes live on are now a preferred target for drug smuggling. ${ }^{\text {iii }}$ Although the media is quick to condemn these tribes for their inability to control drugs on their own land, they overlook the fact that U.S. legal history and the current state of the law puts tribes at a disadvantage with respect to enforcing drug laws.

In this paper, I examine how the law affects drug enforcement on reservations. In particular, I look at the Lummi Nation, a border tribe that is struggling to control drugs on its reservation in the State of Washington. For ease of discussion I have divided this paper into three sections. In the first section I give background information about drug abuse in the United States generally and on Indian reservations specifically. In the first section I also introduce the Lummi Nation and lay out the current tactics they use to fight drug abuse. In section two I walk through the relevant legal history and attempt to demonstrate that the law's past legacies coupled with its current state hinders tribes from being able to control drugs on their own lands.

Specifically, I explain how the law has destroyed many social controls within Native communities, which in turn has contributed to the drug problem on reservations. In essence, I explain how the law has created a jurisdictional quagmire that makes the work of police and courts unnecessarily complicated. In the final section of this paper I mention some steps that tribes might consider taking in order to continue fighting the War on Drugs. I then end the paper with a few concluding remarks.

\section{Part One: The War on Drugs and the Lummi Nation}

\section{A. America's War on Drugs}

The United States' struggle with illegal drugs is by no means new. It has existed for decades, perhaps even centuries. ${ }^{\text {iv }}$ It was, however, pushed to the forefront of America's consciousness in 1982 when President Ronald Reagan declared the beginning of the War on Drugs. $^{\mathrm{v}}$ Twenty-five years later, the War wages on. ${ }^{\mathrm{vi}}$

The magnitude of America's drug problem cannot be overstated. For instance, in the year 2000 alone, Americans consumed nearly 260 metric tons of cocaine and over 13 metric tons of heroin. ${ }^{\text {vii }}$ More recently, in 2004, the National Drug Threat Assessment reported that more than half of all adults age eighteen to twenty-five had tried marijuana, while more than 15 percent had tried both ecstasy and cocaine. ${ }^{\text {viii }}$ These statistics demonstrate just how pervasive drug use is in America, but they only tell part of the story. In addition to the obvious harms that drugs cause an individual, there are countless social harms associated with drug abuse. As Justice Weinstein, a member of the West Virginia Supreme Court of Appeals, puts it: 
As illegal drug entrepreneurs protect their lucrative businesses, guns abound and people are killed. Communities live in fear. Police and community leaders and politicians are caught in a vicious cycle, trying to protect the community from the violence that is caused by the failed drug policy itself. In large part because of the current "War on Drugs," the police and the criminal justice system are seen in many poor and minority communities-by many fully law-abiding and hardworking people-as more a part of the problem, than as a part of the solution. ${ }^{\text {ix }}$

In order to combat this enormous problem, the United States' annual budget with respect to stopping drug use and drug trafficking has increased to over $\$ 12$ billion with further increases anticipated. ${ }^{\mathrm{x}}$ This money is not used solely to fight drugs within U.S. borders; much of it is actually used to stop drug trafficking into America. ${ }^{x i}$ The U.S. justifies its foreign policy decisions by admitting that the majority of drug producers live in jurisdictions outside the country and therefore the only way to win the War on Drugs is to take the fight to the source of the problem. ${ }^{\text {xii }}$ Whether this, or any of America's policy decisions relating to drugs will be successful remains to be seen.

\section{B. Native America's War on Drugs}

The drug problem in America is not an isolated one. It affects every community nationwide, including Native American communities. As one author puts it:

Among the most difficult and challenging problems in Indian Country is the problem of drug and alcohol abuse. Virtually every Indian tribe-small or large, wealthy or destitute, landed or landless - must deal with this problem. ${ }^{\text {xii }}$

Although there has been much debate recently about the accuracy of Indian criminal statistics, ${ }^{\text {xiv }}$ the numbers seem to suggest that both alcohol and drug abuse are, generally speaking, an even bigger problem for Native American communities than for other Americans. ${ }^{\mathrm{xv}}$ Research shows that, on average, Native youths begin using drugs at younger ages than other racial groups. ${ }^{\text {xvi }}$ Another study conducted at a post-high school institution noted that more than 70 percent of students had used marijuana; 31 percent of students had used inhalants; and 13 percent had used cocaine. ${ }^{\text {xvii }}$ More recent investigations indicate that drug abuse treatment among Native Americans over the age of twelve is estimated at $7.8 \%$ of the population, double the rate of the next closest racial group. $^{\text {xviii }}$ As bad as the problem is on reservations, it has been suggested that the perception painted by the media is actually worse than the reality, ${ }^{\text {xix }}$ but either way, there can be no denying that action must be taken to fight this War on the reservations.

The Native American drug problem is magnified on certain border reservations. Although this issue has been largely overlooked, several newspapers have recently begun writing about it. $^{\mathrm{xx}}$ There are more than twenty-five tribes that govern land which either directly borders another country or that borders a body of water accessible by another country. ${ }^{\text {xxi }}$ These border reservations have an even harder time with drugs than non-border reservations because the vast majority of illegal drugs are brought into this country via a border. Given that most Indian reservations borders are less heavily guarded than other parts of the border, Indian reservations are attractive to smugglers. ${ }^{\text {xii }}$ Some of the advantages to smuggling drugs into the U.S. via Indian reservations include: tribes do not have enough manpower to effectively monitor reservation borders; jurisdictional confusion caused by Indian law and tribal sovereign immunity makes arresting and prosecuting smugglers difficult; tribal distrust of outside law enforcement 
and outside court systems combined with loyalty or corruption within the reservation hinders investigations and prosecutions. ${ }^{\text {xxii }}$

To illustrate the struggle border tribes are having with drug trafficking, we need look no further than the Mohawk reservation in New York. The Mohawk reservation straddles the U.S.Canada border with about 6,000 members on the American side. ${ }^{\text {xxiv }}$ Investigators estimate that at least ten major Indian criminal organizations and multiple drug rings successfully move more than $\$ 1$ billion of drugs across the Canadian border, through the Mohawk Reservation, and into the northeastern United States. ${ }^{\mathrm{xxv}}$ Law enforcement officers are only able to confiscate about 2\% of the contraband that crosses through the Mohawk Reservation annually due to the difficulties associated with law enforcement on Indian reservations. ${ }^{\text {xxvi }}$

The breadth of the drug problem on Indian reservations is substantial, but Native American communities are coming up with unique ways to fight the War on Drugs. For instance, tribes have generally been open to more innovative and unique manners of fighting drug use on the reservation. ${ }^{\text {xxvii }}$ Some examples include specialized drug courts, drug treatment centers, traditional healing methods, and other non-punitive measures to fight drugs on the reservation. ${ }^{\text {xxviii }}$ Some of these methods have been extremely successful, and yet, just like with the rest of America, whether these methods alone can win the War on Drugs remains to be seen.

\section{The Lummi Nation's War on Drugs}

One nation that is actively fighting against drugs on its reservation is the Lummi Nation. The Lummi Nation is a federally recognized tribe located in northern Washington about one hundred miles north of Seattle and fifty miles south of Vancouver. ${ }^{x i x}$ Traditionally, the Lummi Nation occupied the whole of the northern San Juan Islands and the mainland stretching from Bellingham Bay to Point Roberts. ${ }^{\mathrm{xxx}}$ The current reservation boundaries were originally established in The Point Elliot Treaty of 1855, but were then altered in 1873 . ${ }^{\text {xxxi }}$ Today, the Lummi Nation consists of more than 12,500 upland acres and more than 5,000 acres of tidelands. ${ }^{\text {xxxii }}$ The Tribe has more than 5,000 members ${ }^{\text {xxxiii }}$ and the reservation contains a diverse population that includes substantial numbers of non-member Indians, non-Indians and even nonU.S. citizens. ${ }^{\text {xxiv }}$ In fact, more than $40 \%$ of the reservation is currently under non-Indian ownership. ${ }^{\mathrm{xxv}}$

Although all communities struggle with drug abuse, the Lummi Nation has two characteristics that pose unique challenges to their efforts in the War on Drugs. First, the location of the reservation itself creates problems for the Lummi. The Nation is within twelve miles of the Canadian border ${ }^{\mathrm{xxxvi}}$ and is situated directly on the coastline, "with direct point of entry and access to Canada." ${ }^{x x x v i i}$ Since the majority of drugs are smuggled into the United States across its borders, the location of the Lummi Nation means it has to deal with the very real possibility that smuggling is occurring along its borders. ${ }^{\text {xxxviii }}$ In addition to the Tribe's location, the racial diversity found on the reservation poses a second unique obstacle in fighting against drug abuse. As I will examine more thoroughly in the next section, the law disadvantages Indian nations that wish to enforce drug laws on their reservation. In particular, reservations with large percentages of non-member Indians and non-Indians will encounter many jurisdictional challenges to their authority even within the boundaries of their reservation.

Regardless of the causes, the Lummi Nation's drug problem is very real. Research indicates that more than $10 \%$ of tribal members are addicted to prescription drugs and nearly $5 \%$ are addicted to heroin. ${ }^{\text {xxix }}$ The drug of choice on the reservation, however, is OxyContin. ${ }^{\mathrm{xl}}$ It is estimated that more than $40 \%$ of the tribal members need drug treatment of some kind. ${ }^{\text {xli }}$ 
Despite these challenges, the Lummi Nation has been pro-active in fighting drug use within its territory. First and foremost, the Tribe itself has acknowledged the existence of a drug problem on the reservation and has actually made solving this problem a top priority. ${ }^{\text {xlii }}$ As Gary James, the Chief of Police for the Lummi Nation in 2002, put it:

The number one priority at Lummi is healthy spirits - healthy spirits for our entire community, especially our children. What we mean by that is that there seems to be an epidemic of substance abuse on our reservation. We know that. We have hired an extra drug detective. We have set up a drug court. We are going to build a treatment center. We have doubled our youth activities-all of this to set a clear path of opportunity for our children, to make sure that the homes they live in are safe and they are healthy. ${ }^{\text {xliii }}$

In addition to merely acknowledging the problem, the Lummi have started documenting the extent of the problem. For instance, the Tribe has noted a considerable increase in the number of incidents their police officers respond to each year. ${ }^{\text {xliv }}$ More specifically, a significant number of tribal members have been arrested in recent years for their involvement in drug smuggling. ${ }^{\text {xlv }}$

Although admitting the problem and documenting its existence are important first steps, they alone cannot win the War on Drugs, and for that very reason the Lummi Nation has taken other measures to fight against drugs on their reservation. To begin with, the Lummi people have established a well-organized government that allows them to implement policies against drug abuse. Unlike many other tribes, the Lummi Nation is not organized in the manner proscribed by the Indian Reorganization Act (IRA). ${ }^{\text {xlvi }}$ Rather, the Lummi Nation passed its own constitution on April 10, 1970. ${ }^{\text {xlvii }}$ The Lummi Indian Business Council (LIBC), is the governing body that was put in place by the constitution. This council is comprised of eleven members and elected by the adult enrolled members of the Tribe. ${ }^{\text {xlviii }}$ In 1994, the Federal Government recognized the efforts made by the Tribe when Congress passed self-governing legislation for the Lummi Nation. ${ }^{\text {xlix }}$ Now, "[a]n effective government, including law enforcement, is a daily service provided to all Lummi Reservation residents." ${ }^{1}$

Without an effective governing system, the Lummi would be unable to implement any of their anti-drug strategies. Fortunately, the Tribe has taken significant steps to combat drugs on the reservation. They have a Law and Order office consisting of more than 20 sworn police officers. ${ }^{\text {li }}$ Additionally, a program called "Community Mobilization Against Drugs” (CMAD) operates on the reservation to educate and coordinate efforts to fight drugs. ${ }^{\text {lii }}$ The Tribe also has several chemical dependency counselors and has secured funding for a community drug treatment center. ${ }^{\text {liii }}$

The Lummi Nation also boasts an independent Tribal Court System that includes two full-time judges. ${ }^{\text {liv }}$ To more effectively fight the War on Drugs, the Lummi Nation also has a Drug Court:

The Lummi drug court model is based on traditional tribal and family dispute resolution processes. Traditionally, Lummi families meet as a group to address and resolve problems, each family member bringing a unique perspective to the gathering. The Lummi Drug Court operates in the same manner by bringing together the Judge, Prosecutor, Pubic Defender, and Probation officers. It also brings treatment professionals and law enforcement officials to the table so that there is true accountability for the drug court participant. ${ }^{\mathrm{lv}}$ 
The tribal court system is an important player in fighting drug abuse as it is usually the Tribe that has to take care of drug crimes on the reservation. ${ }^{\text {lvi }}$ This is the case in part because the closest federal court is nearly one hundred miles away and the federal prosecutors routinely decline jurisdiction over Indian drug offenders. ${ }^{\text {lvii }}$

The Lummi judicial system has several sentencing options for drug offenses, including jail (up to 365 days), electronic home monitoring, and rehabilitation. ${ }^{\text {lviii }}$ In addition, the Lummi Code has a unique provision that allows tribal judges to banish offenders for certain drug crimes. "lix The Tribe calls this process "exclusion." "lx Exclusion is an act of traditional justice. ${ }^{\text {lxi }}$ An individual who is excluded is exiled from the reservation and loses all tribal benefits (including rights related to hunting, fishing, education, and health care). ${ }^{\text {xii }}$ The Exclusion Committee - a body created by the Tribe's government-is responsible for creating the policies associated with exclusion, but ultimately it is the tribal courts that decide who to exclude based upon the evidence proved in court. ${ }^{\text {lxiii }}$ Generally speaking, after five years, an excluded individual may apply for reinstatement. ${ }^{\text {lxiv }}$ The Lummi Tribe has extensively debated the merits of exclusion, with community leaders arguing both for and against its use. ${ }^{\text {lxv }}$ For now, however, the Tribe is willing to use this traditional method of justice to fight drug abuse.

The Lummi's dedication to the drug problem on their reservation cannot be questioned. And yet, despite all their efforts, the problem continues. Why is this the case? It has been argued that a lack of funding is at least partially responsible for the state of things. ${ }^{\text {lxvi }}$ In conjunction with this argument, a lack of manpower is often cited. ${ }^{\text {lxvii }}$ For instance, in our post9/11 society, many tribes who relied on the Federal Government for all or part of their policing needs have found that much of the federal workforce has since been diverted to anti-terrorism activities. ${ }^{\text {lxviii }}$ Clearly a lack of money and manpower contribute to the state of things, but if these were the only causes of the problem, or if they were the primary sources of the problem, then winning the War on Drugs on the Lummi reservation would be relatively straightforwardall that would be needed is more funding and more well-trained bodies. That is not to say that such things could be secured quickly or easily, but at least once they were secured things would improve. It is my contention that money and manpower are not the most significant hurdles to overcome in fighting the War on Drugs. Rather, the law itself is an underlying - and routinely overlooked-cause for the pervasiveness of drugs on the reservation. Although the state of the law is not solely responsible for the problem, it is one of the major underlying causes and one that can and should be addressed.

\section{Part Two: The Legal History \\ A. Introduction}

In this section I give a brief overview of the legal history of Native Americans in the United States. What will become clear is that the legal history has very real consequences for tribes today. Specifically, the law's legacy of colonization and discrimination has contributed significantly to the current drug abuse problem on reservations by destroying Indian culture and social controls, which are necessary for a society to thrive; and by creating a complex jurisdictional framework that unnecessarily complicates police work on reservations and needlessly limits tribes' powers with respect to crime in their own territory.

\section{B. The Law's Destruction of Social Controls 1. Introduction}


One of the overriding legacies of the law with respect to Native Americans is that it has been responsible for the continuous and systematic destruction of social norms and controls. Any society is made up of an infinite number of interlocking components-including prominent components like religion, the family, and the government, but countless more exist. Societies rely on these components to operate in conjunction with one another-not independently of one another-in order to ensure harmony in everyday life. For instance, to control something like drug abuse, a society will rely on many social norms: religious norms, family or clan values, and laws that threaten punishment. Any number of social pressures are used to keep a particular individual away from drugs. When even one of these social norms is displaced, the entire society begins to unravel and suffer. ${ }^{\text {lxix }}$

A brief trip through the legal history of Native Americans in the United States will reveal that these social norms have been systematically attacked by the legal system. The easiest way to examine this phenomenon is to divide history into six eras and examine the law and federal policy during each eras: the contact era; the treaty era; the assimilation era; the attempted reorganization era; the termination era; and the self-determination era. ${ }^{\text {lxx }}$ Each of these eras will be discussed in turn.

\section{The Contact Era (1492-1776)}

This journey through history begins with the time of Christopher Columbus' landing in the so-called "New World." Even in this early stage-the contact era-the law was working against Native American social norms, and thus against the very being of Native American communities themselves. Every boy and girl that goes to school in this country knows that Columbus landed in 1492, but one must take a more careful look at history and the laws of the time to understand precisely why Columbus was able to claim an inhabited land for another country. Columbus's claim was considered a valid legal claim at the time because of what is known as "the doctrine of discovery." ${ }^{\text {lxxi }}$

The doctrine of discovery was a rule of law that was understood by all European nations during the late fifteenth century-in effect, it is one of the earliest examples of public international law. ${ }^{\text {lxii }}$ The doctrine of discovery was promulgated by the Church of Rome and effectively said that any European country that discovers an uninhabited land is entitled to claim that land and its resources for itself. For purposes of this law, a land was uninhabited so long as it had no Christians on it. ${ }^{\text {lxxiii }}$ Non-Christians were seen as "savages" who were unable to use the land effectively and therefore were unworthy of possessing it. ${ }^{\text {lxxiv }}$ Thus, it was both legal and presumably moral to take control of such lands so that they might be put to good use. ${ }^{\operatorname{lxv}}$ The significance of this law is that it allowed many countries to make claims of discovery in the "New World" and, ultimately, the doctrine of discovery was used by the United States Supreme Court as a justification for the colonization of the country and for the taking of Indian lands. ${ }^{\text {lxvi }}$ The doctrine of discovery was the groundwork for all that would follow. It gave society a legal and moral reason to treat Indians differently than other humans. If Columbus could not have made his discovery claim legally, then perhaps the events that led to the decimation of Native Americans over the next 500 years would never have happened.

\section{The Treaty Era (1776-1871)}

After more than 250 years of colonization following Columbus' landing, the United States of America was formed in 1776, and with this event the treaty era began. Shortly after the U.S. was formed, the new Federal Government was forced to make a decision about what its 
Indian policy should be. Initially, the decision was made to push the Indians westward and to slowly assimilate them. ${ }^{\text {lxxvii }}$ In the words of George Washington:

[P]olicy and [economy] point very strongly to the expediency of being upon good terms with the Indians, and the propriety of purchasing their Lands in preference to attempting to drive them by force of arms out of their Country; which as we have already experienced is like driving the Wild Beasts of the Forest which will return as soon as the pursuit is at an end and fall perhaps on those that are left there; when the gradual extension of our Settlements will as certainly cause the Savage as the Wolf to retire; both being beasts of prey tho' they differ in shape. In a word there is nothing to be obtained by an Indian War but the Soil they lie on and this can be had by purchase at less expense, and without that bloodshed[.] ${ }^{\text {lxxviii }}$

It was during this era that the United States set out to make treaties with tribes and to set up boundaries and reservations for the various tribes. ${ }^{\text {lxxix }}$ The treaties were largely set up to avoid conflicts (as indicated by Washington's words) so that the U.S. could recover from the Revolutionary War before having to deal with Indians. ${ }^{\text {lxx }}$

The treaties between the U.S. and the tribes varied greatly. Most treaties created boundaries for a given Indian nation and then went on to discuss briefly the power the tribe had within those boundaries. ${ }^{\text {lxxi }}$ In addition, many treaties had provisions that provided tribes access to traditional hunting or fishing lands and/or traditional religious lands, even if such lands were outside the boundaries of the reservation. ${ }^{\text {lxxii }}$ Treaties also covered a wide variety of other topics including any duties the U.S. government was willing to impose upon itself with respect to the tribe. Issues of jurisdiction sometimes arose as well. ${ }^{\text {lxxiii }}$ Oftentimes with a treaty, an Indian nation was removed from its traditional homeland or the borders of its traditional homeland were modified. The ramifications of such actions cannot be overstated. Forced removal and isolation resulted in the destruction or alteration of a tribe's culture, a tribe's religion, and even the very manner in which a tribe survives. ${ }^{\text {lxxiv }}$ In fact, this was a stated goal of creating reservationsthe hope was that tribes would slowly become "civilized" if given land and allowed time to assimilate to the Western culture that surrounded them. ${ }^{\text {lxxxv }}$

How did this era affect the Lummi Nation? In 1855, the Lummi Nation became a party to the Point Elliot Treaty, which the Lummi Nation understands as giving them the right to "govern [their] own lands, people and people who enter these lands voluntarily." ${ }^{\text {xxxvi }}$ Like many other treaties, the Point Elliot Treaty shrunk the Lummi's traditional land base. By the 1880s, the Lummi Nation was denied access to many of its traditional lands. ${ }^{\text {lxxxvii }}$ Even with these difficulties imposed on them, the Lummi Nation still controls some of their traditional land base and has, through much effort, been able to maintain a traditional lifestyle of fishing. ${ }^{\text {lxxxvii }}$ Thus the life-altering affects of the contact era were clearly felt by the Lummi people.

The Point Elliot Treaty was one of the final treaties the U.S. entered into with Indians. By 1870, there was a strong sentiment that the Federal Government's policy with respect to Indians needed to change. ${ }^{\text {lxxix }}$ The reservations weren't living up to expectations and non-Indian settlers now desired the Indian-controlled land. ${ }^{\mathrm{xc}}$ The argument was that allowing Indians to collectively own their land hindered them from learning how to farm and cultivate the land and, ultimately, prevented them from becoming self-sufficient. ${ }^{\text {xci }}$ The proposed solution for this problem was to allot the land into individual parcels. The desired effect of this policy was to 
force individual Indians into farming and to help them see the value of owning and working their own piece of land. ${ }^{\text {xcii }}$ In addition, this policy had the added benefit of freeing up additional land for non-Indian settlement. This policy shift marked the beginning of the assimilation era.

\section{The Assimilation Era (1871-1928)}

The Assimilation Era was a time filled with anti-Indian legislation. Of greatest significance was the General Allotment Act. ${ }^{\text {xciii }}$ The Act was passed in 1887, but its effects are still felt today. The Act allowed Congress to open reservations to non-Indian settlement. To do this, Congress had to pass a specific piece of legislation for a specific tribe. The legislation would divide the land into parcels, or allotments, and then would assign each individual Indian or each Indian family a specific parcel of land. The remaining parcels of land would be put on the open market for non-Indian settlement. Up until the time of this Act, Indians were prohibited by law from selling their land to anyone; after the passage of this Act, individual allotments could be sold freely. ${ }^{\text {xciv }}$

This Act has had lasting consequences. First and foremost, the process of allotment reduced Indian land holdings in the United States by over $60 \% .{ }^{\mathrm{xcv}}$ In addition, the opening of land to non-Indians resulted in a large number of non-Indians settling on reservation lands. This, predictably, has resulted in racial tensions for a variety of reasons. ${ }^{\text {xcvi }}$ The creation of these multi-racial reservation communities after the General Allotment Act has also resulted in the creation of special jurisdictional rules for these communities. It is one of my contentions that these complex and confusing rules that are largely responsible for the current ineffectiveness of law enforcement on many reservations. Additionally, allotment was responsible for the further destruction of Indian culture because it forcibly altered how tribes thought about land and subsistence. ${ }^{\text {xcvii }}$ Since the focus of allotment was on assimilating Indians into mainstream culture, the policy also resulted in wiping out many tribal governing practices. ${ }^{\text {xcviii }}$

The legacy of allotment can be felt on the Lummi reservation to this very day. In 1884, much of the upland area was assigned to individual Indian households, and by 1914 the remainder of the reservation had been allotted to individual Indian households. ${ }^{\text {xix }}$ Today, due to allotment, the land controlled by Indians is largely allotted land, and a substantial percentage of the reservation is made of up lands controlled by non-Indians. ${ }^{\mathrm{c}}$ Life for the Lummi people has altered considerably due to this inter-racial community and one of the great challenges of the Tribe is to govern its own members while trying to serve and keep order over the non-Indians who now co-exist in their community.

\section{The Attempted Reorganization Era (1928-1945)}

Starting in the late 1920s, federal policy towards Indians once again took a massive shift and thus began the attempted reorganization era. It was clear that allotment wasn't helping the tribes become self-sufficient and that something needed to be done. ${ }^{\mathrm{ci}}$ After substantial research, ${ }^{\text {ii }}$ the Federal Government ultimately passed the Indian Reorganization Act (IRA) of 1934. ${ }^{\text {ciii }}$ This Act put an end to allotment and attempted to return control of Indian affairs to tribes. Specifically, the Act allowed tribes to pass constitutions and begin governing themselves. ${ }^{\text {civ }}$

The IRA was an important first step in attempting to reverse the trend of Indian oppression, but it was not without its problems. Most significantly, although the IRA encouraged tribes to establish governments and constitutions, generally speaking the governments set up by the IRA (many of which are still in use) did not match the culture for 
which they were designed. ${ }^{\mathrm{cv}}$ Having a government that is designed around cultural norms and beliefs of a community is important because it allows individuals of that community to trust the institutions and principles that are in place. ${ }^{\text {cvi }}$ The importance of having governments that "culturally match" the people they are serving is something that wasn't well documented at the time of the IRA, but its importance has been clearly established today. ${ }^{\text {cvii }}$ An additional failing of the IRA is that it largely produced governments where separation of powers were nonexistent. ${ }^{\text {cviii }}$ Thus, the governments that were established - though better than nothing-were not ideal for long-term governmental success.

Despite its shortcomings, the IRA was a large step forward for Indian self-determination and sovereignty. For those tribes that accepted the IRA - and the Lummi Nation was not one of them-it marked a time where tribes finally had some amount of formal autonomy. Unfortunately, the era of attempted reorganization would not be long lasting.

\section{The Termination Era (1945-1961)}

After less than 15 years of attempting to reorganize and empower tribes, the Federal Government's policy completely reversed itself as the termination era was ushered in. The major legacy of the termination era was the Federal Government's decision to actually eliminate certain tribes. This was done for a number of reasons. First, terminating reservations was cost-effective because it meant that the Federal Government no longer had to act as a guardian for those tribes. ${ }^{\text {cix }}$ Second, eliminating the reservations would force Indians to assimilate to American culture. $^{\mathrm{cx}}$ Third, getting rid of the reservation system meant that all peoples-regardless of race-would be viewed equally under the law. ${ }^{\text {cxi }}$ At this point in time there are many academics and politicians who struggle with the very existence of reservations because in essence they represent special treatment for Indians. ${ }^{\text {cxii }}$

During this era, many federal policies were put into place to start eliminating Indian nations. When it was all said and done, the Federal Government terminated approximately 109 tribes and the total amount of Indian land was reduced by more than 3\%. ${ }^{\text {cxii }}$ I have already alluded to the devastating effects that the loss of land can have on any society. Add to that the social upheaval and psychological upheaval associated with the termination of a group's identity, and one can only imagine the lasting consequences of the Federal Government's actions in this area. ${ }^{\text {cxiv }}$

\section{The Self-Determination Era (1961-present)}

Finally, in the 1960s, federal policy moved into its current stage, the self-determination era. The hope has been to return power back to the tribes so that they can effectively govern themselves and make their own decisions on how they want to live their lives. ${ }^{\text {cxv }}$ Former President Richard Nixon ushered this era in. On July 8, 1970 he delivered a message to the U.S. Congress that changed federal Indian policy substantially. The basics of his vision can be found in this address where he stated:

It is long past time that the Indian policies of the Federal government began to recognize and build upon the capacities and insights of the Indian people. Both as a matter of justice and as a matter of enlightened social policy, we must begin to act on the basis of what the Indians themselves have long been telling us. The time has come to break decisively with the past and to create the conditions for a new era in which the Indian future is determined by Indian acts and Indian decisions. $^{\text {cxvi }}$ 
Although not without its flaws, this era has produced substantial improvement in the quality of life for many tribes and offers Indian nations a chance to once again decide for themselves how best to operate within the world.

This review of U.S. legal history is meant to demonstrate how tribal social controls were eroded over time. In each era the law was the primary tool used to achieve federal policy goals. Ultimately, these policies helped destroy the religious and cultural lives of Indians. Without these controls in place, problems like drug abuse can more easily make their way into the lives of Native Americans. Fortunately, since the beginning of the self-determination era, steps are being taken to restore old social controls and to create new ones so that society can function. No one expects 40 years of self-determination to erase the centuries of legal oppression tribes were placed under, but being aware of the legal history and taking deliberate steps to counteract it is a necessary step towards harmony.

\section{The Law's Creation of a Jurisdictional Quagmire}

Perhaps the most poignant effect the law has had on the Native American War on Drugs comes from the jurisdictional quagmire it has produced. In order for police officers to arrest individuals, in order for prosecutors to charge individuals with crimes, and in order for courts to sentence individuals, there must first be jurisdiction to do so. A government's criminal justice system is effectively toothless without jurisdiction. In this section I will walk through the basic legal principles that operate on Indian reservations. Specifically, I will focus on the ability of tribes to handle crime on their own reservations since the possession of illegal drugs is a criminal offense. What will become clear is that the current legal framework substantially hinders tribes who wish to fight the War on Drugs.

Before I discuss the current state of the law on reservations, it is useful to have a basic understanding of how Indian law operates in this country because Indian law operates in a truly unique fashion when compared with other areas of law. The foundations of Indian law can be found in three cases from the 1820s and 1830s commonly referred to as "the Marshall Trilogy." cxvii The Marshall Trilogy sets forth three principles that are the foundation for all of Indian law.

The first principle that comes out of the Marshall Trilogy is known as the doctrine of "Congressional plenary powers." This doctrine, quite simply, states that Congress has absolute and final control over Indian affairs. ${ }^{\text {cxviii }}$ At first glance this doctrine is simple to understand, but its ramifications are hard to imagine. This doctrine means that Congress could elevate all tribes to the status of states tomorrow, or Congress could eliminate them from existence altogether, and Congress could do anything in between. The power of Congress over Indians affairs is complete - that is, Congress is not bound by anything found in treaties, the Constitution or by the Supreme Court itself when it acts in the area of Indian law. ${ }^{\text {xix }}$ The Supreme Court has cited this doctrine again and again as settled law. ${ }^{\mathrm{cxx}}$

The second foundational principle of the Marshall Trilogy is that of "diminished tribal sovereignty." The Supreme Court has repeatedly held that tribes are sovereign entities, but that their sovereignty is not unlimited, rather, it is diminished. ${ }^{\text {cxxi }}$ Specifically, the Supreme Court relied upon the doctrine of discovery to conclude that, by the time the U.S. was formed, Indians no longer had the right to alienate (or sell) their lands; nor did they have the right to make treaties with other nations. ${ }^{\text {cxii }}$ Because tribes lost rights when they were “discovered,” they 
were labeled "diminished sovereigns." Ever since that proclamation came down from the Supreme Court the question has always been: What powers do tribes still have and what powers have they lost? Generally speaking, the phrase "whatever has not been taken away, still remains" is the answer to that question. Meaning, that if Congress has not taken a specific power away from tribes (for instance, by passing legislation that removes a power from the tribes), then the tribes still retain that power. ${ }^{\text {cxiiii }}$

The final principle derived from the Marshall Trilogy of cases is the idea that tribes are "domestic dependent nations." ${ }^{\text {cxxiv }}$ The easiest way to understand this doctrine is to break down each word. First and foremost, tribes are nations. They existed as nations long before Europeans ever set foot in America, and even after the U.S. was formed, they entered into treaties with them as one nation would with another. ${ }^{\text {cxxv }}$ They are not conquered peoples, but are distinct political entities. However, they are not nations in the same sense that the U.S. or Canada are nations. Tribes are "domestic dependent" nations. In effect, they are nations within a nation. As such, they must rely on the Federal Government for at least some of their needs-including protection from international foes. ${ }^{\text {cxxvi }}$ Thus, while tribes are nations in title, they are not allowed to conduct foreign affairs or join the U.N., etc. If they wish to do anything along those lines, they must go through the U.S. Federal Government. ${ }^{\text {cxxvii }}$

The idea that tribes are "domestic dependent nations" has given way to what is now often called the "trust responsibility." ${ }^{\text {cxxviii }}$ In the Marshall Trilogy, the Supreme Court suggests that the relationship between the Federal Government and Indian nations is like a guardian-ward relationship. ${ }^{\text {cxix }}$ That is, the U.S. has a duty to act in the best interest of Indian tribes because, according to the Court, the tribes cannot care for themselves. ${ }^{\mathrm{cxxx}}$ This paternalistic notion has been the source of large quantities of litigation over the past few decades. ${ }^{\text {cxxxi }}$ Some tribes have used the Federal Government's trust responsibility to secure health care, law enforcement and other necessities, while other tribes refuse to acknowledge the trust responsibility in defiance of its paternalistic and racist foundations. ${ }^{\text {cxxxii }}$

Since tribes are considered domestic dependent nations; and since the principle of Congressional plenary powers exists; the question I pose is: What powers do tribes have with respect to crime-specifically, drug crimes? The short answer is that tribes don't have a lot of power when it comes to crime. For instance, whereas the Federal Government can always detain, arrest, prosecute and sentence individuals who commit crimes (subject to the limitations found in the Constitution), tribes are not afforded such power, at the very least not to the same extent. ${ }^{\text {cxxxiii }}$

In addition to these major principles, there are four major pieces of federal legislation that govern criminal jurisdiction for tribes. To understand these pieces of legislation, the legal term "Indian Country" must first be understood Congress has defined Indian Country to include: (1) reservation lands; (2) dependent Indian communities within the U.S.; and (3) all Indian allotments that have not been extinguished. ${ }^{\text {cxxxiv }}$ Generally speaking, state law has no effect in Indian Country, although there are an increasing number of exceptions to that rule. ${ }^{\text {cxxxv }}$

One major piece of legislation relating to Indian criminal jurisdiction is the Major Crimes Act, which was originally passed in $1885 .{ }^{\text {cxxxvi }}$ Essentially, this Act gives the Federal Government exclusive jurisdiction to prosecute Indian defendants who have committed any of the crimes defined by the Act against another Indian. ${ }^{\text {cxxxvii }}$ The Act has been amended numerous times-most recently in 1988 - and now includes twelve major crimes. ${ }^{\text {cxxxviii }}$ This Act does not give the states or tribes any jurisdiction, and it is important to note that it applies solely to Indian defendants who commit crimes against other Indians and it applies only in Indian Country. 
A second important law is the Indian Countries Crime Act. ${ }^{\text {cxxxix }}$ This Act governs nonIndians who commit crimes or who are victims of crimes in Indian Country. In effect, the federal courts will assume jurisdiction if there is a crime involving a non-Indian defendant and an Indian victim, or if there is a crime involving an Indian defendant and a non-Indian victim. ${ }^{\text {cxl }}$ As written, the Act would also seem to apply to crimes committed by non-Indians against nonIndians in Indian Country, but in 1881 the U.S. Supreme Court handed down what is now called the "McBratney rule." ${ }^{\text {cxli }}$ This rule states that when one non-Indian commits a crime against another non-Indian in Indian Country it is the state, and not the Federal Government, that has jurisdiction to prosecute.

Another Act that affects criminal jurisdiction in Indian Country is the Assimilative Crimes Act. ${ }^{\text {cxlii }}$ Generally speaking, individuals who live in Indian Country are subject to federal and/or tribal laws, but not state laws. This Act makes certain state laws applicable in Indian Country. Anytime there is a crime under state law that has no counterpart in federal law, this Act gives federal courts the opportunity to prosecute under the state law. ${ }^{\text {cxliii }}$ Therefore, an individual cannot escape prosecution from a state criminal law solely by breaking that law in Indian Country. This also means that Indians might be prosecuted under state law even though generally speaking state law has no power in Indian Country.

The final important piece of legislation relating to criminal jurisdiction in Indian Country is commonly known as Public Law 280 (PL-280). ${ }^{\text {cxliv }}$ PL-280 was passed in 1953 and was "an attempt at [a] compromise between wholly abandoning the Indians to the states and maintaining them as federally protected wards." ${ }^{\text {cxlv }}$ This law transferred civil and criminal jurisdiction from the Federal Government to certain states. Originally there were five states that took over federal jurisdiction on reservations and later several more followed suit. ${ }^{\text {cxlvi }}$ Many of these states ultimately returned jurisdiction to the Federal Government. ${ }^{\text {cxlvii }}$ In states where PL-280 is in effect, the State is responsible for policing and enforcing laws on the reservation as opposed to the Federal Government. ${ }^{\text {cxlviii }}$ Thus, which government has criminal jurisdiction is sometimes wholly dependent on how PL-280 operates in a given State.

In Washington, where the Lummi Nation is located, PL-280 is in effect but only in a limited fashion. ${ }^{\text {cxlix }}$ Washington only exercises its jurisdiction on the Lummi reservation in eight distinct areas. ${ }^{\mathrm{cl}}$ None of these areas relate to criminal jurisdiction with the exception that the State had jurisdiction over juvenile delinquency. ${ }^{\text {cli }}$ However, even that jurisdiction may no longer be exercised by the State as Washington is slowly turning those areas of jurisdiction over to the Lummi Nation itself. clii $^{\text {. }}$

Even without going into the details of each Act, it is clear that there are many issues that need to be resolved in order to understand whether the Federal Government, the state, or the tribe has jurisdiction in a given situation. Specifically, in order to determine who has jurisdiction in a given situation, the following questions are relevant: (1) Was the crime committed in "Indian Country"? (2) Does Public Law 280 apply (or any other special Federal statutes)? (3) Was the criminal an Indian? Was the victim? (4) What was the crime committed? cliii $^{\text {che }}$

Determining which government has jurisdiction over a given crime on a reservation depends wholly on the answers to these questions. This differs greatly from criminal acts committed outside of reservations. By and large, when an individual commits a crime outside of a reservation the state, or alternatively the Federal Government, can arrest the individual so long as they have just cause to do so; that same entity can then prosecute the individual so long as a law exists that is relevant to the crime. If the crime occurred within the state's borders, then that fact is all a state patrol officer needs to know in order to know that he/she can legally arrest the 
suspect. This is not the case, generally speaking, for crimes that occur on reservations. So, let's take a look at each of these questions and how the answer to each one affects tribal jurisdiction. ${ }^{\text {cliv }}$

The first question is: Was the crime committed in Indian Country? As mentioned above, Indian Country has a legal definition. ${ }^{\text {clv }}$ If a given crime did not occur in Indian Country, then there is no tribal jurisdiction. Instead, the state has jurisdiction over the case. In certain circumstances the Federal Government may have jurisdiction as well (if the crime committed was a Federal offense), but state criminal law is something that the states are in charge of enforcing.

One question that arises is whether allotments owned by non-Indians qualify as Indian Country. The Supreme Court (and the lower federal courts) have developed an elaborate set of criteria to determine whether such lands should be classified as Indian Country or not. ${ }^{\text {clvi }}$ The courts look at the overall character of the area in question and determine whether it is predominantly Indian or predominantly assimilated (or whether it falls somewhere in between). If an area is predominantly Indian in character, than the tribe will be given jurisdiction over that area. ${ }^{\text {clvii }}$ If an area is deemed predominantly non-Indian in character, then the state will be granted jurisdiction over that land. ${ }^{\text {clviii }}$ Thus, the analysis is truly a case-by-case endeavor. As far as the Lummi Nation is concerned, a recent decision from a federal district court seemed to indicate that the non-Indian owned allotments on the reservation are considered Indian Country for the purposes of jurisdiction. ${ }^{\text {clix }}$

The second question in the analysis asks whether Public Law 280 (or some other Federal statute) applies. If PL-280 or some other special jurisdiction statute applies, then the rules laid out in that statue must be followed. In most PL-280 states it is the state and not the tribe that is given jurisdiction over the criminal matter. ${ }^{\text {clx }}$ The law, however, did not explicitly take any criminal jurisdiction away from tribes. ${ }^{\text {clxi }}$ For the Lummi Tribe, PL-280 has had some application in the past, although with the exception of juvenile delinquents it did not alter tribal criminal jurisdiction with respect to drugs. Ultimately, so long as the crime occurred in Indian Country and PL-280 does not apply, then we continue forward with the analysis.

The third question that is relevant to our analysis concerns the race of the victim and criminal involved in the crime. Unlike most areas of law, which strive to be racially neutral, criminal jurisdiction in Indian Country is highly dependent upon race. Taking into account the race of the victim and the race of the defendant, there are effectively six possibilities we must analyze. In addition to knowing the race of the defendant and victim, the specific crime that was committed also factors into the determination of who has criminal jurisdiction - this is the final question of the analysis: What crime was committed? The table below summarizes the various possibilities and when the tribe, state and Federal Government have jurisdiction.

TABLE \#1

\begin{tabular}{|c|c|c|c|}
\hline $\begin{array}{c}\text { Indian Defendant } \\
\text { Indian Victim }\end{array}$ & $\begin{array}{c}\text { Federal Jurisdiction } \\
\text { Yes, but only if the } \\
\text { Major Crimes Act } \\
\text { applies. }\end{array}$ & $\begin{array}{c}\text { So, assuming PL-280 } \\
\text { doesn't apply. }\end{array}$ & $\begin{array}{c}\text { Tribal Jurisdiction } \\
\text { Yes, but only if the } \\
\text { Major Crimes Act } \\
\text { does not apply. }\end{array}$ \\
\hline $\begin{array}{c}\text { Indian Defendant } \\
\text { Non-Indian Victim }\end{array}$ & $\begin{array}{c}\text { Yes, but only if the } \\
\text { Major Crimes Act, } \\
\text { Indian Country } \\
\text { Crimes Act or }\end{array}$ & $\begin{array}{c}\text { No, assuming PL-280 } \\
\text { doesn't apply. }\end{array}$ & $\begin{array}{c}\text { Yes, but only if the } \\
\text { Major Crimes Act } \\
\text { does not apply. }\end{array}$ \\
\hline
\end{tabular}




\begin{tabular}{|c|c|c|c|}
\hline & Federal Jurisdiction & State Jurisdiction & Tribal Jurisdiction \\
\hline $\begin{array}{c}\text { Assimilative Crimes } \\
\text { Act applies. }\end{array}$ & & No. \\
Indian Victim & $\begin{array}{c}\text { Yes, pursuant to the } \\
\text { Indian Country } \\
\text { Crimes Act or the } \\
\text { Assimilative Crimes } \\
\text { Act. }\end{array}$ & $\begin{array}{c}\text { No, assuming PL-280 } \\
\text { doesn't apply. }\end{array}$ & No. \\
\hline $\begin{array}{c}\text { Non-Indian Defendant } \\
\text { Non-Indian Victim }\end{array}$ & No. & Yes. & Yes. \\
\hline $\begin{array}{c}\text { Indian Defendant } \\
\text { No Victim }\end{array}$ & No. & No. \\
\hline $\begin{array}{c}\text { Non-Indian Defendant } \\
\text { No Victim }\end{array}$ & $\begin{array}{c}\text { Yes, pursuant to the } \\
\text { Indian Country } \\
\text { Crimes Act or the } \\
\text { Assimilative Crimes } \\
\text { Act. }\end{array}$ & $\begin{array}{c}\text { Maybe, this area of } \\
\text { law is not wholly } \\
\text { settled. }\end{array}$ & \\
\hline
\end{tabular}

As you can see, the current state of the law with respect to tribal criminal jurisdiction is very murky. I have simplified and condensed it considerably and yet my explanation is still several paragraphs long. Although the analysis itself can be confusing, the bottom line is all too clear: Indian nations are given very little power when it comes to criminal matters within their borders. Effectively, they can enforce laws against Indians but not non-Indians; and they can only enforce those laws which are not mentioned in the Major Crimes Act and which carry a punishment of less than one year in prison. ${ }^{\text {clxii }}$

This legal system has profound effects on a tribe's ability to fight drug abuse. A large number of these effects are directly felt by tribal police officers. ${ }^{\text {clxiii }}$ Specifically, this jurisdictional puzzle leaves tribal police asking questions like: Should we respond to non-Indian calls for help? After we've determined the race of the victim and/or defendant, how do we proceed? These type of questions are not the questions society generally wants their law enforcement personnel worrying about. But this is what happens in Indian Country. ${ }^{\text {clxiv }}$ In addition, research has shown that because these questions need to be answered, tribal police end up spending valuable time determining these matters, which directly hinders investigation into the actual facts and evidence of crimes on the reservation. ${ }^{\text {clxv }}$ Even after the jurisdictional maze is successfully navigated tribal police may be powerless to continue with an investigation at which point they must contact the appropriate authorities (whether state or federal) and either get permission to proceed, or wait for the appropriate authorities to arrive. ${ }^{\text {clxvi }}$ This requires tribal police members to work extensively with officers who are not under tribal command and who may not listen to the tribal police whatsoever. This set-up also means that multiple departments may be working on the same investigation. While there are benefits to this type of cooperation, there are also many instances where this forced relationship merely obstructs an effective investigation from ever getting underway. ${ }^{\text {clxvii }}$

The problems associated with this jurisdictional system can also be felt in other areas of the tribal criminal justice system. In particular, the tribal prosecutors and tribal court system will be routinely confronted with jurisdictional questions. ${ }^{\text {clxviii }}$ Assuming an arrest is made, the duty to determine whether tribal jurisdiction actually exists or not will fall on the tribal prosecutor and 
on tribal judges. If no jurisdiction exists, then the criminal must be released, either completely or to a government that has jurisdiction over the criminal. Besides being a time-consuming and costly process, repeatedly setting criminals free due to lack of jurisdiction on the tribe's part and lack of interest in prosecuting on either the state's or Federal Government's part can harm the social fabric of a community. For instance, the community may see their own government as powerless. In addition, the realization that nothing will happen to criminals on the reservation eliminates any deterrent value the justice system may normally possess. ${ }^{\text {clxix }}$ To put it another way, if there is no serious threat of being prosecuted, what is to stop an individual from breaking the law when it suits his/her interests? In addition to the law, there are of course social controls that prevent crime, but without the backing of a criminal justice system these social controls are likely to become far less effective. ${ }^{\text {clxx }}$

\section{Part Three: The Next Steps}

\section{A. Introduction}

The purpose of this paper is to analyze how U.S. law affects tribes' ability to fight the War on Drugs; and more specifically, how the law affects the Lummi Nation's ability in this area. With that being said, I thought it prudent to at least briefly touch on three possible areas of action that ultimately may help tribes more effectively fight the War on Drugs. I will consider each area in turn, starting with the most local opportunity for action and expanding to action that would require national support in order to be effective.

\section{B. Culturally Matched Criminal Justice Institutions}

The importance of having both well-run governing institutions and well-respected governing institutions cannot be overstated. There is a large body of research in existence that demonstrates how tribal legislatures, police, courts, etc., will fail if they are not in line with the culture and values of the reservation. ${ }^{\text {clxxi }}$ This ides is oftentimes called "cultural match." ${ }^{\text {clxxii }}$ In order to successfully govern, tribes must make certain that the governing institutions they have designed are respected and trusted by tribal members. Without this "cultural match," solving social and economic problems is nearly impossible. ${ }^{\text {clxxiii }}$

What does this mean with respect to fighting the War on Drugs? First and foremost it means that tribes do not simply need a criminal justice system, but that they need a criminal justice system that is designed specifically for their own unique culture and circumstances. As one author puts it:

The war on drugs, declared by every president since Ronald Reagan, is a fight that Indians and Indian tribes should work very hard to keep away from the reservation. Although no tribe will be able to keep the Border Patrol, the Drug Enforcement Agency, and the Federal Bureau of Investigation off the reservation, and many tribes in Public Law 280 states will not be able to keep the state officers away, a tribe's internal affairs, especially employment in tribal government, can and must be controlled by the tribe. Since tribes have the power to implement their own customs and traditions to prevent drug and alcohol abuse and addiction, it makes no sense to adopt the ways of the conqueror. ${ }^{\text {clxxiv }}$

This means that tribes should not be bound by outside expectations for their governing institutions. Rather, tribes should find something that reflects their own values and that works for their own people. ${ }^{\text {clxxv }}$ For some tribes that might mean having a parliamentary 
style government versus having a government with a strong executive. More importantly for the War on Drugs, it might involve re-inventing the tribal police force so that "community policing" can occur, ${ }^{\text {clxxvi }}$ or it might mean developing some sort of oversight body for the police (or other areas of government). ${ }^{\text {clxxvii }}$ Or, it might involve re-vamping the court system (or adding a new branch to the court system) that offers alternative dispute resolution mechanisms. clxxviii $^{\text {. }}$

For the Lummi, this has meant the creation of a court system that the people can trust and a return to traditional justice methods by creating a drug court and codifying exclusion as a punishment. Despite these efforts, the need to continually look at the values and history of the community in developing new practices and revising new ones always exists.

Another well-documented problem at the local level of reservations is that of undue political influence in tribal policing and in the tribal judicial system. ${ }^{\text {clxxix }}$ For effective crime control, tribal judges should not be afraid to make unpopular decisions based on the law. Tribal police should not be afraid to arrest the relative of a political leader if that person broke the law. And tribal members should not be afraid to come forward with information about crime simply because they believe there will be political ramifications for doing so. One step that tribes can take is ensuring that there is a separation of powers within the tribe. This means not only separating the executive, legislative and judicial branches from one another, but more importantly taking steps to make certain that no governmental body is beholden to another. Research (both in and out of Indian Country) has repeatedly found that removing political influence from the various governing institutions of any nation is one of the most effective ways to see actual progress when it comes to fighting social problems. ${ }^{\text {clxxx }}$

In many cases, separating powers may only be a first step. Even with separate powers, if a community does not understand the dangers of something like drug use, then the system may be unable to function. Efforts to educate individuals about both the problem and the available solutions may be required. In many communities - especially smaller, close-knit communitiesdrug use might not seem like a serious problem, or individuals may not trust the system enough to turn in friends and family members over to it. ${ }^{\text {clxxxi }}$ Efforts must be taken to gain citizen trust and to change the social consciousness of the reservation so that the systems set up by the tribes can work in meaningful manner.

The Lummi Constitution puts reservation power in the Business Council and calls for the creation of a court system. ${ }^{\text {clxxxii }}$ This court system operated independently of the tribal legislature and, according to one of its judges, operates without undue political or community pressure. ${ }^{\text {clxxxiii }}$ Despite this, given the small size of the Lummi population and the alleged widespread use of drugs on the reservation, it is necessary to continually watch for signs of corruption and undue influence in the Tribe's government and businesses. ${ }^{\text {clxxxiv }}$ In small communities it may be impossible to completely separate family from politics, and politics from law enforcement and business, but efforts to do so should be continually explored to increase trust in the fairness of the local systems.

\section{Coalition Building}

In addition to changes made within a Indian nation itself, there are other steps that can be taken under the current state of the law that can help arm tribes in the War on Drugs. Given the jurisdictional quagmire that exists on Indian lands, one of the most effective ways to improve law enforcement is by building coalitions with other tribes, states and the Federal Government through inter-governmental agreements. ${ }^{\text {clxxxv }}$ Cross-deputization is an example of this. ${ }^{\text {clxxxvi }}$ 
Agreements can be reached that effectively increase the power tribal police officers have, or that effectively increases the manpower available to act on tribal lands. An additional benefit that cross-deputization provides is the ability to work with states to monitor non-Indian behavior on the reservation. This ability is especially useful in areas where federal courts are unresponsive to crime on Indian reservations because a tribal-state coalition may allow tribes to access local, county, and state courts. ${ }^{\text {cxxxvii }}$ This means that non-Indians who may have gotten away with crimes in the past could no longer do so.

Similarly, coalition building can work in other contexts such as tribal courts, tribal prisons, or tribal treatment facilities. The advantage of having government-to-government relationships with states and the federal government is that many problems can be addressed before they arise. Specifically, intergovernmental agreements of this nature can be used to eliminate jurisdictional confusion preemptively. Furthermore, limited law enforcement resources may be put to better use if there is cooperation amongst multiple governments.

The Lummi nation has made great strides in coalition building. Lummi police regularly meet with FBI agents to discuss law enforcement issues and have increasingly been working with state police as well. ${ }^{\text {clxxxviii }}$ There is no evidence that cooperation with Canadian authorities occurs, and that would be an area to look into in the future (perhaps with the help of the Federal Government). Like the tribal police, the Lummi court system has also been involved in coalition building. The court system works closely with the State of Washington on numerous issues, particularly in the area of juveniles. ${ }^{\text {cxxxix }}$ In addition, full faith and credit has been worked out between the Tribe and the Washington Supreme Court as well as Whatcom County courts. ${ }^{\text {cxc }}$ These efforts should be commended and care should be taken to grow and nurture them in the future.

\section{Changing Federal Policy}

The final opportunity for change comes at the national level. Even though the law has created all sorts of barriers to fighting the War on Drugs in Indian Country, the good news is that the law can be changed. In fact, since the doctrine of Congressional plenary powers exists, the law in Indian Country is actually more susceptible to change than other areas because many Constitutional concerns that arise elsewhere do not apply to Indian Country. ${ }^{\text {cxci }}$ I am not saying that the doctrine of Congressional plenary powers is, in and of itself, a good thing; rather, I am suggesting that it might be put to good use with respect to drug abuse. Any change at the national level would, of course, require support from a large number of tribes and likely a large number of non-Indians as well. But the possibilities for change in Indian Law are limitless. The Lummi Nation has already gone before the Senate Committee on Indian Affairs and suggested changes along the lines of increasing tribal sovereignty and re-affirming Indian treaties. ${ }^{\text {cxii }}$ More such efforts should be made - and not simply by Indian nations, but by large coalitions of Indians and non-Indians alike. In addition to promoting sovereignty, the law could be changed to straighten out the jurisdictional maze that currently exists; to increase funding for tribal governments; or to increase the criminal jurisdiction and sentencing power of tribal courts.

\section{The Conclusion}

I started this paper by implying that the War on Drugs could not be won. Whether that is true or not, one must admit that great effort has been put into the War and oftentimes without very encouraging results. But I maintain that the War is still worth fighting and I think anyone who has been touched by drug abuse or felt its consequences in any way would likely agree. In 
this paper I have tried to bring to light facts about one very specific aspect of the War on Drugs - namely, how the law hinders this War on Indian lands. What I have tried to convey is that the law is a tool. For centuries this tool has been used to destroy Indian culture and to create hurdles with respect to law enforcement on Indian reservations. Now, it is time to take this tool and start using it for good. It is time to use tribal law to help set-up culturally specific systems that the community trusts and that therefore can be effective. It is time to use the law and the tribe's status as a nation to engage in government-to-government agreements that pool resources and respect one another's powers. It is time to use the law to change federal policy and to start undoing the centuries of oppression it has brought with it. The law can be one of our strongest weapons in the War on Drugs. Now is the time to begin using it.

\section{Notes}

${ }^{\mathrm{i}}$ Jeanette Rankin (1880-1973).

ii Sarah Kershaw, Through Indian Lands, Drugs’ Shadowy Trail, N.Y. Times (February 29, 2006).

iii See e.g. Sarah Kershaw, Dizzying Rise and Abrupt Fall For a Reservation Drug Dealer, N.Y. Times (February 20, 2006); see also Lynda V. Mapes, A Tribe Desperate to Survive Considers Banishing Its Own, Seattle Times (August 10, 2003).

iv See e.g. Drugs and Drug Policy in America (Steven R. Belenko, ed., Primary Docs. in Am. History \& Contemporary Issues, Greenwood Press 2000).

${ }^{v}$ Matthew L. M. Fletcher, The Drug War on Tribal Government Employees: Adopting the Ways of the Conqueror, 35 Colum. Hum. Rts. L. Rev. 1, 3 (Fall 2003).

${ }^{v i}$ Anne Bowen Pouin, Symposium: New Voices on the War on Drugs: Foreword, 47 Vill. L. Rev. 747, 747 (2002).

vii Joe Swanson, Drug Trafficking in the Americas: Reforming United States Trade Policy, 38 Geo. Wash. Int'l L. Rev. 779, 780-781 (2006).

viii $I d$. at 780 .

${ }^{\text {ix }}$ Matthew L. M. Fletcher, The Drug War on Tribal Government Employees: Adopting the Ways of the Conqueror, 35 Colum. Hum. Rts. L. Rev. 1, 6-7 (Fall 2003) (quoting the West Virginia Supreme Court).

x Joe Swanson, Drug Trafficking in the Americas: Reforming United States Trade Policy, 38 Geo. Wash. Int'l L. Rev. 779, 780 (2006).

${ }^{\mathrm{xi}} I d$.

${ }^{x i i}$ Peter S. McCarthy, United States v. Verdugo-Urquidez: Extending the Ker-Frisbie Doctrine to Meet the Modern Challenges Posed by the International Drug Trade, 27 New Eng. L. Rev. 1067, 1067-1068 (Summer, 1993).

xiii Matthew L. M. Fletcher, The Drug War on Tribal Government Employees: Adopting the Ways of the Conqueror, 35 Colum. Hum. Rts. L. Rev. 1, 16 (Fall 2003). 
${ }^{\text {xiv }}$ See e.g. David Lester, Crime and the Native American (Charles C. Thomas Publisher LTD. 1999).

${ }^{\mathrm{xv}}$ Luana Ross, Native Women, Mean-Spirited Drugs, and Punishing Policies, Social Justice Vol. 31 Social Justice 54, 55 (No. 4, 2004).

${ }^{\text {xvi } I d .}$

xvii David Lester, Crime and the Native American 15 (Charles C. Thomas Publisher LTD. 1999).

xviii Luana Ross, Native Women, Mean-Spirited Drugs, and Punishing Policies, Social Justice Vol. 31 Social Justice 54, 55 (No. 4, 2004).

xix Matthew L. M. Fletcher, The Drug War on Tribal Government Employees: Adopting the Ways of the Conqueror, 35 Colum. Hum. Rts. L. Rev. 1, 16 (Fall 2003).

${ }^{x x}$ See e.g. Sarah Kershaw, Through Indian Lands, Drugs’ Shadowy Trail, N.Y. Times (February 19, 2006); see also Sarah Kershaw, Dizzying Rise and Abrupt Fall For a Reservation Drug Dealer, N.Y. Times (February 20, 2006).

${ }^{x x i}$ Sen. Comm. on Indian Affairs, Contemporary Tribal Governments: Challenges in Law Enforcement Related to the Rulings of the U.S. Supreme Court, $107^{\text {th }}$ Cong. 11 (July 11, 2002).

xxii Id. at 19.

xxiii Sarah Kershaw, Through Indian Lands, Drugs' Shadowy Trail, N.Y. Times (February 19, 2006).

${ }^{\text {xxiv }} I d$.

${ }^{\mathrm{xxv}} I d$.

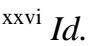

${ }^{x x v i i}$ Matthew L. M. Fletcher, The Drug War on Tribal Government Employees: Adopting the Ways of the Conqueror, 35 Colum. Hum. Rts. L. Rev. 1, 16 (Fall 2003).

xxviii Id.

xxix Tiller's Guide to Indian Country: Economic Profiles of American Indian Reservations 973 (Veronica E. Verlarde Tiller ed., BowArrow Publishing Company 2005).

${ }^{\mathrm{xxx}} I d$.

${ }^{\mathrm{xxxi}} I d$.

xxxii Sen. Comm. on Indian Affairs, Contemporary Tribal Governments: Challenges in Law Enforcement Related to the Rulings of the U.S. Supreme Court, $107^{\text {th }}$ Cong. 28 (July 11, 2002).

xxxiii Sen. Comm. on Indian Affairs, The Role of Tribal Governments in Assuring America's Homelands are Secure, $108^{\text {th }}$ Cong. 69 (July 29, 2003).

xxxiv Sen. Comm. on Indian Affairs, Contemporary Tribal Governments: Challenges in Law Enforcement Related to the Rulings of the U.S. Supreme Court, $107^{\text {th }}$ Cong. 28 (July 11, 2002). 
${ }^{\mathrm{xxxv}}$ Kurt Russo, The Lummi in Washington, in Endangered Peoples of North America: Struggles to Survive and Thrive Endangered Peoples 97, 98 (Tom Greaves, ed., Greenwood Press 2002).

${ }^{\text {xxxvi }}$ Sen. Comm. on Indian Affairs, The Role of Tribal Governments in Assuring America's Homelands are Secure, $108^{\text {th }}$ Cong. 69 (July 29, 2003).

xxxvii $I d$. at 70 .

xxxviii $I d$.

${ }^{x x x i x}$ Luana Ross, Native Women, Mean-Spirited Drugs, and Punishing Policies, Social Justice Vol. 31 Social Justice 54, 59 (No. 4, 2004).

${ }^{\mathrm{xl}}$ Lynda V. Mapes, A Tribe Desperate To Survive Considers Banishing Its Own, The Seattle Times (August 10, 2003).

${ }^{\text {xli } I d . ~}$

xlii Sen. Comm. on Indian Affairs, Contemporary Tribal Governments: Challenges in Law Enforcement Related to the Rulings of the U.S. Supreme Court, $107^{\text {th }}$ Cong. 5 (July 11, 2002).

xliii $I$.

${ }^{\text {xliv }}$ Id. at 31.

xlv Sen. Comm. on Indian Affairs, The Role of Tribal Governments in Assuring America's Homelands are Secure, $108^{\text {th }}$ Cong. 70 (July 29, 2003).

xlvi Tiller's Guide to Indian Country: Economic Profiles of American Indian Reservations 973 (Veronica E. Verlarde Tiller ed., BowArrow Publishing Company 2005).

xlvii $I d$.

xlviii $I d$.

${ }^{x l i x}$ Kurt Russo, The Lummi in Washington, in Endangered Peoples of North America: Struggles to Survive and Thrive Endangered Peoples 97, 108-109 (Tom Greaves, ed., Greenwood Press 2002).

${ }^{1}$ Sen. Comm. on Indian Affairs, Contemporary Tribal Governments: Challenges in Law Enforcement Related to the Rulings of the U.S. Supreme Court, $107^{\text {th }}$ Cong. 28 (July 11, 2002).

${ }^{\mathrm{li}} I d$. at 4-5.

lii Tiller's Guide to Indian Country: Economic Profiles of American Indian Reservations 975 (Veronica E. Verlarde Tiller ed., BowArrow Publishing Company 2005).

liii $I d$.

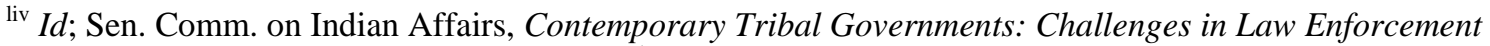
Related to the Rulings of the U.S. Supreme Court, $107^{\text {th }}$ Cong. 4-5 (July 11, 2002).

${ }^{\text {lv }}$ Sen. Comm. on Indian Affairs, Contemporary Tribal Governments: Challenges in Law Enforcement Related to the Rulings of the U.S. Supreme Court, $107^{\text {th }}$ Cong. 30-31 (July 11, 2002). 
${ }^{\text {lvi }}$ Telephone Interview with Hon. Randy Doucet, Chief Judge of Lummi Nation Tribal Court (April 30, 2007).

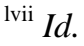

lviii $I d$.

lix 12 Lummi Nation Code of Laws §§ 1-5 (Native American Rights Fund, 2007) (available at: http://narf.org/nill/Codes/lummi/12exclusionsupp.pdf).

${ }^{\mathrm{lx}} I d$.

lxi Id.; see also Luana Ross, Native Women, Mean-Spirited Drugs, and Punishing Policies, Social Justice Vol. 31 Social Justice 54, 60 (No. 4, 2004).

lxii Id. at 59-60.

lxiii Telephone Interview with Hon. Randy Doucet, Chief Judge of Lummi Nation Tribal Court (April 30, 2007).

${ }^{1 x i v}$ Luana Ross, Native Women, Mean-Spirited Drugs, and Punishing Policies, Social Justice Vol. 31 Social Justice 54, 60 (No. 4, 2004).

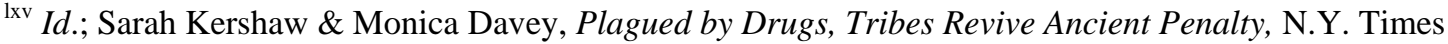
(January 18, 2004).

lxvi Sen. Comm. on Indian Affairs, The Role of Tribal Governments in Assuring America's Homelands are Secure, $108^{\text {th }}$ Cong. 71 (July 29, 2003).

lxvii Stewart Wakeling, Miriam Jorgenson, Susan Michaelson \& Manley Begay, Policing on American Indian Reservations: A Report to the National Institute of Justice, 9, 15 (July 2001).

Ixviii Sen. Comm. on Indian Affairs, Contemporary Tribal Governments: Challenges in Law Enforcement Related to the Rulings of the U.S. Supreme Court, $107^{\text {th }}$ Cong. 32 (July 11, 2002).

lxix See Jack Gibbs, Control: Sociology's Central Notion, (University of Illinois Press, 1989); See also Sarah Kershaw, Crisis of Indian Children Intensifies as Families Fail, N.Y. Times (April 5, 2005) (describing the breakdown of the family unit on Indian reservations and some consequences).

${ }^{\mathrm{lxx}}$ David H. Getches, Charles F. Wilkinson, Robert A. Williams, Jr., Cases and Materials on Federal Indian Law: Fifth Edition chs. 2-4 (West 2005).

Ixxi See Robert A. Williams, Jr., The American Indian in Western Legal Thought: The Discourses of Conquest (Oxford University Press 1990).

Ixxii David H. Getches, Charles F. Wilkinson, Robert A. Williams, Jr., Cases and Materials on Federal Indian Law: Fifth Edition 36 (West 2005) (quoting Robert A Williams, Jr., Columbus's Legacy: The Rehnquist Court's Perpetuation of European Cultural Racism Against American Indian Tribes, 39 Fed.B. News \& J. at 357$69)$.

\footnotetext{
lxxiii Id. at 36-37.

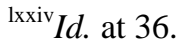

${ }^{\text {lxxv }} I d$. at 36-37.
} 
${ }^{\mathrm{lxxvi}}$ Id.

${ }^{\text {lxxvii }}$ Ltr. From George Washington to James Duane (September 7, 1783), in Documents of United States Indian Policy 1-2 (Francis Prucha ed., 1990).

lxxviii $I d$.

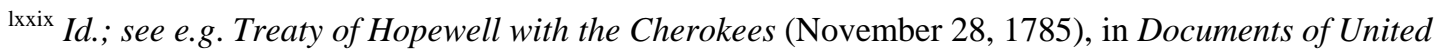
States Indian Policy 6-8 (Francis Prucha, ed., 1990).

${ }^{\text {lxxx }}$ David H. Getches, Charles F. Wilkinson, Robert A. Williams, Jr., Cases and Materials on Federal Indian Law: Fifth Edition 85 (West 2005)

lxxxi See e.g. Treaty of Hopewell with the Cherokees (November 28, 1785), in Documents of United States Indian Policy 6-8 (Francis Prucha, ed., 1990).

lxxxii See e.g. The Treaty of Point Elliot of 1855 (lays out rights of Lummi Tribe).

lxxxiii See e.g. Treaty of Hopewell with the Cherokees (November 28, 1785), in Documents of United States Indian Policy 6-8 (Francis Prucha, ed., 1990).

lxxxiv Francis Paul Prucha, American Indian Policy in the Formative Years: Indian Trade and Intercourse Acts, 1790-1834 224-48 (Harvard University Press, 1962).

${ }^{\operatorname{lxxxv}} I d$. at $1-3,43-50$.

lxxxvi Sen. Comm. on Indian Affairs, Contemporary Tribal Governments: Challenges in Law Enforcement Related to the Rulings of the U.S. Supreme Court, $107^{\text {th }}$ Cong. 28 (July 11, 2002).

$$
\begin{aligned}
& { }^{\text {lxxxvii }} I d \text {. at } 102 . \\
& \text { lxxxviii } I d .
\end{aligned}
$$

lxxxix David H. Getches, Charles F. Wilkinson, Robert A. Williams, Jr., Cases and Materials on Federal Indian Law: Fifth Edition 148 (West 2005).

${ }^{\mathrm{xc}} I d$.

xci 25 U.S.C. $\S 331$ (1897)

${ }^{x c i i}$ Delos Sacket Otis, The Dawes Act and the Allotment of Indian Lands (University of Oklahoma Press, 1973).

xciii 25 U.S.C. § 331 (1897)

${ }^{\text {xciv }} I d$.

${ }^{\mathrm{xcv}}$ Memo. from John Collier, to Congress The Purposes and Operation of the Wheeler-Howard Indian Rights Bill, 15-18 (1934) (copy found at 73d Cong. 2d Sess.).

${ }^{x c v i}$ See Fredrick E. Hoxie, A Final Promise: The Campaign to Assimilate the Indians, 1880-1920 (University of Nebraska Press, 2001).

xcvii Judith V. Royster, The Legacy of Allotment, 27 Ariz. St. L.J. 1, 9 (Spring 1995). 


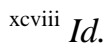

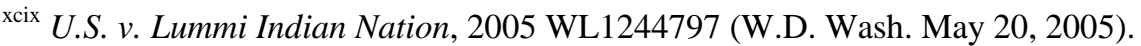

c Tiller's Guide to Indian Country: Economic Profiles of American Indian Reservations 973 (Veronica E. Verlarde Tiller ed., BowArrow Publishing Company 2005).

${ }^{c i}$ David H. Getches, Charles F. Wilkinson, Robert A. Williams, Jr., Cases and Materials on Federal Indian Law: Fifth Edition 186-87 (West 2005).

cii See e.g. Institute for Govt. Research, Studies in Administration, The Problem of Indian Administration (John Hopkins Press 1928) (commonly called "The Merriam Report").

ciii25 U.S.C.S. §§ 461 et seq. (Lexis 2007).

${ }^{\text {civ } I d .}$

${ }^{\mathrm{cv}}$ Duane Champagne, Challenges to Naïve Nation Building in the $21^{\text {st }}$ Century, 34 Ariz. St. L.J. 47, 48-9 (Spring 2002).

${ }^{\text {cvi }}$ Stephen Cornell \& Joseph P. Kalt, Two Approaches to Economic Development on American Indian Reservations: One Works, the Other Doesn't 16 (Harvard Project on American Indian Economic Development \& the Native Nations Institute for Leadership, Management and Policy 2005) (JOPNA No. 2005-02 located at http://www.jopna.net/pubs/jopna_2005-02_Approaches.pdf).

cvii See Stephen Cornell \& Joseph P. Kalt, Two Approaches to Economic Development on American Indian Reservations: One Works, the Other Doesn't (Harvard Project on American Indian Economic Development \& the Native Nations Institute for Leadership, Management and Policy 2005).

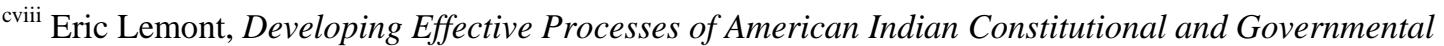
Reform: Lessons From the Cherokee Nation of Oklahoma, Hualapai Nation, Navajo Nation, and Northern Cheyenne Tribe, 26 Amer. Indian L. Rev. 147, 162 (2001/2002). 1983).

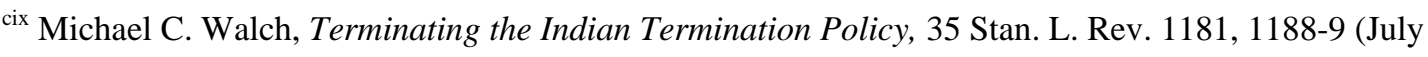

${ }^{\mathrm{cx}} I d$. at 1184 .

${ }^{\mathrm{cxi}} \mathrm{Id}$. at 1188.

cxii Gary Orfield, A Study of the Termination Era (Denver: National Congress of American Indians, 1965) (reprinted in Sen. Comm. On Labor and Public Welfare, $91^{\text {st }}$ Cong. $1^{\text {st }}$ Sess. at 674-90).

cxiii Charles F. Wilkinson \& Eric R. Biggs, The Evolution of the Termination Policy, 5 Am. Indian L. Rev. 139, 151-154 (1977).

${ }^{\text {cxiv }}$ See Erik H. Erikson, Childhood and Society (2d ed., Norton 1963).

${ }^{\mathrm{cxv}}$ Richard M. Nixon, Speech, Message From the President of the United States Transmitting Recommendations for Indian Policy (Washington D.C., July 8, 1970) (copy of speech can be found at H.R. Doc. No. 91-363, $91^{\text {st }}$ Cong., 2d Sess.).

${ }^{\mathrm{cxvi}} I d$. 
cxvii Johnson v. McIntosh, 21 U.S. 543 (1823); Cherokee Nation v. Georgia, 30 U.S. 1 (1831); Worcester v. Georgia, 31 U.S. 515 (1832).

cxviii Alex Tallchief Skibine, Reconciling Federal and State Power Inside Indian Reservations with the Right of Tribal Self-Government and the Process of Self-Determination, 1995 Utah L. Rev. 1105, 1119-37 (1995).

${ }^{\text {cxix }}$ United States v. Lara, 124 S. Ct. 1628 (2004).

${ }^{\mathrm{cxx}}$ See e.g. Id.; Duro v. Reina, 495 S. Ct. 676 (1990).

cxxi Johnson v. McIntosh, 21 U.S. 543 (1823); Cherokee Nation v. Georgia, 30 U.S. 1 (1831); Worcester v. Georgia, 31 U.S. 515 (1832).

cxxii Cherokee Nation v. Georgia, 30 U.S. 1, 31-4 (1831).

cxxiii See Felix S. Cohen, Handbook of Federal Indian Law, (U.S. G.P.O. 1945) (Cohen writes that whatever powers have not been taken away from tribes, remain for their use).

cxxiv Cherokee Nation v. Georgia, 30 U.S. 1, 26-7 (1831).

${ }^{\mathrm{cxxv}}$ Id. at 25-6.

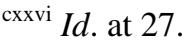

cxxvii See United Nations Crimes and Justice Information Network, Database on Bilateral Agreements on Extradition, Judicial/Legal Assistance, Control of Narcotic Drugs, and Prisoner Transfer by Country, http://www.uncjin.org/Laws/extradit/intro.pdf (June 1996).

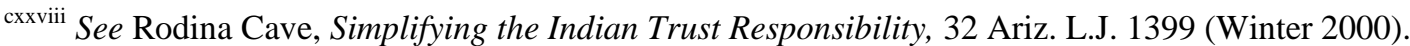

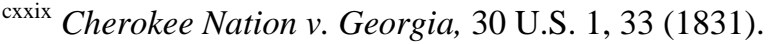

${ }^{\mathrm{cxxx}} I d$.

cxxxi See e.g. Cobell v. Babbit, 52 F. Supp. 2d 11 (D.D.C. 1999); David H. Getches, Charles F. Wilkinson, Robert A. Williams, Jr., Cases and Materials on Federal Indian Law: Fifth Edition 353-6 (West 2005).

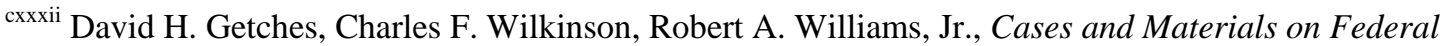
Indian Law: Fifth Edition 340-76 (West 2005).

cxxxiii See Robert N. Clinton, Development of Criminal Jurisdiction Over Indian Lands: The Historical Perspective, 17 Ariz. L. Rev. 951 (1975).

cxxxiv 18 U.S.C. $\S 1151(1948)$.

${ }^{\mathrm{cxxxv}}$ See e.g. Worcester v. Georgia, 31 U.S. 515 (1832).

${ }^{\text {cxxxvi }} 18$ U.S.C. $§ 1153$ (1885).

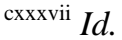

cxxxviii 18 U.S.C.S. $§ 1151$ (Lexis 2007).

${ }^{\text {cxxxix }} 18$ U.S.C.S. $\$ 1152$ (Lexis 2007). 
${ }^{\mathrm{cxl}} I d$.

${ }^{\text {cxli }}$ United States v. McBratney, 104 U.S. 621 (1881).

cxlii 18 U.S.C.S. $§ 13$ (Lexis 2007).

cxliii $I d$.

cxliv 83 P.L. 280 (1953).

cxlv Carole E. Goldberg, Public Law 280: The Limits of State Jurisdiction Over Reservation Indians, 22

U.C.L.A. L. Rev. 535, 537 (1975).

cxlvi $I d$.

cxlvii Id. at 537-59.

cxlviii Carole Goldberg \& Duane Champagne, Is Public Law 280 Fit for the Twenty First Century? Some Data at Last, 38 Conn. L. Rev. 697, 701-2 (May 2006).

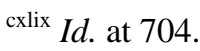

${ }^{\mathrm{cl}}$ Wash. Rev. Code § 37.12 .010 (2007).

cli $I d$.

clii Sen. Comm. on Indian Affairs, Contemporary Tribal Governments: Challenges in Law Enforcement Related to the Rulings of the U.S. Supreme Court, $107^{\text {th }}$ Cong. 6 (July 11, 2002).

cliii David H. Getches, Charles F. Wilkinson, Robert A. Williams, Jr., Cases and Materials on Federal Indian Law: Fifth Edition 488-92 (West 2005).

${ }^{\text {cliv }}$ Id. (my analysis mirrors there but I will not cite it henceforth).

clv 18 U.S.C. $\S 1151$ (1948).

${ }^{c l v i}$ See e.g. David H. Getches, Charles F. Wilkinson, Robert A. Williams, Jr., Cases and Materials on Federal Indian Law: Fifth Edition 461-75 (West 2005).

clvii See e.g. Mattz v. Arnett, 412 U.S. 481 (1973).

clviii See e.g. DeCouteau v. District County Court, 420 U.S. 425 (1975).

${ }^{c l i x}$ U.S. v. Lummi Indian Nation, 2005 WL1244797 (W.D. Wash. May 20, 2005).

${ }^{c l x}$ Carole Goldberg \& Duane Champagne, Is Public Law 280 Fit for the Twenty First Century? Some Data at Last, 38 Conn. L. Rev. 697, 699-707 (May 2006).

${ }^{\mathrm{clxi}}$ Id. at 701.

clxii Oliphant v. Suquamish Indian Tribe, 435 U.S. 191 (1978); Telephone Interview with Hon. Randy Doucet, Chief Judge of Lummi Nation Tribal Court (April 30, 2007).

clxiii $C f$. Stewart Wakeling, Miriam Jorgenson, Susan Michaelson \& Manley Begay, Policing on American Indian Reservations: A Report to the National Institute of Justice, 9-10 (July 2001). 
${ }^{\text {clxiv } I d .}$

${ }^{\mathrm{clxv}} C f$. id.

clxvii $C f$. id.

clxviii Telephone Interview with Hon. Randy Doucet, Chief Judge of Lummi Nation Tribal Court (April 30, 2007).

clxix See Joshua Dressler, Understanding Criminal Law 14-15 (3d ed., Lexis Publishing 2001).

clxx See Jack Gibbs, Control: Sociology's Central Notion, (University of Illinois Press, 1989).

clxxi See e.g. Stephen Cornell \& Joseph P. Kalt, Two Approaches to Economic Development on American Indian Reservations: One Works, the Other Doesn't (Harvard Project on American Indian Economic Development \& the Native Nations Institute for Leadership, Management and Policy 2005).

clxxii Id. at 12 .

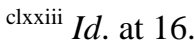

clxxiv Matthew L. M. Fletcher, The Drug War on Tribal Government Employees: Adopting the Ways of the Conqueror, 35 Colum. Hum. Rts. L. Rev. 1, 61-62 (Fall 2003).

${ }^{c l x x v}$ Kurt Russo, The Lummi in Washington, in Endangered Peoples of North America: Struggles to Survive and Trhive Endangered Peoples 97, 99-100 (Tom Greaves, ed., Greenwood Press 2002).

clxxvi Stewart Wakeling, Miriam Jorgenson, Susan Michaelson \& Manley Begay, Policing on American Indian Reservations: A Report to the National Institute of Justice, 54-6 (July 2001).

clxxvii See Eileen M. Luna, Law Enforcement Oversight in the American Indian Community, 4 Geo. Pub. Pol'y Rev. 149 (Spring 1999).

clxxviii Matthew L. M. Fletcher, The Drug War on Tribal Government Employees: Adopting the Ways of the Conqueror, 35 Colum. Hum. Rts. L. Rev. 1, 13 (Fall 2003).

clxxix Stewart Wakeling, Miriam Jorgenson, Susan Michaelson \& Manley Begay, Policing on American Indian Reservations: A Report to the National Institute of Justice vii (July 2001).

clxxx Stephen Cornell \& Joseph P. Kalt, Two Approaches to Economic Development on American Indian Reservations: One Works, the Other Doesn't 15 (Harvard Project on American Indian Economic Development \& the Native Nations Institute for Leadership, Management and Policy 2005).

clxxxi Lynda V. Mapes, A Tribe Desperate to Survive Considers Banishing Its Own, The Seattle Times (August 10, 2003) (quoting a tribal council member as saying, "Until we realize the dealers are an enemy of the people, we are not going to change this situation...").

clxxxii Lummi Const. art. VI, § 1(k).

clxxxiii Telephone Interview with Hon. Randy Doucet, Chief Judge of Lummi Nation Tribal Court (April 30, 2007).

clxxxiv C.f. Sarah Kerhaw, Dizzying Rise and Fall For a Reservation Drug Dealer, N.Y. Times (February 20, 2006). 
clxxxv See Sen. Comm. on Indian Affairs, Contemporary Tribal Governments: Challenges in Law Enforcement Related to the Rulings of the U.S. Supreme Court, $107^{\text {th }}$ Cong. 4 (July 11, 2002) (statement by Senator Akaka) (the importance of solutions coming in a government-to-government context as opposed to a colonizer-tocolonized context cannot be overstated).

clxxxvi See e.g. Cross-Deputization in Indian Country Michael L. Barker, Cross-Deputization in Indian Country, Police Studies 157 (Winter, 1993).

clxxxvii Id. at 161.

clxxxviii Sen. Comm. on Indian Affairs, Contemporary Tribal Governments: Challenges in Law Enforcement Related to the Rulings of the U.S. Supreme Court, $107^{\text {th }}$ Cong. 7 (July 11, 2002). 2007).

clxxxix Telephone Interview with Hon. Randy Doucet, Chief Judge of Lummi Nation Tribal Court (April 30,

${ }^{c x c}$ Sen. Comm. on Indian Affairs, Contemporary Tribal Governments: Challenges in Law Enforcement Related to the Rulings of the U.S. Supreme Court, $107^{\text {th }}$ Cong. 7 (July 11, 2002).

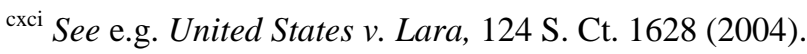

cxcii Sen. Comm. on Indian Affairs, Contemporary Tribal Governments: Challenges in Law Enforcement Related to the Rulings of the U.S. Supreme Court, $107^{\text {th }}$ Cong. 33-34 (July 11, 2002). 